\title{
HOW TO ACCELERATE LEARNING: ENTREPRENEURIAL VENTURES PARTICIPATING IN ACCELERATOR PROGRAMS
}

\author{
Susan L. Cohen
}

A dissertation submitted to the faculty of the University of North Carolina at Chapel Hill in partial fulfillment of the requirements for the degree of Doctor of Philosophy in the KenanFlagler School of Business.

Chapel Hill

2013

Approved by:

Howard Aldrich

Richard Bettis

Christopher Bingham

Atul Nerkar

Albert Segars 
(C) 2013

Susan Lee Cohen

ALL RIGHTS RESERVED 


\begin{abstract}
SUSAN L. COHEN: How to Accelerate Learning: Entrepreneurial Ventures Participating in Accelerator Programs

(Under the direction of Christopher B. Bingham)
\end{abstract}

This study uses theory building and theory elaboration methods to suggest how firms accelerate learning. Although prior research establishes that firms learn at different rates, less is known about how some firms, especially those in knowledge-based industries, accelerate learning. The research setting is nine accelerators - entrepreneurship education programs that accelerate learning during venture gestation. Since 2005, these modern incubators have offered cohorts of nascent firms seed financing, education, and mentorship during intensive three-month programs that culminate in high-stakes pitch presentations. Today, there are approximately 300 accelerators across five continents that have collectively helped 2500 firms raise $\$ 1.8$ billion in funding. Thus, accelerators are an important phenomena and an ideal setting to observe accelerated learning. There are several findings. First, learning is accelerated by mentor overload - time-compressed interactions with external advisors that delay implementation. Mentors expand strategic options. Second, learning is accelerated by director experts who rapidly accumulate and transfer expertise to nascent ventures. Directors narrow strategic options. Third, learning is accelerated by divided teams-founding team members who split up rather than band together during experience accumulation. Finally, learning is accelerated by cohort peers - peer ventures who are concurrently rivals and helpers. More broadly, this study contributes to organizational theory by bringing to light the central but heretofore hidden role of learning-coordination costs. This study also contributes 
to strategy by challenging the widely held assumption of time-compression diseconomies and to entrepreneurship by shifting the emphasis from changing strategic direction, often referred to as "pivoting," to making strategic commitments. Finally this study contributes to entrepreneurship by pioneering academic research on the purpose and effectiveness of accelerators, explaining what they do and comparing them to incubators and angel investors.

KEYWORDS: Organizational learning, accelerated learning, entrepreneurship, accelerators, entrepreneurship education, learning-coordination costs, cohort peers 


\title{
DEDICATION
}

\author{
To Zachary, Ali, Sophie
} and Neil 


\section{ACKNOWLEDGEMENTS}

Words can only begin to express how grateful I am for the amazing support I received from so many people. My husband, Neil, treated my academic training as a job. His respect and belief in me and my education not only kept me going when times were tough but also made me feel important. I love him and am thankful for his support! I am also grateful for my children, Zachary, Ali and Sophie, who always made me smile. They listened to me talk about my research and provided surprisingly insightful comments. They are the center of my world. My mother and stepfather, Nancy and Jerry, provided encouragement and reality checks throughout. I could always count on them for support. I'm also grateful for the help my in-laws, Sheila and Joel, provided. I especially thank my step-brother and sister-in-law Dan and Lotta who inspired me to pursue my doctorate.

I am so very grateful for Virginia Kay’s friendship and camaraderie. We even had fun studying for comps, so long as we moved ever 20 minutes the lights even stayed on. I am also fortunate to be a part of a fabulous group of doctoral students. I extend a special thank you to Songcui Hu who always smiled when sharing her experiences with me. I'm grateful for my very good friend Jennie Schott who listened to my trials and tribulations, and for the never ending hospitality of Amanda and Jeff Peppercorn and Amy and Nick Shaheen.

I am extremely grateful for the thoughtful advice provided by my dissertation committee. Al Segars believed in me from the very start. Most of all, he taught me the importance of committing. From my first semester as a doctoral student, Howard Aldrich patiently and kindly reminded me to study big, important questions and taught me how to do 
so. He believed that my research could make a difference, which continues to inspire me. Atul Nerkar taught me the importance of scholarly "taste" and was always ready to strategize with me. Atul sharpened my thinking during every stage of my doctoral studies. I am also grateful for the many long conversations with Rich Bettis, mostly over "real" coffee.

Above all, I am grateful for all that my advisor, Chris Bingham, has sacrificed to advance my research — reading through pages of transcripts, listening to my crazy ideas, and even reading drafts while on vacation. I appreciate so much about Chris, particularly his patience, intellect and genuine intellectual curiosity. I consider myself extremely fortunate to have studied under Chris, and I am certain that there will be an impressive entourage of students behind me.

I also acknowledge many scholars who provided feedback on my work, especially Mike Christensen, J.P. Eggers, Marianne Feldman, Nathan Furr, Ben Hallen, David Kirsch, Ethan Mollick, Fiona Murray, Jeff Pollack, Alicia Robb, Scott Rockart, Kristin Wilson and Ted, Zoller. I'd also like to thank Mary Tripsas and Lisa Jones Christensen for taking me under their wings.

I'm grateful for the anonymous informants who took time from their own start-ups, investments and accelerators to speak to me. I literally could not have completed this research without their help. Although I cannot thank them by name, I am extremely appreciative. I'd like to extend a special thank you to my pilot site and the affiliated accelerator directors and venture founders who spoke to me, sometimes for several hours.

Finally, I acknowledge the generous financial support of the Batten Institute of the Darden Business School and the Kenan-Flagler Business School at the University of North Carolina. 


\section{TABLE OF CONTENTS}

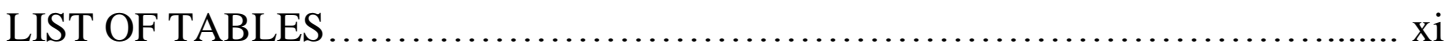

LIST OF FIGURES ...............................................................

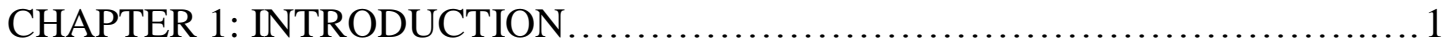

CHAPTER 2: THEORETICAL AND EMPIRICAL BACKGROUND................5

2.1. Organizational learning .................................... 5

Accelerated Learning Definition.............................. 5

2.2. Learning Modes............................................ 6

2.2.1. Experiential....................................... 6

2.2.2. Learning from Others................................10

2.2.3. Experimental........................................ 13

2.2.4. Trial and Error...................................... 14

2.2.5. Improvisation..................................... 15

2.2.6. Learning Mode Discussion...........................17

2.3. Time Compression....................................... 17

2.3.1. Time Compression Diseconomies.................. 17

2.3.2. Time Compression Economies......................... 19

2.4. Organizational Speed.................................... 20

2.4.1. Pacing ............................................. 21

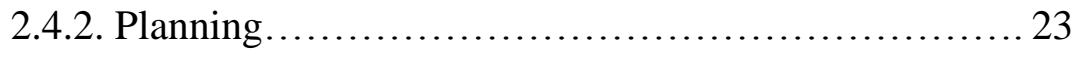

2.4.3. Prior Experience................................... 25

2.4.4. Team Composition and Traits......................... 26

2.5. Literature Discussion.................................... 27 
CHAPTER 3: METHODS ....................................................... 32

3.1. Research Setting.......................................... 32

3.2 Definition of Accelerators.................................... 32

3.3 History of Accelerators....................................... 34

3.4. Comparison: Accelerators, Incubators and Angels............... 36

3.5 Research Setting.......................................... 38

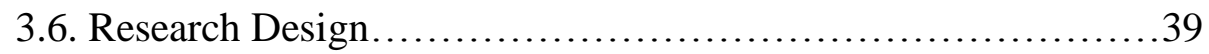

3.7. Exploratory Work........................................ 42

3.8. Data Sources............................................... 43

3.9. Data Analysis.............................................. 44

3.10. Accelerated Learning ................................... 46

CHAPTER 4: HOW TO ACCELERATE ORGANIZATIONAL LEARNING.......50

4.1. Mentor overload........................................... 50

4.2. Director experts........................................ 63

4.3. Divided Teams................................................... 75

4.4. Cohort Peers................................................ 84

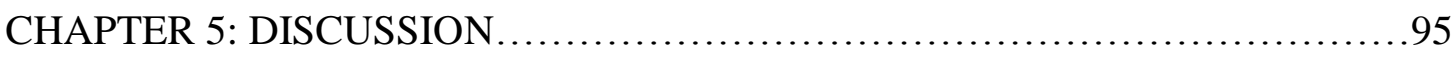

5.1. Framework: Accelerated Learning......................... 95

5.2. Organization Theory....................................... 99

5.3. Strategy ................................................ 102

5.4. Entrepreneurship........................................ 104

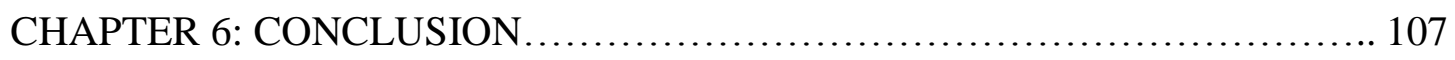

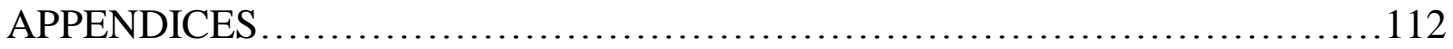


APPENDIX 1-ACCELERATOR DIRECTOR INTERVIEW GUIDE............112 APPENDIX 2-VENTURE FOUNDER INTERVIEW GUIDE................ 117 APPENDIX 3-MENTOR INTERVIEW GUIDE.......................... 123 REFERENCES ..................................................... 128 


\section{LIST OF TABLES}

Table

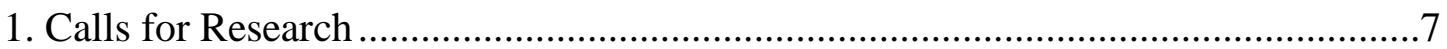

2. Selected Studies on Learning Processes ........................................................

3. Selected Studies Finding Time-Compression Economies ..................................22

4. Selected Organizational Speed Studies..........................................................29

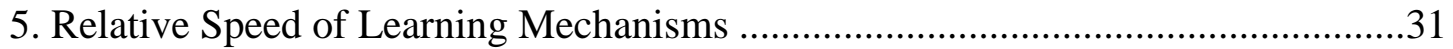

6. Summary of the Differences between Incubators, Investors,

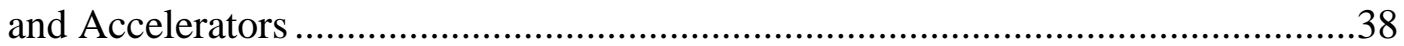

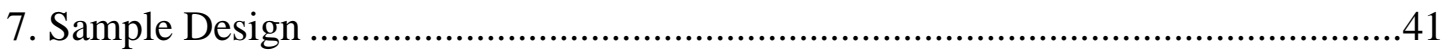

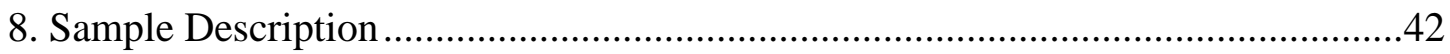

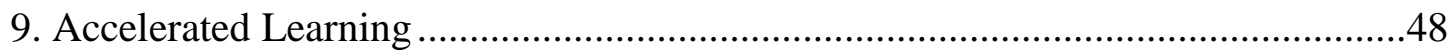

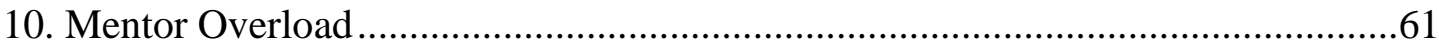

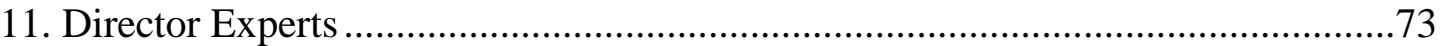

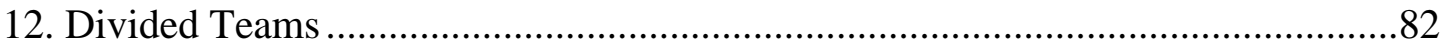

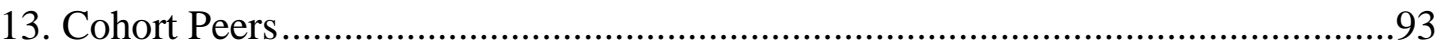

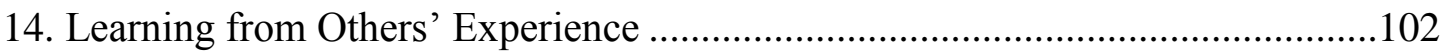




\section{LIST OF FIGURES}

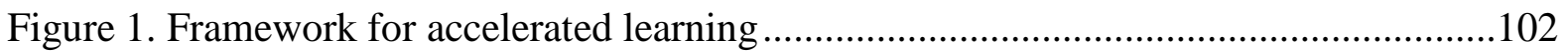




\section{CHAPTER 1}

\section{INTRODUCTION}

"Increasing the rate of organizational learning is the heart of a fast cycle-time strategy. To become a fast cycle-time competitor, it is essential that senior management embrace organizational learning as a strategic objective."

(Meyer \& Purser, 1993)

Organizational learning is central to strategy and organization theory (Winter \& Szulanski, 2001; Zander \& Kogut, 1995; Zollo \& Winter, 2002). Thus it is no surprise that researchers have described many ways organizations learn, including from others (Haunschild \& Miner, 1997; Haunschild, 1993); experimentation (Pisano, 1994; Sitkin, 1992); improvisation (Baker, Miner, \& Eesley, 2003; Miner, Bassoff, \& Moorman, 2001; Moorman \& Miner, 1998); and doing (Argote, 1999; Arrow, 1962; Rapping, 1965). Despite the abundance of research on organizational learning, including several studies that find firms learn at different rates (Argote \& Epple, 1990; Argote, 1999; Darr, Argote, \& Epple, 1995; Dutton \& Thomas, 1984; Lieberman, 1984; Pisano, Bohmer, \& Edmondson, 2001; Reagans, Argote, \& Brooks, 2005) and many that suggest how learning improves the production function (Adler \& Clark, 1991; Argote \& Epple, 1990; Benkard, 2000; Ittner et al., 2001; Levin, 2000), surprisingly few studies examine how firms accelerate learning.

Organizational acceleration, however, is central to strategic management theory (D’Aveni \& Gunther, 1994; Eisenhardt \& Martin, 2000). Pioneering firms carve out favorable strategic positions with temporary or even sustainable competitive advantages (D’Aveni \& Gunther, 1994; Dierickx \& Cool, 1989; Santos \& Eisenhardt, 2009). First- 
movers erect barriers to entry by locking up strategic resources, such as limited supply and distribution channels, or establishing industry standards that favor their unique capabilities (Lynn, Skov, \& Abel, 1999). Other firms use speed advantage to quickly imitate and then pass competitors(Hawk, Pacheco-De-Almeida, \& Yeung, 2012; Lieberman \& Montgomery, 1998). By delaying implementation until after competitors identify winning strategies, these fast-following firms reduce risk and costly experimentation. Finally, faster product development is associated with lower costs and higher profitability (Clark \& Fujimoto, 1991).

Considering the emphasis on acceleration in organizational research, in general, relatively few studies suggest how to accelerate learning. Extant work on accelerated learning largely suggests how firms improve production efficiency (e.g., Darr et al., 1995; Ittner et al., 2001; Lapré \& Van Wassenhove, 2001; Terwiesch \& Bohn, 2001). This stream of research examines how firms reduce production costs (Adler \& Clark, 1991; Lapré \& Van Wassenhove, 2001) or production time (Darr et al., 1995; Pisano et al., 2001). However, Argote (1999) notes that there are two types of learning: learning what to produce and learning how to produce it efficiently; much learning happens before the first unit is produced (Argote, 1999), including learning what to produce, when to begin production, and even whether to produce the first unit at all. Prior work on accelerated learning has focused more on learning how to improve production efficiency and less on how learning what to produce.

However, much organizational learning is unrelated to production. Firms learn from acquisitions (Barkema \& Schijven, 2008; Haleblian \& Finkelstein, 1999; Hayward, 2002), alliances (Hamel, 1991; Khanna, Gulati, \& Nohria, 1998), and international entries (Bingham 
\& Haleblian, 2012; Vermeulen \& Barkema, 2002). For example, Bingham and Haleblain (2012) found that firms learn heuristics from international entry experiences and Hayward (2002) found that firms learn more from prior acquisitions that are neither too similar nor to distant to focal acquisitions and result in small performance shortfalls. Although some studies (Hayward, 2002; Vermeulen \& Barkema, 2002) suggest that time has an effect on learning, little work has been done to suggest how organizations might accelerate learning.

In particular, there is little research on how firms accelerate learning during organizational gestation (Yang \& Aldrich, 2012), yet learning during gestation might have a lasting effect on organizations (Stinchcombe, 1965). In a rare study of learning in entrepreneurial firms, Bingham and Davis (2012) examined nine late-stage entrepreneurial firms entering new international markets. They found firms that began by learning vicariously performed better over time. More generally, research suggests that organizations learn from others prior to developing their own experience (Argote, 1996). Though this work suggests that firms learn vicariously prior to market entry, it does not suggest how firms might accelerate such learning.

This dissertation investigates how firms accelerate organizational learning. The research setting is seed acceleration programs (hereafter "accelerators")—organizations that accelerate organizational learning during venture gestation by providing cohorts of nascent ventures with mentorship and formal education during temporally condensed programs. Given the state of theory related to accelerated learning and lack of empirical studies on accelerators, I use theory building (Eisenhardt, 1989a) and theory elaboration (Lee, 1999) methods to investigate how organizations might accelerate learning. 
This study makes several contributions. Principally, it contributes to organizational theory by highlighting the central but often overlooked role of learning-coordination costs. Firms expend learning coordination costs to set-up learning engagements. Because prior work typically begins with the learning interaction, it omits the time and effort expended prior to learning. This study also portrays a more nuanced view of vicarious learning. In particular, this study finds that firms learn "what" from heterogeneous groups with distributed expertise but learn "how" from homogenous groups with centralized expertise.

This study also contributes to strategy by suggesting that accelerating learning reduces biases and improves learning. This conflicts with prior theory which suggests that learning diminishes when it is temporally compressed (Dierickx \& Cool, 1989; Levinthal \& March, 1981). The ventures in this study accelerated learning by delaying implementation until they committed to a strategy, rather than beginning with learning by doing, as suggested by prior work (Eisenhardt \& Tabrizi, 1995; Pisano, 1994). This study also extends work on social learning by showing that ventures form aspirational groups with their cohort, even when cohort peers are in different industries.

Finally, this study contributes to entrepreneurship research by initiating scholarship on accelerators, explaining what they do and evaluating their relative effectiveness. Moreover, this study suggests that entrepreneurs focus on committing to strategy rather than pivoting it (Ries, 2011). That is, rather than solely focusing on changing, entrepreneurs may want also to focus on making strategic commitments central to strategic management (Porter, 1996). 


\section{CHAPTER 2}

\section{THEORETICAL AND EMPIRICAL BACKGROUND}

This chapter reviews prior work on organizational learning, time compression and organizational speed in order to set the theoretical setting for this study. I review prior work published in the organization studies, strategy, and entrepreneurship fields, and synthesize research related to organizational learning and speed. Throughout, I draw attention to concepts related to learning speed. I conclude with a discussion which includes opportunities for further research.

\subsection{Organizational learning}

This section discusses prior work on organizational learning. After defining key terms, I review some of the mechanisms firms use to acquire knowledge, including experiential learning (Argote, 1999), learning from others (Haunschild, 1993) by experimentation (Pisano, 1994), trial-and-error (Van de Ven \& Polley, 1992), and improvisation (Miner et al., 2001). I conclude by synthesizing the research on organizational learning, highlighting opportunities for future research.

(See Table 1 for calls for research and Table 2 for selected studies on organizational learning processes.)

\section{Accelerated Learning Definition}

As is customary in organizational learning research, I define organizational learning as a change in the range of an organization's potential behaviors (Huber, 1991), routines (Cyert \& March, 1963; Levitt \& March, 1988), cognition (Miner et al., 2001) or performance 
(e.g., Argote \& Epple, 1990; Dutton \& Thomas, 1984; Lieberman, 1984) due to processing of information or experience (Argote, 1999; Cyert \& March, 1963; Fiol \& Lyles, 1985, 1985; Huber, 1991). I also follow the behavioral view of the firm (Cyert \& March, 1963), which portrays learning as a process that "requires loops of stimulus and feedback, which trigger changes in performance and cognition" (Fiol \& Lyles, 1985).

Accelerated learning is organizational learning that happens faster than it would under typical conditions. (See "Accelerated Learning" in the methods section of this study for a description of how I measure accelerated learning.)

\subsection{Learning Modes}

Research on how organizations learn are germane to accelerated learning and include studies on learning by doing (Argote, 1999), from others (Haunschild, 1993), by experimentation (Pisano, 1994), by trial-and-error (Miller \& Shamsie, 2001), and through improvisation (Miner et al., 2001).

\subsubsection{Experiential}

Early research on organizational learning showed that as firms accrue experience by producing more units (Lieberman, 1984) their performance improves. However, the rate of performance improvements diminishes over time, which produces "learning curves" (Rapping, 1965). Organizations within the same industry and even plants within the same firm learn at different rates (Adler \& Clark, 1991). This empirical regularity has been found in several industries, including aircraft producers (Benkard, 2000), shipyards (Argote, 1996; Rapping, 1965), medical teams (Pisano et al., 2001), and service providers (Darr et al., 1995). Different measures of performance, such as production cost (Darr et al., 1995) and quality (Levin, 2000), produce similarly shaped learning curves. Empirical work in the learning 
curve tradition generally assumes that learning happens when the production function improves (e.g., Adler \& Clark, 1991; Ittner et al., 2001; Lapré \& Van Wassenhove, 2001), though changes to the production function could be driven by factors unrelated to learning, such as decreasing raw material costs (Devinney, 1987).

Table 1: Calls for Research

\begin{tabular}{|c|c|c|}
\hline Paper & Gap & Quote \\
\hline $\begin{array}{l}\text { Pisano et al. } \\
\text { (2001) }\end{array}$ & $\begin{array}{l}\text { Why firms have } \\
\text { different learning rates }\end{array}$ & $\begin{array}{l}\text { "The first concerns the specific organizational and } \\
\text { managerial factors that underlie the differences in } \\
\text { learning rates that I observed ... much more in- } \\
\text { depth comparative work is required to draw more } \\
\text { specific conclusions about the drivers of learning. } \\
\text { An exploration of organizational-level differences in } \\
\text { incentives, organizational processes, management, } \\
\text { and practices is clearly warranted." }\end{array}$ \\
\hline $\begin{array}{l}\text { Perlow et al. } \\
\text { (2002) }\end{array}$ & $\begin{array}{l}\text { Speed and } \\
\text { organizational } \\
\text { processes }\end{array}$ & $\begin{array}{l}\text { "How an emphasis on speed affects organizational } \\
\text { processes remains unclear." }\end{array}$ \\
\hline Huber (1991) & $\begin{array}{l}\text { Field work on fast } \\
\text { learning }\end{array}$ & $\begin{array}{l}\text { "The interesting finding that fast learning is } \\
\text { sometimes disadvantageous (Levinthal and March } \\
\text { 1981; Herriott, Levinthal, and March 1985; } \\
\text { Lounamaa and March 1987) seems plausible as } \\
\text { developed and discussed by Levitt and March } \\
\text { (1988), but the frequency and nature of this } \\
\text { phenomenon deserve investigation in field settings." }\end{array}$ \\
\hline $\begin{array}{l}\text { Vermeulen and } \\
\text { Barkema (2002) }\end{array}$ & Diseconomies of time & $\begin{array}{l}\text { "Diseconomies of time compression may be more or } \\
\text { less prevalent under different circumstances" }\end{array}$ \\
\hline Huberman (2001) & $\begin{array}{l}\text { How does the model } \\
\text { correspond to firm } \\
\text { learning processes? }\end{array}$ & $\begin{array}{l}\text { "The existence of a learning curve for organizations } \\
\text { has been thoroughly documented and studied since } \\
\text { 1936, but the underlying mechanisms that cause it to } \\
\text { be a power law are still not clearly understood." }\end{array}$ \\
\hline $\begin{array}{l}\text { Lapre and Van } \\
\text { Wassenhove } \\
\text { (2001) }\end{array}$ & $\begin{array}{l}\text { What organizational } \\
\text { structures and routines } \\
\text { accelerate learning? }\end{array}$ & $\begin{array}{l}\text { "Further research is needed to better understand } \\
\text { organizational structures and problem solving } \\
\text { routines that allow firms to accelerate learning } \\
\text { curves." }\end{array}$ \\
\hline $\begin{array}{l}\text { Aldrich and Yang } \\
\text { (forthcoming) }\end{array}$ & $\begin{array}{l}\text { Can entrepreneurial } \\
\text { firms learn fast } \\
\text { enough? }\end{array}$ & $\begin{array}{l}\text { "Whether nascent entrepreneurs can learn fast } \\
\text { enough during the startup process to avoid being } \\
\text { selected out is a critical question for } \\
\text { entrepreneurship and organization theory." }\end{array}$ \\
\hline
\end{tabular}


Table 2: Selected Studies on Learning Processes

\begin{tabular}{|c|c|c|c|c|c|}
\hline Article & $\begin{array}{l}\text { Learning } \\
\text { Type } \\
\end{array}$ & $\begin{array}{l}\text { Research } \\
\text { question }\end{array}$ & $\begin{array}{l}\text { Sample \& } \\
\text { DV }\end{array}$ & Main concept & $\begin{array}{l}\text { Gap related } \\
\text { to speed }\end{array}$ \\
\hline $\begin{array}{l}\text { Pisano et al. } \\
\text { (2001) }\end{array}$ & $\begin{array}{l}\text { Learning-by- } \\
\text { doing }\end{array}$ & $\begin{array}{l}\text { Do firms } \\
\text { learn from } \\
\text { experience at } \\
\text { different } \\
\text { rates? }\end{array}$ & $\begin{array}{l}660 \text { cardiac } \\
\text { surgeries at } 16 \\
\text { hospitals } \\
\text { DV: Surgery } \\
\text { procedure } \\
\text { duration }\end{array}$ & $\begin{array}{l}\text { Hospitals learned at } \\
\text { different rates. } \\
\text { some firms learned } \\
\text { more from similar } \\
\text { amounts of experience. }\end{array}$ & $\begin{array}{l}\text { How did } \\
\text { some } \\
\text { hospitals } \\
\text { learn more } \\
\text { quickly? }\end{array}$ \\
\hline $\begin{array}{l}\text { Miner et al. } \\
(2001)\end{array}$ & Improvisation & $\begin{array}{l}\text { How are } \\
\text { improvisation } \\
\text { and learning } \\
\text { related? }\end{array}$ & $\begin{array}{l}50 \text { NPD } \\
\text { meetings at } \\
\text { established } \\
\text { firms } \\
\text { DV: Learning }\end{array}$ & $\begin{array}{l}\text { Improvisation is } \\
\text { real-time, short-term } \\
\text { learning that happens } \\
\text { when strategic design } \\
\text { and implementation } \\
\text { converge in real-time. }\end{array}$ & $\begin{array}{l}\text { Does } \\
\text { improvisation } \\
\text { accelerate } \\
\text { learning? } \\
\text { How? }\end{array}$ \\
\hline $\begin{array}{l}\text { Pisano } \\
(1994)\end{array}$ & $\begin{array}{l}\text { Learning } \\
\text { before doing } \\
\text { (experiments) } \\
\text { vs. Learning- } \\
\text { by-doing }\end{array}$ & $\begin{array}{l}\text { How do firms } \\
\text { learn new } \\
\text { routines? }\end{array}$ & $\begin{array}{l}23 \text { pharma- } \\
\text { ceutical and } \\
\text { biotechnology } \\
\text { process } \\
\text { development } \\
\text { projects } \\
\text { DV: lead time }\end{array}$ & $\begin{array}{l}\text { Learning-by-doing is } \\
\text { faster when low } \\
\text { theoretical knowledge; } \\
\text { learning before doing is } \\
\text { faster when theoretical } \\
\text { knowledge is high. }\end{array}$ & $\begin{array}{l}\text { When does } \\
\text { learning } \\
\text { before doing } \\
\text { and learning- } \\
\text { by-doing } \\
\text { accelerate } \\
\text { learning? }\end{array}$ \\
\hline $\begin{array}{l}\text { Van de Ven } \\
\text { and Polley } \\
(1992)\end{array}$ & $\begin{array}{l}\text { Trial and } \\
\text { error }\end{array}$ & $\begin{array}{l}\text { How do firms } \\
\text { learn by trial } \\
\text { and error? }\end{array}$ & $\begin{array}{l}\text { A single bio- } \\
\text { medical } \\
\text { innovation } \\
1983-1988 \\
\text { Large firm }\end{array}$ & $\begin{array}{l}\text { Firms adapt when trials } \\
\text { fall short of } \\
\text { expectations. Trial-and- } \\
\text { error learning scant } \\
\text { during expansion, } \\
\text { found during } \\
\text { contraction period. }\end{array}$ & $\begin{array}{l}\text { How can } \\
\text { trial-and-error } \\
\text { learning be } \\
\text { accelerated? }\end{array}$ \\
\hline $\begin{array}{l}\text { Haunschild } \\
\text { and Miner } \\
\text { (1997) }\end{array}$ & $\begin{array}{l}\text { Learning } \\
\text { from } \\
\text { others- } \\
\text { Vicarious }\end{array}$ & $\begin{array}{l}\text { Are different } \\
\text { modes of } \\
\text { vicarious } \\
\text { learning } \\
\text { independent? }\end{array}$ & $\begin{array}{l}539 \\
\text { acquisitions } \\
63 \text { Investment } \\
\text { banking firms }\end{array}$ & $\begin{array}{l}\text { Three types of } \\
\text { vicarious learning: } \\
\text { frequency, trait, and } \\
\text { outcome. Differences } \\
\text { between copying } \\
\text { success and failure. }\end{array}$ & $\begin{array}{l}\text { Which } \\
\text { modes, if any, } \\
\text { can be } \\
\text { accelerated? }\end{array}$ \\
\hline $\begin{array}{l}\text { Haunschild, } \\
\text { (1993) }\end{array}$ & $\begin{array}{l}\text { Learning } \\
\text { from others - } \\
\text { Vicarious }\end{array}$ & $\begin{array}{l}\text { Do firms } \\
\text { imitate } \\
\text { acquisition } \\
\text { strategies } \\
\text { observed via } \\
\text { direct ties? }\end{array}$ & $\begin{array}{l}327 \text { firms } \\
\text { with over } \\
\$ 35 \mathrm{M} \text { in } \\
\text { revenue } \\
\text { DV: number } \\
\text { of } \\
\text { acquisitions } \\
\text { over } \$ 1 \mathrm{M}\end{array}$ & $\begin{array}{l}\text { Outcomes affect } \\
\text { likelihood of imitation. } \\
\text { The amount of average } \\
\text { premium paid by firms } \\
\text { using a specific bank } \\
\text { influences the } \\
\text { likelihood of imitation. }\end{array}$ & $\begin{array}{l}\text { How do direct } \\
\text { ties affect } \\
\text { learning } \\
\text { speed? }\end{array}$ \\
\hline $\begin{array}{l}\text { Lapre and } \\
\text { Wassenhove } \\
\text { (2001) }\end{array}$ & $\begin{array}{l}\text { Experiment- } \\
\text { ation vs. } \\
\text { learning-by- } \\
\text { doing }\end{array}$ & $\begin{array}{l}\text { Can firms } \\
\text { accelerate } \\
\text { learning with } \\
\text { incomplete } \\
\text { knowledge of } \\
\text { production } \\
\text { function? }\end{array}$ & $\begin{array}{l}4 \text { production } \\
\text { lines in single } \\
\text { manufacturing } \\
\text { organization }\end{array}$ & $\begin{array}{l}\text { Formal learning via } \\
\text { experimentation } \\
\text { accelerates learning } \\
\text { when knowledge } \\
\text { diversity is high. }\end{array}$ & $\begin{array}{l}\text { How can } \\
\text { firms build } \\
\text { knowledge } \\
\text { diversity? }\end{array}$ \\
\hline
\end{tabular}


Much research has investigated how to improve the production function either by reducing production costs (Adler \& Clark, 1991; Lapré \& Van Wassenhove, 2001) or production time (Darr et al., 1995; Pisano et al., 2001). Organizations improve production function in manufacturing settings by conducting training (Adler \& Clark, 1991), making engineering changes (Adler \& Clark, 1991), experimenting (Terwiesch \& Bohn, 2001), increasing knowledge diversity (Lapré \& Van Wassenhove, 2001), or improving quality (Ittner et al., 2001). Although important, this body of work has limitations. First, it omits early learning. For example, in their study of four steel wire production lines at a Belgian multinational corporation, Lapré and Van Wassenhove (2001) found that management buy-in and knowledge diversity improved formal learning resulting in productivity improvements. However, they did not examine learning that happened prior to production. Adler and Clark (1991) also investigated how to improve the production function. They found that engineering changes and employee training improve the production function either by reducing costs or by improving quality. However, they also do not address learning that happened prior to production. Thus, these studies are left truncated. Moreover, in some knowledge-intensive industries learning what to produce might be more important than learning how to produce efficiently.

Other work has begun to investigate how some firms learn faster than others in nonmanufacturing settings. For example, Pisano, Bohmer and Edmondson (2001) and Edmondson (2003) studied 16 hospitals whose cardiac surgery teams learned a new operating procedure. After finding that some of the surgery teams learned the new procedure more quickly than others, the authors conducted a post-hoc comparison between a fast- and a slowlearning hospital to explore why some learned the new procedure more quickly. Compared to 
the slow-learning hospital, the fast-learning hospital had a stable team that attended training together, had strong intra- and interdepartmental communication, planned, analyzed process and outcome data, and had a surgeon who encouraged input from team members. This study examined how operating teams learned an existing procedure. However, because the procedure itself was invented elsewhere, it is a study of accelerated learning of a known process, not an innovation.

Prior work on accelerating learning-by-doing is limited to learning during production ramp-up, which results in process improvements. Less is known about how to accelerate earlier learning (including learning what to produce) or learning in knowledge intensive, nonmanufacturing industries.

\subsubsection{Learning from Others}

Another way firms learn is by observing others, sometimes called vicarious learning (Haunschild \& Miner, 1997; Haunschild, 1993; Huber, 1991). Scholarship on learning from others is rooted in individual social learning theory (Bandura, 1977) and studies of organizational imitation (DiMaggio \& Powell, 1983). Research shows that firms learn by observing alliance partners (Brown \& Eisenhardt, 1997; Khanna et al., 1998), franchisees (Darr et al., 1995), industry peers (Zuckerman \& Sgourev, 2006), or firms sharing board members (Davis, 1991; Haunschild, 1993; Westphal, Seidel, \& Stewart, 2001).

There are several advantages to learning from others. Perhaps the most salient to acceleration is that firms can learn without the burden of "accumulating experience" (Ingram, 2002), making learning from others widely available (Baum, Li, \& Usher, 2000) and relatively inexpensive (Ingram, 2002; Miner \& Haunschild, 1995). Vicarious learning also expedites gathering heterogeneous information, because learners can observe many firms 
simultaneously (Bingham \& Davis, 2012). Heterogeneous information improves performance (Beckman \& Haunschild, 2002) and expands learning by changing a firm's range of potential behaviors (Huber, 1991). Cognitive limits to learning from heterogeneous experiences are higher when firms learn from other firms' experiences than when firms learn from their own (Barkema \& Schijven, 2008).

Learning from others accelerates learning prior to market entry (Bingham \& Davis, 2012; Darr et al., 1995; Haunschild \& Miner, 1997; Haunschild, 1993; Huber, 1991). For example, Argote's (1996) study of shipyards established that organizations learn vicariously prior to the start of production, which advances learning because firms can learn vicariously even before they create their own experience. Learning from others is faster when firms are related by a superordinate structure (Kane, Argote, \& Levine, 2005). For example, Darr and coauthors' (1995) study of 36 franchised pizza stores found that stores with the same franchisee ownership learned a novel pepperoni spreading technique faster than stores owned by other franchisors. Firms can also enhance vicarious learning by learning from geographically proximate competitors (Kim \& Miner, 2007) and via social ties (Bell \& Zaheer, 2007). Thus proximity, in general, seems to accelerate learning from others. Another way to improve learning from others is to plan to learn (Hamel, 1991; Khanna et al., 1998). For example, in his detailed qualitative study of nine international alliances, Hamel (1991) not only found firms that planned to learn from partners learned more, he also found firms that formed alliances with the intention to substitute external knowledge for a deficiency in internal knowledge learned less than firms that had an internalization or learning intent. Firms that lack foundational absorptive capacity may not be able to internalize the strategies of focal firms (Cohen \& Levinthal, 1990; Zahra \& George, 
2002). Khanna and coauthors (1998) expanded on Hamel's notion of intent and found that partnering firms race to learn from each other. Racing increases the speed of learning when the partnering firm that completes learning first subsequently terminates the relationship. Although Khanna and coauthors (1998) found evidence that firms race to learn in alliances, they did not explain how some firms learn faster than their partners. Thus, like the research on learning curves, this research provides more evidence that firms learn at different rates but falls short of suggesting how firms might accelerate learning.

Some research suggests that in turbulent or fast-paced markets vicarious learning can be slower than learning from experience, because observers need to wait for others to accumulate experience (Bourgeois \& Eisenhardt, 1988) prior to constructing their own experience. Thus, although research suggests that firms might accelerate learning by learning vicariously, it also raises questions about whether learning vicariously is expeditious in uncertain markets.

In sum, prior research has established that learning from others is most effective when it travels via direct ties to firms with adequate levels of absorptive capacity. Planning or intent further improves learning from others. Learning firms benefit from observing heterogeneous firms as well as firms with heterogeneous experiences. However researchers caution that vicarious learning can be incomplete, leading vicarious learners to undesirable outcomes (Denrell, 2003). Although much is known about learning from others, questions remain. Bingham and Davis (2007) note that some firms begin learning sequences with vicarious learning, yet research has not yet determined whether vicarious learning accelerates overall learning. That is, does learning from others enable firms to accelerate learning? Finally how might firms accelerate learning from others? 


\subsubsection{Experimental}

Like organizations that learn from others, organizations that learn from experiments can begin learning before creating their own direct experience. Firms learn from experiments by planning and conducting experiments and analyzing results (Miner et al., 2001). They test hypotheses about causal relationships by creating "contrasting situations in order to generate systematic experience” (Miner et al., 2001) sometimes using prototypes (Pisano, 1994). Inputs are deliberately varied, and the level of heterogeneity is controlled by the experimental design. Thus, planning, execution and analysis are central to experimental learning.

Prior work suggests that experimental learning may help firms accelerate learning within a particular domain (Levitt \& March, 1988) when two important conditions are met: First, learners must have a cogent theoretical understanding of their problem to hone in on key variables, otherwise experimental learning might progress more slowly (Pisano, 1994) or lead to proficiency in a sub-optimal specialty (Levinthal, 1997). Second, the laboratory setting must closely resemble the real environment or information garnered from a laboratory setting may not apply in the real environment (Pisano, 1994). Repeated shifting between laboratory and production settings improves organizational learning in general (Tyre \& Von Hippel, 1997). Finally, experimentation is preferable when environmental conditions are relatively stable (Pisano, 1994, 1996). When the environment is turbulent, learning by doing is preferred (Pisano, 1994, 1996).

Although some prior work seems to address the speed of experimental learning, it actually assumes that learning speed is fixed. For example, Pisano (1994) examined the elapsed calendar time (net of idle time) between the start and completion of process development projects and then proportionally attributed the amount of learning acquired 
during each phase based on the amount of time a firm spends in each project phase — research and pilot. Thus, Pisano (1994) assumed that learning speed is fixed and that all modes of learning produce learning at the same speed. Using transportation as a metaphor, this is like calculating distance traveled based on travel time - regardless of whether you are traveling by plane or horse. If some modes of learning are more efficient, then elapsed time underestimates the amount of learning that occurs during a specified amount of time. Thus, further investigation is necessary to determine how experiments might accelerate learning.

\subsubsection{Trial and Error}

Firms also learn from on-line trial-and-error (Miller \& Shamsie, 2001; Miner et al., 2001). To learn by trial and error, firms repeatedly try strategies and retain those strategies that generate performance that meets or exceeds their aspiration levels but shift to a new strategy when performance falls short of aspirations (Greve, 2003; Van de Ven \& Polley, 1992). Trial-and-error learning happens after a firm evaluates outcomes from attempted strategies. Moreover, firms use trial-and-error learning when they have their own experience - this distinguishes it from off-line experimental learning, which is available to firms prior to developing their own experience.

Like other forms of learning, trial-and-error learning has limitations. For one, firms need to wait for feedback after each trial and then decide whether or not to retain the trial strategy. This sequential process can be laborious; when strategies fall short of aspirations firms only know which strategies to eliminate, not what strategy to pursue. Yet another limitation is that firms might not know the potential of a strategy when they first try it (Levinthal \& March, 1993). As firms acquire experience with retained strategies, performance of those strategies will likely improve through learning from experience. When 
firms compare the performance of a trial strategy with a retained strategy that has the benefit performance improvements garnered through experience, the performance of the trial strategy is likely to seem insufficient, because the trial strategy has not benefitted from experience (Levinthal \& March, 1993; Levitt \& March, 1988). Thus, learning from trial and error tends to favor retained strategies that have benefited from learning from experience.

As firms learn from trial and error, they eliminate poorly performing strategies. Thus, firms must have a tolerance for failure. Even so, firms learn more from small shortfalls than from larger gaps, which can cause rigid responses, or large successes, which can reduce learning motivation (Hayward, 2002; Sitkin, 1992). However, learning iteratively from small losses might limit the speed of learning, because firms take only small steps toward desired outcomes. Even more, shifting to a new strategy resets the "learning clock back to zero," further disadvantaging new strategies and delaying learning (Van de Ven \& Polley, 1992: 95).

\subsubsection{Improvisation}

Learning new strategies is not always intentional. Sometimes, firms spontaneously create and try new strategies, aptly named improvisational learning (Miner et al., 2001). Firms learn by improvisation when they try new strategies "on the fly," often because they encounter constraints or uncover newly unfolding opportunities (Miner et al., 2001). To be considered improvisational, an activity's design and implementation must happen nearly simultaneously. The primary difference between improvisational and other forms of learning is that an alternate strategy is implemented without advance planning.

Because improvisational learning merges design with implementation (Moorman \& Miner, 1998), it can be quick. Miner and coauthors (2001) observed that new product 
development teams were more likely to use improvisational methods when they were under time pressure, further suggesting that firms may rely on improvisational learning when they do not have time to plan. Improvisation might accelerate learning because it reduces time spent in planning while still introducing new knowledge to the firm (Miner et al., 2001).

Though improvisation requires unplanned changes to strategy, firms can nevertheless encourage improvisation. Miner and coauthors (2001) suggested that improvisational learning can be intentionally stimulated without specifying the content. That is, firms can develop routines that lead to improvisation even though the outcome of improvisation is unknown a priori. Firms foster opportunities for improvisational learning by improving communication (Edmondson, Winslow, Bohmer, \& Pisano, 2003) and developing tolerance for cognitive reframing (Edmondson et al., 2003; Miner et al., 2001). Through rich communication, organizational members exchange tacit information that may unfold new opportunities for the firm. Moreover, when firms improvise, strong communication keeps other members in the team informed of new strategies, which reduces confusion (Eisenhardt \& Martin, 2000).

Although researchers have suggested that firms rely on improvisation when they are under time pressure, we do not yet know how firms might accelerate improvisational learning. Research suggests there might be a tradeoff between speed and novelty: Moorman and Miner (1998) found that increases in procedural memory accelerated improvisational activities but reduced their novelty, while increases in declarative memory reduced the speed but increased the novelty of improvisational activities. How might firms use improvisation to accelerate learning yet not restrict the novelty of what is learned? 


\subsubsection{Learning Mode Discussion}

Empirical investigations clearly establish that organizations learn at different rates but rarely explore how some firms learn more quickly than others. Those studies that have examined how to accelerate learning tend to answer the question in terms of how to accelerate improvements in the production function, therefore concentrating on learning after the first unit is produced and omitting learning prior to production. Less is known about how to accelerate learning related to inventing new products and in knowledge-intensive industries.

Much of the literature on learning speed simply compares the speed of learning-bydoing to another type of learning — e.g., vicariously or experimentation - to identify the faster mode (Bourgeois \& Eisenhardt, 1988; Pisano, 1994). Generally, this research finds that when uncertainty is high, learning-by-doing is faster, but when firms have a high theoretical understanding of the market, then experimentation might be faster (Pisano, 1994). This stream of research assumes that the speeds of different learning modes are fixed; rather than suggesting how to accelerate learning, work that compares learning modes generally assumes that learning speeds are constant. Thus, my research question is: How might firms accelerate learning?

\subsection{Time Compression}

\subsubsection{Time Compression Diseconomies}

Foundational work on organizational learning favors slow, rather than fast, learning (Dierickx \& Cool, 1989; Levinthal \& March, 1981; Levitt \& March, 1988). A widespread assumption in the literature is that, due to time compression diseconomies, the amount of organizational learning absorbed diminishes as it is temporally compressed. For example, 
Dierickx and Cool (1989) explained that squeezing a two-year MBA program into a single year would leave students with less learning, even if all other aspects of the program remained constant. In an organizational context, firms that learn too quickly risk specializing a sub-optimal strategy (Levinthal, 1997; Levitt \& March, 1988), failing to absorb knowledge (Cohen \& Levinthal, 1990), or even declining overall firm performance (Vermeulen \& Barkema, 2002).

Generally, organizational learning theory posits that organizations that learn too quickly choose inferior solutions. For example, based on an extensive literature review, Levitt and March (1988), caution that "there is a tendency for organizations to specialize and for faster learners to specialize in inferior technologies" (Levitt \& March, 1988). Simulation models concur that fast learning may inadvertently lead firms quickly down inferior paths (Levinthal, 1997). Not only is fast organizational learning of concern, but fast learners within an organization are also a concern, because organizations with a greater proportion of fast individual learners drive out individual-level heterogeneity before the organization's optimal strategy is found (March, 1991).

The core premise of this work is that organizations that hone in on a solution too quickly are more likely to optimize on an inferior strategy and then build experience near the chosen strategy. Comparatively, organizations that patiently explore more possible solutions ultimately find better strategies, albeit more slowly (March, 1991). However, an assumption is rife in this work: heterogeneity is directly related to speed. That is, the heterogeneity of ideas is directly related to elapsed calendar time such that the greater the elapsed time, the broader the set of considered ideas. Thus, the real conclusion of this work might not be that learning slowly, or embracing slow learners, enables organizations to reach more optimal 
solutions but rather that heterogeneity during the organizational learning process improves outcomes (Huber, 1991; Schilling, Vidal, Ployhart, \& Marangoni, 2003). However, firms may vary in the speed at which they gather and evaluate heterogeneous ideas, questioning the relationship between the number of ideas considered and elapsed calendar time. Moreover, "more time" in a simulation model is typically a larger number of runs of the simulation model. Overall, the effects of time compression on learning remain relatively unexplored empirically. It is unknown how firms might time compress the benefits of increased heterogeneity.

\subsubsection{Time Compression Economies}

Although theoretical work on time-compressed learning suggests that accelerated learning is ill-advised, empirical work in new product development (Chen, Reilly, \& Lynn, 2005; Kessler \& Bierly, 2002; Lynn et al., 1999; Schoonhoven, Eisenhardt, \& Lyman, 1990; Wheelwright \& Clark, 1994), technology commercialization (Markman, Gianiodis, Phan, \& Balkin, 2005), and decision making (Bourgeois \& Eisenhardt, 1988; Eisenhardt, 1989b) finds the opposite: Acceleration leads to improved performance. Time compression economies have been found for multiple conceptualizations of performance, including economic value (Schoonhoven et al., 1990), quality (Kessler \& Bierly, 2002), perception (Lynn et al., 1999), and revenue (Markman et al., 2005). For example, Kessler and Bierly (2002) found that innovation speed more closely correlates with new product development (NPD) success than either increased quality or reduced cost. (For a summary of literature suggesting timecompression economies, including what is economized, see Table 3.)

Research espouses many reasons why acceleration leads to improved outcomes.

Some reasons, like locking up distribution channels and establishing industry standards stem 
from pioneering new markets (Lynn et al., 1999), because speed is intrinsically related to first-mover advantages (Klepper \& Simons, 2000; Lieberman \& Montgomery, 1988) as well as fast-follower strategies (Hawk et al., 2012; Lieberman \& Montgomery, 1998). Speed might also enhance performance because firms that are intrinsically faster than their competitors can delay entry decisions until uncertainty is lower, avoiding the risks of early entry (Hawk et al., 2012). Other reasons for improved outcomes under time compression reflect improvements in internal processes and might be more relevant to time-compressed learning. For example research shows that time pressure improves communication and stabilizes goals (Lynn et al., 1999). Although this research finds benefits to time compression, it has not yet investigated the effects of time compressed learning.

In sum, the organizational learning and speed literatures come to opposing conclusions: Organizational learning theorists posit that acceleration reduces the amount that is learned. To the contrary, scholars of organizational processes, such as new product development speed find time-compression economies. However, neither stream has empirically studied time-compression economies of learning. Thus, the literatures on organizational learning and speed have not been adequately bridged.

\subsection{Organizational Speed}

I now turn to research on how firms accelerate other organizational activities, such as commercialization, decision making, and new product development. I begin by reviewing the acceleration strategies available to firms, including pacing, continuous change, and planning. (See Table 4 for selected studies on how to speed up.) 


\subsubsection{Pacing}

One way firms accelerate organizational activities is by pacing events in regular intervals (Gersick, 1991, 1994, 1988). Firms that pace activities, such as internationalization (Vermeulen \& Barkema, 2002) and product launches (Turner, Mitchell, \& Bettis, 2011), in a regular, rhythmic pattern perform better than firms that follow more random patterns (Vermeulen \& Barkema, 2002). By pacing, firms maintain forward momentum through repetitive deadlines and coordinating internal and external actors (Bingham \& Eisenhardt, 2011; Eisenhardt \& Brown, 1998).

Ostensibly, Vermeulen and Barkema (2002) explore the relationship between pacing and learning. They posited that regularly paced international entries enabled firms to learn between country entries. Although they found that firms that entered countries at a regular pace outperformed those that followed a more irregular time-pattern, it is not clear that they actually observed learning speed because they measure the rate of internationalization rather than the rate of learning. Moreover, rather than directly observe learning, they inferred it based on changes in profitability. The authors then assumed that diminishing returns to profitability were due to time-compression diseconomies of learning; however they neither measured learning outcomes nor learning speed.

Pacing can be either time-based or event-based, but time-pacing accelerates organizational activities because it gives managers more control over speed. Event-based pacing puts more emphasis on outcomes than speed (Gersick, 1994). Groups engage in transformative change halfway between a project's start and completion date (Gersick, 1988), or if there is no deadline then when the project is about half completed (Gersick, 1994). This empirical regularity has been observed both in empirical and experimental 
studies and holds regardless whether the duration of the project is a few hours or several months (Gersick, 1989, 1988; Waller, Zellmer-Bruhn, \& Giambatista, 2002). Seven out of eight of the teams in Gersick's (1988) foundational study were fairly inertial until halfway through their allotted time and did not initially explore broadly. At the halfway point, seven of the teams experienced major transitions in the form of a "burst" of changes. After this burst, teams experienced a period of momentum, which concluded with a secondary burst prior to the end of the task time.

Table 3: Selected Studies Finding Time-Compression Economies

\begin{tabular}{|l|l|l|l|}
\hline Study & Time-compression & Process & Outcome variable \\
\hline $\begin{array}{l}\text { Kessler and } \\
\text { Bierly (2002) }\end{array}$ & $\begin{array}{l}\text { "faster development time is } \\
\text { related to higher quality } \\
\text { products" }\end{array}$ & NPD & Quality \\
\hline $\begin{array}{l}\text { Schoonhoven, } \\
\text { Eisenhardt, \& } \\
\text { Lyman (1990) }\end{array}$ & $\begin{array}{l}\text { "Shorter development times } \\
\text { created greater economic value } \\
\text { for the innovating } \\
\text { organization," }\end{array}$ & NPD & Economic value \\
\hline $\begin{array}{l}\text { Lynn, Skov, and } \\
\text { Abel (1999) }\end{array}$ & $\begin{array}{l}\text { "Projects brought to market } \\
\text { quickly were more likely to be } \\
\text { perceived as successful." }\end{array}$ & NPD & $\begin{array}{l}\text { 8-item scale of NPD } \\
\text { success }\end{array}$ \\
\hline $\begin{array}{l}\text { Hawk, Pacheco- } \\
\text { De-Almeida, and } \\
\text { Yeung, (2012) }\end{array}$ & $\begin{array}{l}\text { sample (with a market } \\
\text { capitalization of \$27.6 billion), } \\
\text { a two-month } \\
\text { acceleration in average project } \\
\text { execution speed results in a } \\
\text { \$94.6 million increase in } \\
\text { predicted } \\
\text { entry performance" }\end{array}$ & $\begin{array}{l}\text { Internationaliza- } \\
\text { tion }\end{array}$ & $\begin{array}{l}\text { Cumulative } \\
\text { abnormal stock } \\
\text { market return at the } \\
\text { time when a firm } \\
\text { announces entry }\end{array}$ \\
\hline $\begin{array}{l}\text { Markman, } \\
\text { Gianiodis, Phan, } \\
\text { and Balkin (2005) }\end{array}$ & $\begin{array}{l}\text { Faster commercialization of } \\
\text { university technology leads to } \\
\text { more licensing revenue and } \\
\text { more start-up ventures }\end{array}$ & $\begin{array}{l}\text { Tech Transfer } \\
\text { initial investment and first } \\
\text { earnings create greater } \\
\text { economic value }\end{array}$ & $\begin{array}{l}\text { Revenue and Start- } \\
\text { ups }\end{array}$ \\
\hline Gilman (1982) & $\begin{array}{l}\text { Innovation } \\
\text { anorter elapsed time between }\end{array}$ & $\begin{array}{l}\text { Innovation } \\
\text { introduction rate }\end{array}$ \\
\hline
\end{tabular}


In sum, although much work has been done to examine how pacing might help firms accelerate activities such as new product development and internationalization, this literature has omitted learning. Thus, questions remain about how pacing might accelerate learning.

\subsubsection{Planning}

Another way for organizations to accelerate is by planning and then compressing steps. Planning may expedite organizational activities, because firms use plans to allocate resources, coordinate activities, and avoid mistakes (Delmar \& Shane, 2003; Song, Im, van der Bij, \& Song, 2011). Planning is particularly effective when environments are stable; in turbulent environments, plans can become outdated before being implemented (Eisenhardt \& Tabrizi, 1995). Planning activities (e.g., planning meetings, market and scenario analysis, portfolio analysis) accelerate firms, though codifying plans delays them (Brinckmann,

Grichnik, \& Kapsa, 2010). Established small firms benefit more from planning than newer small firms because they have more knowledge and established routines (Brinckmann et al., 2010).

In their survey of 72 product mangers in computer corporations with sales of over \$50M, Eisenhardt and Tabrizi (1995) compared planning and compressing steps to implementing without a plan. When markets were uncertain, planning and compressing rational steps extended time to market while experiential strategies, including testing and multiple design iterations, reduced time to market. When markets were more stable, teams that compressed new product development steps by involving suppliers and overlapping development steps brought products to market more quickly. Although frequent milestones accelerated product development, rewarding for schedule did not. 
Theoretically, there are several reasons why planning may delay rather than accelerate organizations. Organization theory suggests that time spent in planning may detract managers from implementation, which might more directly impact speed (Ocasio, 1997). Also, planning causes rigidities, especially when plans are formalized or when resources are acquired according to the plan (Leonard-Barton, 1992). Rigidities can delay product development when modifications are required, which is especially likely in rapidly changing markets. Finally, firms may never encounter the anticipated problems that surfaced during planning or may develop unforeseeable solutions to problems; firms that implement without a plan may develop unplanned strategic advantages (Sarasvathy, 2001).

In sum, prior research suggests that more time spent planning might shorten product development time by optimizing processes, avoiding mistakes, and coordinating efforts. However, when markets are rapidly changing, planning might delay time to market. Although planning might be considered a learning activity, because planners must envision the future to develop plans (Gavetti \& Levinthal, 2000), the literature linking planning to speed generally fails to address learning. There are two notable exceptions: Recall that the exploratory work done by Pisano and his coauthors (2001) found that the fast-learning hospital planned while the slower learning hospital did not, suggesting that planning might accelerate learning; and Eisenhardt and Tabrizi (1995) integrated learning and planning in their study of new product development teams in the computer industry. However, Eisenhardt and Tabrizi portrayed planning and learning as discrete approaches to new product development, thus did not explore how planning might accelerate learning. Therefore, although prior researchers have contrasted the effects of planning and learning on 
new product development speed, more work is needed to explore how planning might affect learning speed.

\subsubsection{Prior Experience}

The experience of team members and characteristics of teams' compositions also influence organizational speed. The prior experience of entrepreneurial founding teams, in particular, might endure well past the tenure of the team members (Baron, Hannan, \& Burton, 1999; Stinchcombe, 1965), though the specific relationship between prior experience and speed is muddled. Some research suggests that start-ups with a CEO and top management team members (TMT) with prior industry and start-up experience bring products to market more quickly (Heirman \& Clarysse, 2007; Kessler \& Chakrabarti, 1996) and are less likely to fail (Yang \& Aldrich, 2012). Other research failed to find support for a relationship between prior industry experience or prior start-up experience and speed to market (Schoonhoven et al., 1990).

Teams with more experience working together might be more expeditious than newly formed teams, because teams with joint experience might retain previously developed work processes and communication patterns (Brown \& Eisenhardt, 1995), including knowing who knows what (Wegner, 1987). There is mixed support for this proposition. Schoonhoven and coauthors (1990) tested for but did not find that the tenure of a team improved speed. Heirman and Clarysse (2007) found that team joint experience accelerated product launches for software teams but had the opposite affect for telecom and medical companies. Having a stable team within a firm has been found to expedite new product development (Cooper \& Kleinschmidt, 1994). Thus there are questions about when a team's joint experience transfers to a new firm and when it might accelerate learning. 


\subsubsection{Team Composition and Traits}

Team composition also affects organizational speed. Cross-functional teams accelerate new product introductions, both in entrepreneurial teams (Cooper \& Kleinschmidt, 1994; Schoonhoven et al., 1990) and in established firms (Eisenhardt \& Tabrizi, 1995). Homogenous management teams respond more quickly to competitor moves but launch innovative products more slowly (Hambrick, Cho, \& Chen, 1996).

The nature of the CEO or team leader also impacts organizational speed. Strong leaders bring products to market more quickly (Cooper \& Kleinschmidt, 1994; Eisenhardt \& Tabrizi, 1995; Kessler \& Chakrabarti, 1996; Wheelwright \& Clark, 1994) and facilitate accelerate decision making (Bourgeois \& Eisenhardt, 1988). This differs with organizational learning studies that suggest that inclusive leaders accelerate learning (Pisano et al., 2001). Given the inconsistency between the speed literature, which suggests that stronger CEOs launch products more quickly, and the learning literature, which suggests that more inclusive CEOs encourage team-learning, questions remain about the relationship between the perceived strength of a CEO or team leader and learning speed.

Teams that have worked together before also accelerate organizational speed, though theory points us in opposing directions. On one hand, teams with joint experience may be faster, because they have developed transactive memory systems that store knowledge about team member's individual competencies, group coordination, communication, and trust, thus might accelerate learning by expediting searching for information known by the collective team (Wegner, 1987). On the other, shared experience may constrain knowledge sharing (Stasser \& Titus, 1987), knowledge combinations (Kogut \& Zander, 1992), and search (Leonard-Barton, 1992), leading to more incremental learning. Work in this tradition 
generally examines the relationship between teams and the speed of an organizational activity other than learning, and little is known about how team experience and composition might affect learning speed.

Overall, prior work excludes learning from the discussion of the effects of team experience and composition on speed outcomes. The dependent variable in these studies is generally the speed of an organizational process, such as new product development. Some studies discuss how learning might accelerate organizational processes, but extant research falls short of suggesting how firms might accelerate learning. Thus, the relationship between prior industry, start-up, and joint experience and learning speed remains elusive. Finally, the speed and learning literature provide conflicting guidance on the effect of strong leaders. The speed literature suggests that strong leaders bring products to market more quickly, while the learning literature suggests that strong leaders may not elicit divergent opinions and might constrain learning. This study explicitly examines team characteristics on learning speed, addressing the many related gaps discussed in this section.

\subsection{Literature Discussion}

Prior work on organizational learning suggests many ways organizations learn, including by experience, observing others, experimenting, trial and error, and improvisation. Research suggests that firms follow learning curves, whereby more experience leads to more learning (Argote, 1999). Firms learn at varying rates (Argote \& Epple, 1990; Argote, 1999;

Dutton \& Thomas, 1984; Pisano et al., 2001), thus some firms are able to learn more quickly than their peers. Much research examining how firms accelerate learning from experience is limited to learning during production ramp-up after the first product is defined and often examines the speed of an activity other than learning. Moreover, research in this tradition 
compares the speed of different modes of learning, assuming that learning speeds are fixed. (See Table 5 for a summary of studies that compare learning modes.) Thus, questions remain about how to accelerate learning in other contexts. That is, how does accelerated learning happen? 
Table 4: Selected Organizational Speed Studies

\begin{tabular}{|c|c|c|c|c|}
\hline Article & $\begin{array}{l}\text { What is } \\
\text { accelerated? }\end{array}$ & Research question & Sample & Main concept \\
\hline $\begin{array}{l}\text { Eisenhardt and } \\
\text { Tabrizi (1995) }\end{array}$ & NPD & $\begin{array}{l}\text { When do firms use } \\
\text { a compression } \\
\text { model and when do } \\
\text { they use an } \\
\text { experimentation } \\
\text { model of } \\
\text { acceleration? }\end{array}$ & $\begin{array}{l}72 \text { products at } 36 \\
\text { computer } \\
\text { companies in the } \\
\text { United States, } \\
\text { Europe, and Asia } \\
\text { with sales greater } \\
\text { than } \$ 50 \text { million. }\end{array}$ & $\begin{array}{l}\text { NPD speed processes differ } \\
\text { under different levels of } \\
\text { uncertainty. Compression } \\
\text { works best when low- } \\
\text { uncertainty and acceleration } \\
\text { (experimentation) when high } \\
\text { uncertainty. }\end{array}$ \\
\hline $\begin{array}{l}\text { Heirman and } \\
\text { Clarysse } \\
(2007)\end{array}$ & $\begin{array}{l}\text { 1st new } \\
\text { product } \\
\text { launch }\end{array}$ & $\begin{array}{l}\text { When do start-ups } \\
\text { launch their first } \\
\text { product more } \\
\text { quickly? }\end{array}$ & $\begin{array}{l}99 \text { research-based } \\
\text { start-ups founded } \\
\text { in Flanders }\end{array}$ & $\begin{array}{l}\text { Speed to launch is affected by } \\
\text { tangible assets, such as } \\
\text { starting capital and the stage } \\
\text { of product development, and } \\
\text { intangible assets, such as team } \\
\text { tenure, experience of } \\
\text { founders, and collaborations } \\
\text { assets. }\end{array}$ \\
\hline $\begin{array}{l}\text { Brown and } \\
\text { Eisenhardt } \\
\text { (1997) }\end{array}$ & NPD & $\begin{array}{l}\text { How do } \\
\text { organizations } \\
\text { change in fast- } \\
\text { paced industries? }\end{array}$ & 6 computer firms & $\begin{array}{l}\text { Firms continuously change by } \\
\text { continuously linking } \\
\text { sequential projects with } \\
\text { rhythmic processes, extensive } \\
\text { communication, and low cost } \\
\text { probes into the future }\end{array}$ \\
\hline $\begin{array}{l}\text { Schoonhoven, } \\
\text { Eisenhardt and } \\
\text { Lyman (1990) }\end{array}$ & $\begin{array}{l}\text { 1st new } \\
\text { product } \\
\text { launch }\end{array}$ & $\begin{array}{l}\text { What accelerates } \\
\text { first product } \\
\text { shipment for } \\
\text { entrepreneurial } \\
\text { ventures? }\end{array}$ & $\begin{array}{l}98 \text { entrepreneurial } \\
\text { ventures in the } \\
\text { continental United } \\
\text { States } \\
\text { semiconductor } \\
\text { industry }\end{array}$ & $\begin{array}{l}\text { First product launch is } \\
\text { accelerated when product has } \\
\text { lower levels of technological } \\
\text { innovation, firm has low } \\
\text { monthly expenditures, } \\
\text { founding team includes } \\
\text { marketing and manufacturing, } \\
\text { product market has more } \\
\text { competitors, and firm located } \\
\text { in the Silicon Valley. }\end{array}$ \\
\hline $\begin{array}{l}\text { Vermeulen and } \\
\text { Barkema - } \\
(2002)\end{array}$ & $\begin{array}{l}\text { Entry into } \\
\text { foreign } \\
\text { markets }\end{array}$ & $\begin{array}{l}\text { How do different } \\
\text { rates and patterns of } \\
\text { expansion affect } \\
\text { performance? }\end{array}$ & $\begin{array}{l}572 \text { expansions by } \\
22 \text { multinational } \\
\text { firms traded on the } \\
\text { Amsterdam stock } \\
\text { market over } 26 \\
\text { years }\end{array}$ & $\begin{array}{l}\text { The speed, scope, and pace of } \\
\text { internationalization moderate } \\
\text { performance. The main effect } \\
\text { of speed was insignificant. }\end{array}$ \\
\hline $\begin{array}{l}\text { Lynn, Skov, } \\
\text { and Abel } \\
\text { (1999) }\end{array}$ & NPD & $\begin{array}{l}\text { How is speed } \\
\text { related to NPD } \\
\text { success? How can } \\
\text { firms speed NPD? }\end{array}$ & $\begin{array}{l}95 \text { surveys } \\
\text { administered to } \\
\text { NPD managers } \\
\text { affiliate with the } \\
\text { American Society } \\
\text { for Engineering } \\
\text { Management }\end{array}$ & $\begin{array}{l}\text { Reviewing information, } \\
\text { having a NPD process, and } \\
\text { setting clear and stable goals } \\
\text { speed up NPD. }\end{array}$ \\
\hline
\end{tabular}


The effects of time compression on learning are also elusive. Organizational learning theory posits that firms that try to accelerate learning reduce the amount of learning absorbed or optimize on inferior strategies, but organizational speed research finds that acceleration improves outcomes in new product development, technology commercialization, and decision making. Neither of these research streams addresses how to accelerate learning.

The literature on organizational speed suggests that pacing and planning accelerate organizational activities such as new product development, commercialization, and decision making. Team experience and composition also affect organizational speed. However, the speed and learning literatures provide conflicting guidance on the effect of strong leaders. The speed literature suggests that strong leaders bring products to market more quickly, while the learning literature suggests that strong leaders may not elicit divergent opinions and thus might constrain learning. Moreover, prior work on the effect of joint tenure on speed is inconclusive. Overall, this literature examines the speed of an activity other than. Thus we do not know if the same mechanisms accelerate learning.

In summary, I have reviewed the literature on organizational learning and speed to identify some of the factors that might contribute to accelerated learning. There may also be unknown factors, which might be uncovered as a result of this study. 
Table 5: Relative Speed of Learning Mechanisms

\begin{tabular}{|l|l|l|}
\hline Comparison & When faster & When learning-by-doing is faster \\
\hline Experimentation & Cogent theoretical understanding & $\begin{array}{l}\text { Novel technology, lower theoretical } \\
\text { understanding }\end{array}$ \\
\hline Planning & Stable environment & Turbulent environment \\
\hline Trial and error & $\begin{array}{l}\text { Start close to optimum, lab and } \\
\text { environment similar }\end{array}$ & $\begin{array}{l}\text { Unsure where to begin or much to } \\
\text { learn }\end{array}$ \\
\hline Improvisation & $\begin{array}{l}\text { Tolerance for cognitive reframing, } \\
\text { strong communication }\end{array}$ & No comparison \\
\hline
\end{tabular}




\section{CHAPTER 3}

\section{METHODS}

\subsection{Research Setting}

The research setting is accelerator programs: fast-paced, limited-duration entrepreneurship education programs (Miller \& Bound, 2011). Cohorts of nascent ventures enter, participate, and exit programs together. Programs culminate in "Demo Day" events, where venture founders pitch their business concepts to large audiences of potential investors. Accelerators are an ideal setting to study accelerated learning because the limited duration of the programs and grand final presentations create substantial time pressure for participating ventures. A founder described the intensity of the time pressure, "We had a clock that counted down minutes and seconds to Demo Day. It's ridiculous and not sustainable and offensive in terms of humanity." Although the programs' intensity might be challenging for participants, it is ideal for studying business acceleration.

\subsection{Definition of Accelerators}

I begin with the definition provided by NESTA, an independent research organization in the United Kingdom. According to NESTA, accelerators have five main features that distinguish them from other types of investors or business incubators. They are:

- "An application process that is open to all, yet highly competitive.

- Provision of pre-seed investment, usually in exchange for equity.

- A focus on small teams not individual founders.

- Time-limited support comprising programmed events and intensive mentoring.

- Cohorts or 'classes' of startups rather than individual companies." (Miller \& Bound, 2011) 
I discussed the definition of accelerators with industry experts and accelerator founders during exploratory interviews. Based on the information provided by my informants, I relax some of Miller and Bound's (2011) criteria and use the following definition in my research: Accelerators are organizations that provide entrepreneurship education for a limited period of time to cohorts of selected nascent ventures who begin and graduate together. Key to my definition is the concept of cohorts entering and exiting programs together. This distinguishes accelerators from other organizational forms, including incubators and angel investors, who establish and modify relationships with ventures on an ongoing basis.

A typical accelerator invests $\$ 15,000$ to $\$ 20,000$ in two-to-three person venture teams in exchange for 6 to $8 \%$ equity. In general, programs are three months long and cohorts include 10 to 12 ventures. However, there is considerable variation. For example, some accelerators offer office space (e.g., TechStars), but not all (e.g., YCombinator). Cohorts range in size from 5 to over 100 ventures. Some programs offer grants (e.g., RockHealth) or prize money (e.g., MassChallenge) while most provide ventures with investments in exchange for equity. A couple have deals with outside investors who grant all graduating ventures with $\$ 50,000$ to $\$ 150,000$ of convertible debt, priced at the next investment round (e.g., YCombinator, post-2009; Excelerate Labs, post-2011). Most programs are about three months long. Most focus on technology, such as mobile, cloud computing, or software development. However, accelerators help entrepreneurs in a wide range of industries including healthcare (e.g., RockHealth), advertising (e.g., The Brandery), social responsibility (e.g., Bethnal Green Venture), and education (e.g., Imagine k12). Still other programs focus on helping minority (e.g., NewMe) or women (e.g., Women in Mobile) 
entrepreneurs. Some programs have an industry or technology focus (e.g., TechStars Cloud), while others are more general (e.g., MassChallenge). Some programs are affiliated with universities (e.g., StartX), or funded by governments (e.g., MassChallenge), but most are funded by individual investors or successful entrepreneurs.

Some accelerators follow highly structured processes while others are more ad-hoc. Nearly all programs culminate in Demo Days, where venture founders deliver short presentations to large audiences of potential investors. Some programs are closely affiliated with larger organizations, such as ad agencies, government institutions, or universities. Finally, most accelerator founders were formerly entrepreneurs or angel investors, though some were corporate executives or affiliated with public institutions (e.g., incubators or universities). Given the amount of heterogeneity between programs, the accelerator setting provides an interesting opportunity for academic researchers to develop a nuanced understanding of how these programs might impact participating ventures.

\subsection{History of Accelerators}

The first accelerator, YCombinator, was founded in 2005 by Paul Graham, who was an angel investor and former entrepreneur. Since its inception, YCombinator has funded over 450 startups $^{1}$, including Loopt, Reddit, Scribd, Dropbox, Heroku, Posterous, Airbnb, and Hipmunk. According to Forbes Magazine, as of April 2012, the cumulative valuation of YCombinator companies was $\$ 7.8$ billion (Geron, 2012).

Graham founded YCombinator after delivering a speech about how to start a company to a group of undergraduate students at the Harvard Computer Society. During his speech, Graham suggested that budding entrepreneurs raise angel funding from wealthy

\footnotetext{
${ }^{1}$ http://www.ycombinator.com
} 
individuals, preferably successful entrepreneurs with technology backgrounds. When the students turned to him as a potential investor, he immediately added, "Not me," but later decided to invest in a batch of eight ventures (Lee, 2006). An accidental byproduct of simultaneously investing in several ventures founded by young, inexperienced entrepreneurs was batching investments into cohorts and providing education and advice to the group (Levy, 2011). This group of young entrepreneurs included Reddit, which was acquired by Condé Nast for between \$10M and \$13M (Chafkin, 2009), and Loopt, which was acquired for about $\$ 43 \mathrm{M}$ by Green Dot. According to Graham’s blog, batching investments provided unexpected economies. He continued to batch seed-stage investments, eventually forming YCombinator with three cofounders. YCombinator was founded in Cambridge, MA, near Harvard, with a second annual session in the Silicon Valley. Eventually, YCombinator closed the Cambridge office and offered two sessions in the Silicon Valley. Not only is YCombinator the oldest accelerator, but with 84 firms in its last cohort, it is also one of the largest.

YCombinator received much attention in the technology trade press. Given the amount of press it received, it is not surprising that other investors began batching seed investments and offering similar educational programs. One of the first imitators was TechStars. Unlike YCombinator's accidental founding, when TechStars launched in 2007, it had a specific goal in mind: enhance the entrepreneurial community of Boulder, CO. TechStars now has locations in Boulder, Boston, Seattle, New York City, and Austin, TX, as well as a growing global network of 50 affiliated accelerators through the Global Accelerator Network. TechStars' founders and accelerator directors have been prolific public advocates 
of accelerators and entrepreneurship ${ }^{2}$. For example, they aired a reality show on Bloomberg TV that highlighted key events of the 2011 New York cohort, and one of the founders, Brad Feld, has penned several popular entrepreneurship books (e.g., Feld \& Cohen, 2010; Feld \& Mendelson, 2011). Further promoting entrepreneurship, the TechStars Web site includes standard documents such as term sheets.

Today, there are more than 300 acceleration programs on five continents that have collectively helped 2500 firms $^{3}$. These numbers are growing rapidly, making seed accelerators an important, but under-studied, topic for research.

\subsection{Comparison: Accelerators, Incubators and Angels}

Accelerators are similar to but different from incubators and angel investors. (See Table 6 for a summary of the differences between incubators, investors, and accelerators.) Although all three organizational forms assist fledging ventures, a few key variations differentiate accelerators. The most important difference is the duration of the programs. Ventures in incubators stay indefinitely and enter and exit individually (Rothaermel \& Thursby, 2005a). Ventures in accelerators stay for a predetermined amount of time and enter and exit in cohorts. Set timelines and strict graduation dates reduces codependency between ventures and accelerators and forces ventures to face market selection mechanisms. One of the industry's pioneers explained,

The fundamental difference between an incubator and an accelerator is by having a finite duration, it really forces these companies to get a lot done get in a very short period of time.. .. If you have something that has a 6-12 months duration you end up in a co-dependent relationship that is not particularly healthy. We are trying to help very aggressively at the front and then help continually through the life of the

\footnotetext{
${ }^{2}$ See, for example, Brad Feld, David Cohen, and David Tisch.

${ }^{3}$ There is no official count of accelerators, I have hand-collected a database of approximately 300 accelerators operating on five continents.
} 
companies in the next one to ten years. But if you stretch out that intense fun and period you start to build more dependencies between each other and that's not good.

The business models of incubators and accelerators are also different. Incubators charge rent (Allen \& McCluskey, 1990) for physical space (Smilor, 1987) and do not have their own investment funds (Hackett \& Dilts, 2004). In fact, firms in incubators are called "tenants." In contrast, accelerators usually make equity investments in participating firms or, less frequently, are non-profit organizations. The incentives of accelerators that invest in participating ventures are thus more closely aligned with the ventures. Incubators might delay growth or disbanding that would result in reduced profits from rent. Accelerators want growth that leads to positive exit. Firms in accelerators are referred to as "portfolio companies."

Finally, incubators offer limited mentorship, which is typically offered for a fee by professional service providers such as accountants and lawyers. Incubator tenants rarely take full advantage of available advice. On the other hand, intense mentorship is a cornerstone of accelerator programs and often the primary reason ventures participate.

Accelerators are also unlike angel investors. Angel investors continuously make individual investment decisions, but accelerators batch investments and accept ventures based on a competitive application process. Angel investors might have a board seat and meet with their portfolio firms periodically. Angel investors mentor portfolio firms themselves, though they typically do not collocate with portfolio companies. However, accelerator directors work alongside participating ventures and connect them with mentors, including investors and active or former entrepreneurs. An angel investor who was also a mentor at Hickory explained that accelerators are "all about the mentoring process versus the investment business." She elaborated, "There are similarities in that we're evaluating 
opportunities, and looking at the same types of features. However, in the investment business, the goal is to allocate capital as efficiently, and as profitably as possible."

Essentially, accelerators recombine financial resources and knowledge resources previously offered by angels and incubators, providing less money and more advice than either angels or incubators.

Table 6: Summary of the Differences between Incubators, Investors, and Accelerators

\begin{tabular}{|l|lll|}
\hline & Accelerators & Incubators & Angel Investors \\
\hline Duration & 3 months & $1-5$ yrs & Ongoing \\
Cohorts & Yes & No & No \\
Business Model & Investment & Rent; non-profit & Investment \\
Selection & Competitive, cyclical & Non competitive & Competitive, ongoing \\
Venture Stage & Early & Early, or late & Early \\
Education & Seminars & Ad hoc, hr/legal & None \\
Venture location & On-site & On-site & Off-site \\
Mentorship & Intense, by self and & Minimal, tactical & As needed, by investor \\
& others & & \\
\hline
\end{tabular}

\subsection{Research Setting}

Accelerator programs were chosen as the research setting because the principle function of accelerators is to accelerate organizational learning during gestation. My data suggest that some accelerators are more effective at accelerating learning than others, providing an opportunity to compare program attributes and effectiveness.

Studying accelerators and participating ventures has many advantages. First, accelerators and participating nascent firms are young, which avoids left-truncation, an issue with much prior work, because variance in incumbent organizations' learning speeds might be due to variation historical learning capabilities rather than due to variation observed during the studies (Argote, 1999; Yang \& Aldrich, 2012). Also, nascent ventures are 
relatively small. This facilitates observation of learning in groups, which are the building blocks of larger organizations (Argote, 1999; Schilling et al., 2003). Fledging ventures in accelerators are learning prior to scaled production thus providing an opportunity to extend prior work typically set in established manufacturing or service firms (e.g., Argote, 1999). Finally, acceleration programs are generally three months long, forcing temporal compression and placing ventures under duress.

Also, participating ventures learn from multiple actors affiliated with accelerators. Participating nascent ventures learn from directors, who cumulate and then transfer expertise. They also learn from mentors, who might be investors, entrepreneurs, corporate executives, lawyers, or accountants. Finally, participating ventures often learn from each other. Ventures participating in the same program at the same time are collectively called a "cohort." Ventures who have graduated from the same program are collectively called "alumni."

\subsection{Research Design}

The research design is an embedded multiple case inductive study (Eisenhardt \& Graebner, 2007; Eisenhardt, 1989a). An inductive methodology is appropriate for several reasons: (1) There is insufficient extant theory to establish testable hypotheses (Eisenhardt, 1989a; Suddaby, 2006; Yin, 2009); (2) the phenomena - accelerators are a contemporary organizational form with insufficient archival data (Yin, 2009); and (3) this study describes knowledge transfer in detail (Easterby-Smith, Lyles, \& Tsang, 2008). The research design nests ventures and mentors within accelerators, providing information from multiple organizations at multiple levels of analysis (Glaser \& Strauss, 1967; Yin, 2009). The multiple case design grounds theory by using replication logic; findings were replicated across accelerators as well as across ventures within each accelerator (Yin, 2009). Data from each 
accelerator collaborated or disconfirmed theory elaborated from other cases (Yin, 2009). This study's embedded design further grounds emerging theory, improves reliability, and enhances internal validity and depth of understanding.

I collected data from accelerator directors, venture founders, and mentors nested within nine domestic accelerators (See Table 7 for details on sampling strategy and Table 8 for a description of the sample). Accelerator names are disguised with pseudonyms taken from tree names. I followed a theoretically guided sampling strategy (Glaser \& Strauss, 1967) and sampled accelerators in different geographic regions (Eastern, Middle, and Western United States) to improve generalizability to different regions (Ozcan \& Eisenhardt, 2009) and different cohort sizes (small, medium, and large) to probe the possible effects of cohort size.

In general, the accelerators in my sample are general technology accelerators. However, the types and stages of ventures varied significantly. Although most of the ventures in this study are mobile or Web-based firms, there were four consumer products firms (cereal, footwear, women's apparel, and toy) and an airline. A few ventures in my sample are social ventures - for example, one raises money for families incurring extraordinary medical expenses. Several ventures developed technological solutions to traditional industries, such as energy, banking, education, and real estate. Founding teams ranged in size from one to four, with an average of 2.2 founders per team. The average age of venture founders in my sample was 31, slightly higher than that of their cofounders (30.25). Seventy five percent of the founding teams are composed solely of men.

Accelerators also varied. The number of accelerator directors ranged from one who was only available a few hours per week to eight who were available full-time. The physical 
spaces of the accelerators also differed. Redwood did not offer ventures office space;

ventures worked from their homes or offices and gathered onsite for weekly dinners and other special events. Most accelerators in this study had open work space where ventures work alongside each other and accelerator directors. Oak, a large accelerator, had one enormous open floor of a building. Birch and Chestnut offered space, but each venture worked in an individual office.

Table 7: Sample Design, U.S.

\begin{tabular}{|l|lll|}
\hline & East & Middle & West \\
\hline Small & Chestnut & Ash & Pine \\
Med & Birch & Hickory & Fir \\
Large & Oak & Alder* & Redwood \\
\hline
\end{tabular}

* Alder has multiple locations, a Middle US location is the primary source of data for this study, though other locations were also included to assess generalizability. No significant differences were observed. 
Table 8: Sample Description

\begin{tabular}{|l|l|l|l|l|l|}
\hline Name & Duration*+ & Location & Cohort Size & \# of mentors & Convertible Debt \\
\hline Chestnut & 3 months & East & Small & 60 & No \\
\hline Birch & 3 months & East & Medium & 250 & No \\
\hline Oak & 4 months $^{+}$ & East & Large & 350 & No \\
\hline Ash & $10-12$ weeks $^{+}$ & Middle US & Small & 20 & No \\
\hline Hickory & 3 months $^{+}$ & Middle US & Medium & 112 & $\$ 50,000$ \\
\hline Alder & 3 months & Multiple & Medium & 100 & $\$ 100,000$ \\
\hline Pine & 3 months* & West & Small & 200 & No \\
\hline Fir & 10 weeks & West & Medium & 50 & 100,000 \\
\hline Redwood & 3 months & West & Large & 0 & $\$ 150,000$ \\
\hline
\end{tabular}

* Can start before + can stay past end Top row shows primary data collection site, bottom shows all

Convertible debt is offered by external VCs who give favorable terms to all participating ventures at the accelerator. Alder's Middle US location is primary location of study

\subsection{Exploratory Work}

As is customary with grounded theory building research (Eisenhardt, 1989a), I began by conducting exploratory work to understand accelerators and identify opportunities for research. Initially, I read magazine articles (e.g., Levy, 2011), stories in industry trade epublications (e.g., TechCrunch), popular books (Feld \& Cohen, 2010; Feld \& Mendelson, 2011; Ries, 2011), and blog entries written by accelerator directors and participating ventures (e.g., Paul Graham of YCombinator and Brad Feld of TechStars). Simultaneously, I reviewed academic research on incubators (e.g., Rothaermel \& Thursby, 2005a, 2005b; Smilor, 1987) and investors (e.g., Clark 2008, Hallen 2008, Hochberg et al. 2007, Hsu 2007), in addition to the organizational learning literature reviewed above. Next, I conducted exploratory interviews with industry pundits, academic scholars, accelerator directors, and venture founders who had participated in accelerators. Exploratory interviews, which were conducted via telephone and in person, ranged from 45 minutes to several hours. Initially, I asked broad questions about accelerators to grasp what they do, how they interact with participating ventures, and how they differ from angel investors and incubators. I also asked open-ended 
questions about how the accelerator operates and how firms change during the process. All but four interviews were digitally recorded and transcribed. Transcripts were reviewed by two researchers to provide two independent perspectives (Yin, 2009). Exploratory interviews also helped develop interview guides, which were refined after each exploratory interview.

\subsection{Data Sources}

Consistent with prior work employing grounded theory methodology (Bingham \& Eisenhardt, 2011; Eisenhardt, 1989b; Hallen \& Eisenhardt, 2012; Ozcan \& Eisenhardt, 2009), data were collected from retrospective and real-time sources (Eisenhardt \& Graebner, 2007; Yin, 2009), including transcribed semi-structured interviews; email correspondence for clarification and progress updates; and archival data such as accelerator and company Web sites, blogs, LinkedIn profiles, trade publications, field observations, and funding databases such as Crunchbase. This multi-faceted data collection strategy afforded multiple types of triangulation, thus improving reliability and credibility of results (Yin, 2009).

The primary sources of data for this study are semi-structured interviews with accelerator directors (1-2 individuals), founders of graduated ventures (4-6 per accelerator), and mentors (1-2 per accelerator). Approximately 70 interviews were conducted using three protocols, which included open and closed-ended questions. . (See Appendix.) Each protocol has three parts: background information, details on the accelerator programs, and direct questions about progress and learning. I used "courtroom" procedure; I directed informants to step through the progression of the program, beginning with the application process. I then asked what happened between being accepted and beginning the program. Next, I asked what happened during the first day, week, month, and so on. Asking informants to chronologically 
recount events reduces subject bias (Huber, 1985). Next, I posed open-ended questions that focused on different actors, such as directors, mentors, cohort members, and teammates. For example, "How, if at all, did you interact with your cohort?" The interviews concluded by gathering historical information on the performance of the ventures and direct questions about how much they learned from mentors, accelerator directors, cohort members, and customers. I closed by asking if there was anything else that the informant would like to share. The protocols included both nondirective and directive questions to ground theoretical insights and reduce bias (Eisenhardt, 1989b). I continued conducting interviews until responses no longer added novel insights (Glaser \& Strauss, 1967).

Several additional precautions were taken to reduce bias. All interviews were recorded, transcribed, and analyzed by two researchers. All informants were guaranteed anonymity and confidentiality to improve the integrity of responses. Multiple informants were used when possible, so that information could be triangulated (Yin, 2009). To improve recall, informants were all highly involved with the accelerator, either as a founder or managing director of the accelerator, as a founder of a firm that participated in the accelerator, or as an active mentor.

\subsection{Data Analysis}

Data analysis occurred over several stages. The first stage entailed developing interactive case histories for each accelerator and embedded venture (Eisenhardt, 1989a). I induced the programming elements of each accelerator programs, re-creating program timelines and describing the roles of the actors during each phase. Case histories detailed how learning was accelerated during the various stages of the program. For example, they include information about what firms learned from mentor meetings and educational 
programming such as seminars. Developing case histories serves a dual function: Completed histories inform the research report, while the process of creating the case histories helps the researchers become fastidiously familiar with the details of the case (Eisenhardt, 1989a). Thus, I developed case histories as data were collected, and occasionally adjusted interview protocols or other data collection efforts to seize unfolding opportunities. For example, the study design initially sampled more mentors and fewer venture founders. During analysis, I realized that mentors were less involved and provided less insight than venture founders. Thus, I modified the study design to increase the number of venture founders and decrease the number of mentors in my sample. To improve objectivity and more strongly ground theory, a second researcher reviewed interviews and case histories as they were created.

Case histories were then used for within-case and cross-case analyses (Yin, 2009). Within-case analyses compared how different firms participating in the same accelerator program accelerated learning, while cross-case analyses compared different accelerator programs. Both types of analyses used replication logic to ground emergent theory (Yin, 2009). I used a host of strategies suggested by prior research, including placing data in matrices to look for non-obvious patterns, developing timelines, and creating flow-charts (Eisenhardt, 1989a; Miles \& Huberman, 1994). I used MaxQda (version 11.01) software to organize, tabulate, and retrieve data. Quantitative data were tabulated, and summary statistics were calculated and compared across accelerators (Yin 2009). I continued to iterate between data collection, analysis, and existing theory to clarify findings and refine theoretical arguments. 


\subsection{Accelerated Learning}

The unit of analysis for this study is ventures participating in accelerator programs. In this section, I present evidence of accelerated learning. In the findings discussed in the next section, I discuss mechanisms that accelerated learning.

Table 9 summarizes this study's evidence of accelerated learning. I assessed whether learning was accelerated by averaging venture founders' responses to the questions "rate your venture's progress" and "rate the amount your firm learned" and calculating the proportion of venture founders who said the program length was about right. The responses were provided on a seven-point Likert scale. Informants at all but one of the accelerators rated the amount learned higher than the amount of progress made by the venture.

Additionally, I coded learning as accelerated if the informant described his venture's learning as being faster than it otherwise would have been if it had not participated in the accelerator.

Many of the participants said that learning was accelerated, though none were asked directly. For example, one founder answered the question, "How did your relationship with your co-founders change during the program, if at all?" as follows:

It was a great time for us to start together from the beginning of boot camp all the way through working with mentors. It saved us time making silly mistakes that if it was just the three of us on our own could have taken us six months to make those mistakes and then figure out what we should be working on.

Another replied to a question about changing his self-evaluation of his firm's potential,

We were able to get answers to those questions fairly quickly, and then able to develop the business into the answers that we got ... it would have taken us a very long time to answer these questions as well as we did in Hickory, and we were able to do that very great work within a matter of weeks instead of a matter of months. 
Ventures also felt significant time pressure. The time pressure focused founder's attention on extracting all they can from the accelerator before they graduated from the program. As one founder at Oak said,

It's intense because this is your time to really accelerate your company so there's no like, I'm going to take this and sleep on it. You've got to make decisions quickly, make your best effort to take advantage of all those resources that are going to go away once accelerator is done. You really do feel that pressure of this is a once in a lifetime opportunity to have all of these resources, I've got to make the best of it so there is that time pressure for sure.

Given the pressure to learn quickly, we might have expected a trade-off between learning speed and quality (Levinthal \& March, 1981). However, several founders did not experience a tradeoff. For example, a founder at Alder said his venture "moved forward faster and more effectively." A founder at Birch agreed, "An accelerator is definitely that, it's rapid development, rapid marketing and it's making sure that you're still maintaining the path and you're staying in the right direction." Another founder at Birch explained with more nuance,

The development itself is more rapid but the way that we're releasing, the way that we're strategizing between each product release, even though the development is faster, we are a little more careful, we don't push it. May be if this was six months ago we would have just pushed it now we're a little more meticulous in terms of what we're doing, why we're doing it.

Thus, my data suggest that ventures learned quickly, and there was evidence that acceleration did not degrade the quality. To the contrary, the ventures I spoke to described how, almost paradoxically, acceleration enhanced what they learned. They learned faster, but more thoughtfully than before. 
Table 9: Accelerated Learning

\begin{tabular}{|c|c|c|c|}
\hline Accelerator & $\begin{array}{l}\text { Avg. learning }{ }^{4} / \\
\text { progress }\end{array}$ & $\begin{array}{l}\text { \% } \\
\text { length } \\
\text { right }^{5}\end{array}$ & Was Learning Accelerated? \\
\hline Chestnut & 6.00 & $66 \%$ & $\begin{array}{l}\text { Yes "It is more about avoiding mistakes, so it avoiding } \\
\text { loosing time and trying things that take you nowhere." } \\
\text { No "It took me } 2 \text { years to come to that conclusion." }\end{array}$ \\
\hline Birch & $\begin{array}{l}5.33 \\
5.00\end{array}$ & $50 \%$ & $\begin{array}{l}\text { Yes "These past } 3 \text { months would have taken us, I don't even } \\
\text { know, from a product standpoint, probably next year. . . } \\
\text { Your product is going to be exponentially faster in an } \\
\text { accelerator." } \\
\text { No "In hindsight we could have done more in that } \\
\text { timeframe." } \\
\text { Yes "The development itself is more rapid but the way that } \\
\text { we're releasing, the way that we're strategizing between } \\
\text { each products, even though the development is faster." }\end{array}$ \\
\hline Oak & $\begin{array}{l}5.5 \\
5.4\end{array}$ & $75 \%$ & $\begin{array}{l}\text { Yes "I would never have been able to do any of those things } \\
\text { without OAK. I mean, maybe not never, but I can't imagine } \\
\text { how I would have gotten that information." } \\
\text { Yes "Could have taken us six months to make those } \\
\text { mistakes and then figure out what we should be working on } \\
\text { we could have wasted six months and gotten nowhere with } \\
\text { sales. But, you know, as a team, we were just able to learn } \\
\text { much faster." } \\
\text { Yes "It would have definitely taken me another year to get to } \\
\text { the point where I was at the end of the accelerator on my } \\
\text { own." } \\
\text { Yes "Learning that stuff on your own and becoming an } \\
\text { expert on your own is time consuming." } \\
\text { No "My sales didn't increase as a result of Oak." }\end{array}$ \\
\hline Ash & $\begin{array}{l}6.00 \\
5.00\end{array}$ & 0 & $\begin{array}{l}\text { Yes "So while it seems like it took less time it was really } \\
\text { intense but we were a } 100 \text { percent focused on it." }\end{array}$ \\
\hline Hickory & $\begin{array}{l}6.40 \\
6.20\end{array}$ & $80 \%$ & $\begin{array}{l}\text { Yes "It would have taken us a very long time to answer these } \\
\text { questions as well as we did in Hickory, and we were able to } \\
\text { do that very great work within a matter of week instead of a } \\
\text { matter of months." } \\
\text { Yes "I can't expect that kind of introspection in that time, } \\
\text { and you just never get that when you are working alone." } \\
\text { Yes "I don't know if I ever would find that out, or probably } \\
\text { take a lot longer." "It accelerated figuring out that the } \\
\text { business was not going to work." } \\
\text { (mentor) "It's just an amazing opportunity to suck in a lot of } \\
\text { information as your business is in its critical stage, and move } \\
\text { it forward." } \\
\text { (mentor) "An intense period where they learned a lot." } \\
\text { Yes "You have to build the business fast. You have to have a } \\
\text { killer network. And you have to know how to do it. This is a } \\
\text { learned skill. It's not inherent." }\end{array}$ \\
\hline
\end{tabular}

\footnotetext{
${ }^{4}$ Venture founders were asked to rate their venture's overall learning on a seven-point Likert scale

${ }^{5}$ Venture founders were asked, "How do you think the program's length affected what you got out of the program?" Measure is percentage of informants whose answer suggested length was right.
} 


\begin{tabular}{|c|c|c|c|}
\hline Accelerator & $\begin{array}{l}\text { Avg. learning }{ }^{4} / \\
\text { progress }\end{array}$ & $\begin{array}{l}\text { \% } \\
\text { length } \\
\text { right }^{5}\end{array}$ & Was Learning Accelerated? \\
\hline Alder & $\begin{array}{l}6.40 \\
6.00\end{array}$ & $100 \%$ & $\begin{array}{l}\text { Yes "They got us on a track which was ultimately was going } \\
\text { to be a lot more successful. They got us off one that was not } \\
\text { going to be successful and may have taken us six or nine } \\
\text { months to find out." } \\
\text { Yes "It's incredible that that evolution can happen in such a } \\
\text { period of time and I don't think anything like that could have } \\
\text { happened outside of Alder. ... you learn how to make a } \\
\text { decision quickly and see if it's going to work and then move } \\
\text { off of that if it's not going to work." } \\
\text { Yes "It accelerated our education. I mean, our education as } \\
\text { business people." } \\
\text { Yes "I was trying to consume as much information as } \\
\text { possible." }\end{array}$ \\
\hline Pine & $\begin{array}{l}5.33 \\
4 \\
\end{array}$ & $66 \%$ & Yes "It sped us up." \\
\hline Fir & $\begin{array}{l}5.5 \\
4.75\end{array}$ & $66 \%$ & $\begin{array}{l}\text { Yes "It definitely accelerated fundraising abilities. It } \\
\text { accelerated growth of the product user base as well, because } \\
\text { we are at a high end much faster." } \\
\text { Yes "I think we would have done well be would have done it } \\
\text { slower." } \\
\text { No "It did not accelerate that much...other companies in my } \\
\text { cohort...were able to raise funding relatively quickly." }\end{array}$ \\
\hline Redwood & $\begin{array}{l}5.6 \\
6.25\end{array}$ & $100 \%$ & $\begin{array}{l}\text { Yes "It was the same amount of learning I had in two years } \\
\text { of college, or three years of college." } \\
\text { Yes "We learned literally everything we know now." } \\
\text { Yes "I don't know if we would have ever launched, we } \\
\text { would have gotten discouraged before launching." } \\
\text { Yes "It would take other people years to learn just through } \\
\text { the process of like going through the office hours through } \\
\text { the summer." } \\
\text { Yes "We learned lessons that it would take other people } \\
\text { years to learn." } \\
\text { Yes "In that } 10 \text { weeks you basically hack in what could be } \\
\text { the first few years of your company's life." } \\
\text { Yes "A sprint." }\end{array}$ \\
\hline
\end{tabular}




\section{CHAPTER 4 \\ HOW TO ACCELERATE ORGANIZATIONAL LEARNING}

How do accelerators accelerate learning? I discovered that accelerators accelerated learning by reducing the antecedents to learning, which I call learning-coordination costs. I define learning-coordination costs as expenditures such as time or money required to set up learning. Learning-coordination costs include administrative tasks such as scheduling interactions and traveling as well as networking prior to learning interactions. My analysis suggests ventures accelerated learning via four constructs that emerged from the data: (1) mentor overload - time-compressed interactions with external advisors that delayed implementation, (2) director experts - advisors who consolidated and transferred experience to nascent ventures, (3) divided teams - founding team members who split up rather than band together during experience accumulation, and (4) cohort peers-ventures who were concurrently both rivals and supporters.

\subsection{Mentor Overload}

As discussed above, prior work places a high value on learning-by-doing in uncertain markets (Eisenhardt \& Martin, 2000; Eisenhardt \& Tabrizi, 1995; Pisano, 1994) because time spent implementing might more directly impact learning and performance speed than time spent in other learning modes (Ocasio, 1997). In contrast, firms in this study accelerated learning by delaying learning-by-doing. Firms began learning by receiving an abundance of 
advice from a diverse group of mentors ${ }^{6}$. Informants referred to this accelerated learning process as mentor whiplash, or mentor dating. Their descriptions of the process were consistent with theories of cognitive overload. Thus, I named this construct mentor overload. Based on informants' descriptions, I define mentor overload as time-compressed engagement with external advisors who give conflicting feedback while implementation is delayed. Ventures received feedback from mentors on both real and hypothetical products and strategies. Founding teams often became confused as they explored options with mentors prior to implementation. Yet, their vision crystallized by the end of the mentor overload period.

Table 10 summarizes evidence on mentor overload and includes measures along three dimensions: conflicting advice, reduced coordination costs, and an assessment of delayed implementation. I assessed the amount of conflicting advice by measuring the number of meetings founders had with different mentors within the first month of their program and reports of confusing or conflicting advice. I coded overload positively when venture founders reported being confused or overwhelmed. I evaluated reduced coordination costs by comparing the frequency with which accelerator directors or staff scheduled mentor meetings to the frequency with which venture founders scheduled mentor meetings. Finally, I coded implementation as delayed if the informant told me that progress on the venture's product development was delayed during mentor overload.

Hickory provides an example of mentor overload. Nearly all of the Hickory venture founders experienced mentor overload. Hickory scheduled all the ventures' mentor meetings,

\footnotetext{
${ }^{6}$ The term "mentor" typically includes any external advisor and might include guest speakers, advisors who meet with venture founders for 15-60 minutes, and advisors who provide frequent advice during the program and sometimes become board members.
} 
which happened at Hickory's office. According to Hickory's managing director, the ten ventures that participated in the 2011 program collectively held 740 meetings with a total of 140 mentors in just 19 days. Hickory venture founders met with an average of 63 mentors during the first 3 weeks of the program ${ }^{7}$. Further, 80 percent of the founder-informants reported that they received conflicting advice during the mentor dating period.

Hickory's managing director described what founders experience during mentor dating, "They are just getting challenged, and challenged, and challenged, and it sort of like their business plan gets ripped to pieces, but in many different directions, and this is one of the really challenging things. So, one of the mentors tell them to turn left, some say turn right, go up, go down, go backwards, go forwards, every which direction." The founders then figure out "how to put this back together to make it even better."

Hickory scheduled mentor meetings, which saved founders time. As one founder stated, "Access to people I probably would have still met, but it would have taken us much longer to meet, and having them come to us and engaging [sic]. I would have needed several intros and a longer timeframe to get them." Venture founders at Hickory attended four or five mentor meetings per day, repeating their ventures' pitches each time and accumulating feedback from different mentors. A founder of a relatively mature business with $\$ 100,000$ per month of revenue and seed funding prior to the program recounted, "The first month was intense. We did 54 mentor meetings in the first 30 days, and the main thing I remember is not knowing how to simply describe the business, I couldn't say what it was without needing like a half an hour because I didn't really know what it was." Ventures were able to conduct

\footnotetext{
${ }^{7}$ The average number of meetings for the ventures in this study is slightly lower. This could be because this study includes ventures from multiple cohorts.
} 
more mentor meetings because Hickory's director scheduled meetings and meetings happened at Hickory's office.

Because meetings were condensed, founders could hold more meetings per day than they would have been able to if meetings were not condensed. Rapid feedback led to cognitive overload. Interestingly, rather than responding with rigidity or reduced learning (Paas, Renkl, \& Sweller, 2004), mentor overload diminished preconceived ideas about which business strategy to pursue. Once founders became open to change, they recognized patterns among seemingly conflicting mentor feedback. For example, another Hickory venture founder recounted a major decision for his venture, whether to sell directly to consumers or aggregate data on consumer preferences to sell to other business:

I would say probably 20 interviews and 20 sessions in, and I did 70 in that month, every single person but one had answered the question the same which is you should be a data business, and so then we decided alright we are going to be a data business . . . we are not going to have these anymore. This is settled.

Venture founders rarely had time to strategize between meetings, yet their pitches evolved during the mentor dating process. As one founder explained, "You started to see when something sparked someone's interest, and so you started to use those phrases more often." Over time, founders moved from confused and overwhelmed to clear and committed. She continued, "The more people asked us about it, the more we were able to reject those ideas even if they are temporarily rejected. We felt more confident about what we were doing and the direction we were headed." As ventures concluded the mentor dating period, founders became intensely committed to their chosen strategy, which enabled them to implement more quickly the following month by focusing only on implementing the chosen strategy rather than considering alternatives. 
Hickory ventures delayed implementation during mentor dating. The director said, "They got no work done in June" because they were in mentor meetings all day. For most ventures, implementation entailed programming to build a software product, Web site, or mobile application. The focus of the first month was on altering cognition rather than establishing routines. The next month, focus shifted from mentor overload to intense implementation as firms learned by doing.

Alder provides another example of mentor overload. Alder ventures met with an average of 75 mentors during the first month of the program and $83 \%$ reported receiving conflicting advice. Alder directors and associates scheduled mentor meetings for the ventures, and those meetings happened at Alder's office.

When venture founders arrived at Alder's offices each morning, they received their daily schedule from an Alder associate. Alder associates scheduled five or more mentor meetings per day for each venture. Alder's director described the mentor matching process as "semi-structured." Ventures could request meetings with mentors and mentors could request meetings with ventures, but Alder's employees did all of the scheduling.

A venture founder described mentor overload, "the first week is so stressful and overwhelming, it's hard to focus. But you get used to the craziness of the schedule and you sleep when you can and do work when you can and try to absorb as much as you possibly can while you're talking to people." Another founder recalled trying to use "pattern matching" to find recurring themes in seemingly conflicting mentor feedback, which helped the venture choose a direction.

The director explained that the goal of the first month was "to work out if what you are doing is correct." A founder explained how mentor meetings helped them gain 
confidence in their strategy, "We went through a lot of different things. We thought what if we had a mobile app? What about it we either did this or did that and we got to where we are. It wasn't without a lot of steps in between ... That first month was very painful." Another mentor explained how firms considered outlying feedback until they "understood the coalescence" of feedback.

Mentors helped firms identify interesting new opportunities for the team. For example, a mentor told one firm, "With your background you could solve this problem in this way and it's a huge problem. A global, huge, big problem-you have the wherewithal to do it." Forty-eight hours later, the venture pivoted to the new opportunity and was committed to it.

Ventures at Alder delayed implementation during the first month. A director explained the evolution of delaying implementation,

Essentially in month one you spend an awful lot of time externally to your product, so, you know people show up, they have this thing they are working on and this vision of whatever the product is, and in some ways we try to slow them down in term of the amount of time they are spending in front of the computer working on the product because [before] people would show up and spend the next three weeks working on something and then realize that that's just stupid that I'm spending my time working on this midway through. And so rather than have people sort of spend all that time going down dead ends we try to slow them down.

Venture founders who failed to delay implementation often had to "scrap" code they wrote during the first month. When ventures delayed implementation, they were more fluid. As one venture founder explained, "every two days we were changing our minds about what to do but what we ended up with was really compelling." By delaying implementation, venture teams were free to make changes to their business.

In sum, a diverse and impressive set of mentors provided compressed feedback to Alder ventures. A director explained, "We are not saying this is the answer, we are just 
trying to give them lots of data points ... there's no one right answer." Diverse perspectives encouraged venture founders to consider many alternatives, and the high status of the mentors made it difficult for the founders to dismiss their feedback (Merton, 1968; Podolny \& Stuart, 1995) without careful consideration. As an Alder director said, "[Mentors] are going to force you to gain conviction because they're going to give you mentor whiplash. You're going to hear one thing from one person, a totally different thing from another person." The ventures' executive teams had to decide which strategy to pursue, which forced communication and decision making among the founding teams who ultimately coalesced around the emergent firm strategies.

Different accelerators provided different types and levels of mentor interaction for ventures. Some accelerators assigned mentors to ventures rather than pursuing a dating process. My data suggest that accelerators that assigned mentors to ventures accelerated learning less than accelerators that arranged meetings and let ventures and mentors organically develop relationships. For example, Chestnut is an accelerator where mentor overload did not occur. The mentor matching process at Chestnut differed from the process at Alder and Hickory. The Chestnut director matched ventures to mentors at the beginning of the program. The managing director explained that he assigned mentors so that ventures could "get feedback immediately." Though there was no formal mentor dating period, ventures could initiate meetings with other mentors who were listed in a directory.

Expectations and social norms about the intensity of mentor relationships were also different at Chestnut. The director expected mentors to work with two or three companies by meeting with them "regularly," though he did not explicitly describe his expectations to the mentors. Ventures in this study each had fewer than 10 mentor meetings during the three- 
month program. Mentor meetings were stretched over the duration of the program, which meant that ventures typically met with a mentor every week or two. Ventures were responsible for scheduling mentor meetings and meetings most often happened at mentor's offices, thus, learning-coordination costs were considerably higher for ventures at Chestnut.

Only $33 \%$ of Chestnut's ventures reported receiving conflicting advice. Some reported changing directions based on feedback from a single mentor. One venture founder recalled,

At one point someone said you guys should be going into mobile and so, this is the craziest thing and we'll never ever make these mistakes again, but we heard that one piece of feedback and we started looking at mobile... every 2 weeks we had a new project we were building all the way up until Demo Day.

Unlike ventures at Hickory and Adler, who delayed implementation during mentor overload, ventures at Chestnut continuously iterated between mentor advice and implementation throughout the program. Because they did not delay implementation, the ventures at Chestnut shifted strategy while implementing. Sixty-six percent of the firms failed shortly after they graduated from the program.

Mentor overload accelerated learning in several ways: Venture teams adapted their collective cognition in response to abundant feedback, venture teams distributed knowledge across members because individuals cannot store all of the information, and founding CEOs evolved into executives who filter and route knowledge throughout the organization. The director at Alder continued to explain the benefit of overloading founders with mentor feedback,

That's the way the real world works and we're accelerating that. So your customers are going to do it to you; your family is going to do it to you; your investors are going to do it to you. Guess what? You're the entrepreneur and you get to cook, right. That's why you run the company and not us. And you have to be good at 
communicating and you have to be good at taking all of that input and deciding what you want to do.

During the first month, firms "changed directions all the time, it actually happens a lot in the first month but I want to get through that." Alder's director continued, by the end of mentor overload, venture founders had "a lot of conviction about the direction of the arrow before they hit the gas."

Recent work suggests that founder's pre-entry knowledge limits strategic options (Fern, Cardinal, \& O'Neill, 2012; Gruber, MacMillan, \& Thompson, 2012), yet offers few solutions to reduce the constraints of founders' past experience. Mentor overload might be one such solution. Mentor overload breaks down cognitive barriers to considering alternatives. Hickory's director said, "Part of the process is literally breaking them down, and getting them to the point where they aren't that arrogant start-up saying, 'my idea is the best idea in the world.' They realize that there's so much more to it, and that they really only have the seed of an idea" Mentor overload provided ample feedback to break momentum and reverse course (Senge, 1990), which broadened ventures's sets of options. Diverse feedback led to better solutions (Lapré \& Van Wassenhove, 2001).

When accelerators scheduled meetings for founders, the coordination costs for venture founders were negligible, which enabled ventures to meet with more mentors and more diverse mentors than when ventures initiated their own meetings. As an Alder venture founder wrote on his blog, "It would have taken me three months just to schedule $20 \%$ of those same meetings." Locating meetings at the accelerator offices further reduced travelrelated coordination costs for the venture. Venture founders dedicated more time to learning (Ocasio, 1997) because they were freed from time-consuming scheduling and networking 
typically performed by nascent entrepreneurs (Hallen \& Eisenhardt, 2012). Thus, by reducing learning-coordination costs, venture founders accelerated learning.

Rather than diminish learning (Dierickx \& Cool, 1989), mentor overload reduced biases suggested by prior research (Denrell, 2003; Levinthal \& March, 1993; Levinthal, 1997). By meeting with many mentors in a short period of time, founders were able to distinguish outlying feedback and identify commonalities among seemingly conflicting advice (Haunschild \& Sullivan, 2002). For nascent ventures, outlying strategies might be the most valuable. Understanding the distribution may also lead to competitive advantage. On the other hand, at Chestnut where ventures only met with a few mentors and those meetings were not time-compressed, venture founders were unable to distinguish signal from noise and prematurely switched from mentor suggestions to implementation. Only after timeconsuming implementation did these ventures realize that the mentor's advice was poor.

We might have expected venture founders experiencing mentor overload to fall into "failure traps" (Levinthal \& March, 1993) when they received conflicting feedback from mentors rather than consistent support. When feedback was not time-compressed-for example, at Chestnut—ventures experienced failure traps: They continuously built new products and iterated until they failed. However, when implementation was delayed and interactions with mentors were time-compressed, ventures experienced cognitive overload but did not experience failure traps. Time-compressing failure and search and reducing time to interpret and implement might reduce the "trap" aspect of repetitive failure.

Prior work suggests that information overload might lead entrepreneurs to respond with mindless action (Feldman \& March, 1981). Generally, this work suggests that managers respond to information overload by doing the same thing (rigidity) rather than changing. 
However, most work on organizational cognition is set in existing organizations who are experiencing changes to their environments (e.g., Eggers \& Kaplan, 2009; Kaplan \& Tripsas, 2008; Tripsas \& Gavetti, 2000). The firms in this study were very young and may not be as committed to their cognitive frames, especially if they have not converted cognition to routines. The firms in this study reacted more consistently with predictions of Simon (1990) who suggested that firms develop pattern recognition and extrapolation capabilities to reduce cognitive overload. By responding to cognitive overload, ventures reduced seemingly conflicting feedback to the core essence of their business - their strategy.

Another key aspect of mentor overload is delaying implementation. Delaying implementation reduced experience bias (Levinthal \& March, 1993) and escalation of commitment to failing strategies (Staw, 1981). Mentors helped founders eliminate strategies, thus reducing the number of strategic choices, avoiding dead ends and focusing learning on potentially optimal choices (Levinthal, 1997). Consequentially, ventures identified product market fit in a relatively short amount of time. When implementation eventually resumed, it was with full commitment to the chosen strategy. As one venture founder said, "it slowed us down temporarily, but allowed us to speed up later." Strategic stabilization enabled faster implementation (Lynn et al., 1999).

Finally, the mentor dating period first legitimized uncertainty and subsequently reduced it. Learning that reduced risk, even if it resulted in a new strategy, was celebrated rather than avoided. Pre-existing biases, which might ordinarily lead entrepreneurs to "stay the course" were quickly eliminated in favor of adaptation. 
Table 10: Mentor Overload

\begin{tabular}{|c|c|c|c|c|c|c|}
\hline Accelerator & $\begin{array}{l}\text { Avg \# } \\
\text { meetings }\end{array}$ & $\begin{array}{l}\text { Conflicting } \\
\text { advice }\end{array}$ & $\begin{array}{l}\text { Accelerator/ } 10 \\
\text { firm meetings }\end{array}$ & Did overload happen? & Was implementation delayed? & $\begin{array}{c}\text { Learn } \\
\text { mentors } \\
\end{array}$ \\
\hline Chestnut & $<10$ & $33 \%$ & Low / low & $\begin{array}{l}\text { No "Led to way too many changes for me and my } \\
\text { team." } \\
\text { No "Met with our main person twice." } \\
\text { No "Asked them to give us advice on very specific } \\
\text { things." }\end{array}$ & $\begin{array}{l}\text { No "Every } 2 \text { weeks we had a new project we were } \\
\text { building on all the way up until Demo Day" } \\
\text { Yes "It is not until half of the program that we actually } \\
\text { start demoing the product" }\end{array}$ & 5.6 \\
\hline Birch & $25-50$ & $100 \%$ & $\begin{array}{l}\text { Medium/ medium } \\
\text { "Initial meetings } \\
\text { all happen here." }\end{array}$ & $\begin{array}{l}\text { Yes "Felt like drinking water from a fire hose" } \\
\text { Yes "We got a lot of feedback ... Hard to tell what } \\
\text { was what." } \\
\text { Yes "Some people say X, some people say Y and some } \\
\text { people say A." } \\
\text { Yes "Totally conflicting advice." }\end{array}$ & $\begin{array}{l}\text { Yes "Hours would go by and you wouldn't get stuff } \\
\text { done related to your core business." } \\
\text { Yes "It's ok if you lose a day of coding because the next } \\
\text { four days of coding are going to be a little more } \\
\text { structured." }\end{array}$ & 4.83 \\
\hline Oak & 12.5 & $33 \%$ & $\begin{array}{l}\text { Low/ medium } \\
\text { "I just ran around } \\
\text { Boston like a } \\
\text { crazy person." }\end{array}$ & $\begin{array}{l}\text { No "It's very executional, very specific topics ... } \\
\text { almost everyone at Oak at this point has already seen } \\
\text { an opportunity, they've shaped what they want to do } \\
\text { about it and now they're there actually executing it and } \\
\text { doing it." } \\
\text { Yes "I had them all meet together ... We came to a } \\
\text { consensus together." } \\
\text { No "I just ran around Boston like a crazy person." }\end{array}$ & No "working on their product" & 5 \\
\hline Ash & $<20$ & $100 \%$ & Low/ low & $\begin{array}{l}\text { Yes "The first two weeks of it was constant meetings } \\
\text { with mentors ... that situation is kind of chaotic and } \\
\text { my brain was sort of like a bowl of pudding at the end } \\
\text { of it." } \\
\text { Yes "... better for us to hash it out in the meetings with } \\
\text { the mentor, because we had a third ... we didn't have } \\
\text { time to brew over it ... we were prepared to move } \\
\text { forward even when we were not in agreement." }\end{array}$ & $\begin{array}{l}\text { Yes "I'd like to make sure you are pointing in the right } \\
\text { direction before you step on the gas." } \\
\text { Yes "Making sure that they are pointing in the right } \\
\text { direction before we go introducing them to bunch of } \\
\text { customers or may do other things that they might only } \\
\text { get one shot at." }\end{array}$ & 6 \\
\hline Hickory & 63 & $80 \%$ & $\begin{array}{l}\text { High/ } \\
\text { none }\end{array}$ & $\begin{array}{l}\text { Yes "A lot of feedback, great feedback mediocre } \\
\text { feedback and informed feedback; was the whole } \\
\text { gamut." } \\
\text { Yes "The clutter that comes from all mentors giving } \\
\text { you too much advice." } \\
\text { Yes "It's quite overwhelming." } \\
\text { Yes "In the short run, like in the first week, it's totally }\end{array}$ & $\begin{array}{l}\text { Yes "we want the - that evolution to happen virtually } \\
\text { without you are having to actually physically go build" } \\
\text { Yes "It slowed us down temporarily, but allowed us to } \\
\text { speed up later." } \\
\text { Yes "You are inherently out of balance on the strategy } \\
\text { side." } \\
\text { Yes "You are over strategizing and under executing ... }\end{array}$ & 5.8 \\
\hline
\end{tabular}

${ }_{9}^{8}$ Average number of mentor meetings during first month

${ }^{9}$ Percentage of venture founder informants reporting receiving conflicting advice

${ }^{10}$ Assessment of the number of meetings coordinated by the accelerator over the number coordinated by the ventures

${ }^{11}$ Average response to "Rate amount your firm learned from Mentors" Ratings were provided on a seven-point Likert scale 


\begin{tabular}{|c|c|c|c|c|c|c|c|}
\hline & Accelerator & $\begin{array}{l}\text { Avg \# } \\
\text { meetings }\end{array}$ & $\begin{array}{l}\text { Conflicting } \\
\text { advice }\end{array}$ & $\begin{array}{l}\text { Accelerator/ } \\
\text { firm meetings }\end{array}$ & Did overload happen? & Was implementation delayed? & $\begin{array}{c}\text { Learn } \\
\text { mentors }\end{array}$ \\
\hline & & & & & $\begin{array}{l}\text { confusing and overwhelming but in the long run; they } \\
\text { come out stronger and smarter." } \\
\text { Yes "Get really confused, and then start to narrow } \\
\text { down the funnel, and get clear on things." }\end{array}$ & $\begin{array}{l}\text { you are really way behind on execution." } \\
\text { Yes "Very little doing." } \\
\text { Yes "They got no work done in June. They were in } \\
\text { meetings all day." }\end{array}$ & \\
\hline & Alder & 75 & $83 \%$ & High/ low & $\begin{array}{l}\text { Yes "A week into the program, you have no idea at all } \\
\text { what the f*** your company is doing." } \\
\text { Yes "We were really struggling with conflicting advice } \\
\text { our lead mentors were giving us." } \\
\text { Yes "Very wide range of feedback." } \\
\text { Yes "Huge feedback that really helped us to learn." } \\
\text { Yes "Every two days we were changing our minds } \\
\text { about what to do." }\end{array}$ & $\begin{array}{l}\text { Yes "Very little coding happening at any of the } \\
\text { companies." } \\
\text { Yes "When you do build something in the second month } \\
\text {..." } \\
\text { No "I was doing a lot of coding, which I ended up } \\
\text { having to basically scrap anyway." } \\
\text { Yes "Rather than just building, go out and actually ask } \\
\text { people if they'll use it first." }\end{array}$ & 6.2 \\
\hline N & Pine & 15 & $100 \%$ & $\begin{array}{l}\text { Low/ high } \\
\text { "I put a lot of } \\
\text { effort into trying } \\
\text { to look through the } \\
\text { entire list, which } \\
\text { was a bit } \\
\text { overwhelming." }\end{array}$ & $\begin{array}{l}\text { No "They're not going to understand everything that } \\
\text { we're working on." } \\
\text { Yes "Half of the people say you need to charge more } \\
\text { and half the people would say your pricing is just } \\
\text { right." } \\
\text { Yes "Different people, different views-but part of the } \\
\text { CEO's job is to get advice and ultimately you have to } \\
\text { pick your own course." }\end{array}$ & $\begin{array}{l}\text { No "We got a ton of stuff done because we were really } \\
\text { focused." } \\
\text { No "They basically just left us alone to go to work." } \\
\text { No "And for the next } 24 \text { hours, we as a team had to } \\
\text { sprint to see how we can apply that to our business and } \\
\text { sometimes make somewhat sweeping changes to our } \\
\text { business model. The next day, we'd have the next } \\
\text { mentor and we'd do it again." }\end{array}$ & 4 \\
\hline & Fir & 5 & $80 \%$ & Medium / Low & $\begin{array}{l}\text { No “"Look, the mentors are busy. They won't have } \\
\text { time to help you unless you're very specific." } \\
\text { No "I, for the most part, didn't interact a whole lot with } \\
\text { the mentors." } \\
\text { Yes "Conflicting advice is inherently confusing. But } \\
\text { there was good and consistent advice that we needed to } \\
\text { just make decisions and move on, even in the face of } \\
\text { conflicting advice." } \\
\text { Yes "Everybody provided conflicting advice." } \\
\text { Yes "It seemed like they were trying to get you to do } \\
\text { something that either conflicts with something that one } \\
\text { of the other mentor said, or conflicts with your own } \\
\text { vision." }\end{array}$ & $\begin{array}{l}\text { No "We had to spend too much time head-down and not } \\
\text { enough time in the educational and coaching areas-and } \\
\text { that decreased our learning." } \\
\text { No "Very slowly getting into the meetings with the } \\
\text { advisors." } \\
\text { No "They told us that two months in is the last thing that } \\
\text { you'll be at in terms of traction, in terms of product." }\end{array}$ & 4.25 \\
\hline & Redwood & 5 & $25 \%$ & $\begin{array}{l}\text { Low/ high } \\
\text { "Tell them who it } \\
\text { is that you want to } \\
\text { meet and they'll } \\
\text { try to make an } \\
\text { introduction." }\end{array}$ & $\begin{array}{l}\text { No "I can't think of a time when their advice } \\
\text { specifically conflicted with each other or consequential } \\
\text { feedback." } \\
\text { Yes "It was confusing." }\end{array}$ & $\begin{array}{l}\text { No "And they stay out of the way" } \\
\text { No "They expect you to spend the first month at home } \\
\text { alone, writing code." } \\
\text { No "We tell them be heads down, focus on making } \\
\text { something people and then worry about raising } \\
\text { funding." } \\
\text { No "We don't want } 500 \text { different people meeting one of } \\
\text { the startup once and giving them conflicting advice." }\end{array}$ & N/A \\
\hline
\end{tabular}

* Reduction in coordination costs are assessed using the ratio of accelerator- initiated meetings over firm-initiated meetings. When the accelerator initiates mentor meetings, the firm's coordination time and costs are reduced 


\subsection{Director Experts}

Extant research has highlighted the challenges of transferring tacit knowledge (Von Hippel, 1994; Polanyi, 1966), especially when the receiving firm lacks the organizational routines, foundational knowledge, and problem-solving experience required to absorb learning (Cohen \& Levinthal, 1990). However, the nascent ventures in this study learned from director experts who accelerated learning by transferring experience to nascent ventures. I define director experts as advisors who cumulate and transfer experience to nascent ventures.

Table 11 provides evidence on director experts. I assessed director experts as follows: (1) the level of director experience, measured as the number of program alumni; (2) the level of program structure, which was coded as "none" when the program had no structure, "monthly" when the program had a structured progression that shifted every month, and a brief description if the program had another type of structure; (3) the intensity of shaping, which I assessed using the average number of times the director provided feedback on each venture's pitch; and (4) the average response to the closed ended question "rate the amount learned from the accelerators directors." Ratings were provided on a seven-point Likert scale.

Birch provides an example of director experts. There were three co-directors at Birch, all with complimentary expertise: One was a venture capitalist, another was a former CEO, and the third was an engineer by training. The directors were generally available, with at least one in the office most of the time. Although the directors had substantial experience with start-ups prior to forming Birch, they also had interacted with over 25 ventures in their role as directors of Birch. 
The directors transferred what worked in the past, so that the ventures could learn from the directors' past experiences without having participated in or directly observed that experience. For example, one founder said that the directors shared "examples of other people's pitches and what worked well and what did not," which helped his venture prepare its pitch. Birch's directors also helped ventures recognize and correct their "fatal flaws." Experience helped directors predict what flaws might become fatal in the future. Identifying and discussing fatal flaws began during the application process and continued throughout the program. Through director's past experience, they helped founders identify and reduce riskunknown risks became known and defined so that ventures could address them.

Birch's program was highly structured. Based on their experience, Birch's directors developed structure that synchronized learning. Structure conveyed what to learn and how much time to allocate to each learning assignment. For example, Birch's directors developed the program structure, which included three one-month segments. A director explained, "The first month is really focused on product. The second month is more focused on business. And third month is focused on market and fundraising." Not only did the program's structure communicate what ventures needed to learn during each phase of the program, but it also communicated how long to spend on each learning assignment. A venture founder explained that the directors "set a timeline for when you had to have an initial deck and initial draft [of the pitch] ready." Another founder compared their progress to the program structure, "We're pretty much on track except traction we're probably about a week behind." Thus, the program's structure helped ventures determine what they needed to learn, when they needed to learn it, and how much time to spend learning about each aspect of their business. 
Synchronizing learning also reduced knowledge gaps. One founder said, "When you start off, you don't know what you don't know." Beginning with the application and continuing to the program structure, synchronization reduced "unknown unknowns" to unknowns that attracted venture's attention. For example, the application highlighted knowledge gaps and triggered learning for many ventures that searched to find answers to the application questions.

Birch's directors provided feedback on ventures' learning. Directors met with venture founders two-to-three days per week, or more often when founders requested more help. Ventures practiced their pitch twenty to thirty times, and the directors provided feedback to the ventures on their practice pitches. The three directors' feedback and style complemented each other. According to a venture founder, "You'd never walk out of a meeting [with the finance guy] feeling good about it; he'll always rip you apart. The tech guy would always tell you you're doing great, and then the CEO guy would be like the pragmatic optimist." Another said, "Cam would play bad cop, he could be very critical of business ideas and pitches but in a friendly way." While critical feedback was difficult for some founders to receive, one commented that "it makes you stronger." Overall, feedback refined and confirmed venture learning.

Hickory provides another example of director experts. Hickory had two full-time directors who worked in an open space alongside the venture founders. The two directors are serial entrepreneurs, with several startups and successful exits between them. Moreover, Hickory had over 25 ventures that graduated. Based on their experience, the directors of Hickory were able to spot patterns and intervene to redirect ventures that might be on an inferior or failing path. One director commented on a venture's problems, "I have seen this 
movie before; it is going to fail because customer acquisition is too expensive." The director also recalled, "We had to do an intervention of sorts but I recognized what was going on earlier." He went on to explain that the venture's issues reminded him of a venture from the previous year, but by the time he had noticed the problems the previous year, it was too close to the program's completion to provide significant help. The second time, the director spotted the problem earlier and was able to help the venture correct their course.

Hickory's program was highly synchronized. The program was divided into three one-month segments: The first month was mentor dating, the second month was mini-MBA, and the third was pitch. As discussed earlier, during the first month, ventures met with a diverse group of mentors. During the second month, guest speakers lectured on business tactics such as marketing, finance, and fundraising. Ventures also spent a significant amount of time building their product or service during the second month. During the last month, ventures developed and refined the pitch in preparation for Demo Day. Ventures fit learning assignments into the allotted time period. One founder said that "knowing we had a month to put together a story made us put together a story in a month... I don't think we would have done any worse or any better if it was four months."

At a more micro level, Hickory directors synchronized learning by providing templates, which ventures completed. For example, Hickory directors provided ventures with a pitch template. Using the template, ventures focused learning activities to complete each part of the template. A director described the pitch template, "If you believe these three things: It's a huge market, I have a low customer acquisition cost, and I can get a lot of customers at a profitable rate, you're going to want to invest in my business." Ventures then focused learning on the market size and customer acquisition strategy. Some venture 
founders said that completing the application highlighted initial knowledge gaps. As one founder said, "When filling out the application-I did not even know what I didn't know!" Questions on the application focused venture learning on finding answers to the application questions and leveled initial knowledge for ventures prior to the program.

Toward the end of the program, Hickory directors shaped learning by refining the pitch. Venture founders practiced their pitches 100 times-literally. The directors scored the ventures' pitches after each practice. Directors provided critical, if not harsh, feedback. A director commented, "We don't sugarcoat it at all," and one venture founder reported crying during pitch practice. "They would give you somewhere between a zero and a five, and the day that I cried I got two, and I had gotten three the day before." The director further explained how he and his partner shaped venture pitches:

[My partner] is a master at putting the storyline together for the pitch and making sure it flows and make sense, and I'm really good at once we have a storyline, how do we convey those messages really well, what are appropriate slides to go with things like you say, and we get down to word choice and in the last week is literally tweaking individual words.

Pitches were 10 minutes long, requiring ventures to focus on the most important aspects of their business. The process of refining and practicing the pitch helped ventures understand the core drivers of their business.

Ash provides an example of directors that were not experts. Though Ash's director had started several ventures, his accumulated experience through Ash was limited. There were 5 ventures per cohort and fewer than 20 firms had graduated from the program. Ash's program was 2 weeks shorter than others, further reducing the cumulated experience of the director.

Ash did not have a formal structure. A venture founder described the program as "pretty unstructured." The director explained, 
It's not formally broken up, obviously toward the end people are working more of the pitches and getting ready for Demo Day and they are probably more focused on funding if that what their next step is; but every company is different, so what they need is different you know we are not trying to put them into a box we don't really tell them what to do that not really the nature of the relationship. (emphasis added)

Ash's director began each program session by assessing each venture and trying to help them with their unique needs. He explained, "It's different for every company. That that's why this is hard. . . we really spend some time digging in and getting to know them understanding, where they are headed, what they need to focus on." Ash's director repeatedly commented that each venture was unique. In another instance, he said, "What they need is different. We are not trying to put them into a box and we don't really tell them what to do. That is not the nature of the relationship. We are here to help them but we try to identify people that are self motivated they are going to go out and ask for help and then grab the things they need as well." Ash's director did not synchronize learning for the ventures. Nor did he communicate what ventures should learn or how much time they should spend on each aspect of their business. Rather, he provided unique advice to each venture.

I expected and found that accelerators with smaller cohorts and directors of newer accelerators might have accumulated less expertise. However, I expected directors at larger accelerators to cumulate more learning. To the contrary, directors at the largest accelerator did not synchronize or shape learning as much as the directors of the medium-sized accelerators. One explanation could be that the level of interaction between the directors and ventures at the largest accelerators was limited. Although hundreds of ventures pass through larger programs annually, directors of larger accelerators spread their time across large cohorts of ventures, thus they worked less intimately with each venture, which may have reduced the amount they learned from each venture. For example, the director at Oak 
explained how he and his co-director limit their interactions with the ventures, "Our motto is not based on us being the bottleneck but on connecting with our resources." Oak did not synchronize learning by dividing programs into monthly topic areas and did not shape learning by providing feedback on venture practice pitches.

Director experts accelerated learning by cumulating experience from participating ventures and then transferring their experience to novice entrepreneurs. As one Hickory director said, "One of my goals is to expose these guys to all of that stuff-as much of it as I can-in 90 days that took me 11 years [to learn]." Because directors simultaneously cumulated experience from multiple ventures, they quickly became experts. Directors reported seeing "this movie a thousand times," and founders concurred, "She's seen this a hundred times." Directors who repetitively helped start-ups from beginning to end could predict later experience for less experienced founders who were unable to extrapolate into the future. Predicting helped ventures identify future issues and opportunities sooner than learning-by-doing did, which advanced learning forward in time and avoided dead ends before they were experienced.

Director experts synchronized learning, which helped firms focus, refine, select and time learning experiences. For example, Alder's director developed the program's temporal structure: "I break the three months in to the following pattern and again this something that that we learned, we didn't start this way so this is sort of how it happened naturally but then we codified it probably by the third year." Structured templates such as the one described above synchronized learning for nascent ventures (Winter, Szulanski, Ringov, \& Jensen, 2012). Whereas most prior work has examined how organizations, such as franchisors, use templates to replicate routines within a single organization (e.g., Winter et al., 2012), 
accelerators used templates to transfer expertise from the accelerator to participating ventures.

Templates focused founders' attention on learning rather than discovering what to learn because they described what needed to be learned, when it needed to be learned, and how long it should take to learn. For example, directors at Hickory and Alder provided founders with a template for their pitch that dictated the length of the pitch and told founders when to begin preparing. A founder at Alder said that the director led a " 'how to pitch' session and that actually helped guide us a lot as far as how to tell the story of our pitch." Based on the template, founders knew what they need to learn to create their pitch. Ordinarily, founders would need to learn the format of the pitch as well as the content. They would also need to decide when to begin practicing and how much to practice. Templates might be akin to homework assignments that guide student learning. They also may be part of what more experienced firms learn as they develop absorptive capacity ${ }^{12}$ (Cohen \& Levinthal, 1990).

Templates might also be an efficient way for experts to transfer heuristics to novices who lack absorptive capacity. Incidentally, director experts frequently transferred expert heuristics (timing and priority). Heuristics were transferred when accelerator directors sequenced and allotted a certain amount of time for different learning activities. For example, timing heuristics were transferred when directors allotted a certain amount of time for pitch presentations. Timing heuristics also helped ventures maintain forward momentum and avoided complexity traps because ventures moved on to the next learning phase at the

\footnotetext{
${ }^{12}$ Defined as the "ability of a firm to recognize the value of new, external information, assimilate it, and apply it to commercial ends" (Cohen \& Levinthal, 1990).
} 
indicated time. Because heuristics are simple, they might be more easily transferred to and absorbed by novice firms.

Finally, directors shaped and refine learning by providing direct, "intellectually honest" feedback, most often on the venture's pitch. When director's feedback was honest and direct, it was easier for ventures to interpret. Although positive reinforcement is commonly discussed in studies of learning (Van de Ven \& Polley, 1992), negative feedback might be faster, especially when desired behavior infrequently happens - negative feedback avoids waiting for opportunities to give positive feedback.

Director experts provided frequent feedback on ventures' pitches. Director feedback proxied for that of investors or customers. Receiving proxy feedback from directors was faster than receiving feedback from investors or customers, because directors were collocated alongside ventures and widely available. Normally, ventures would need to coordinate meetings and travel to investor's offices for each pitch. To solicit customers ventures would first need to establish relationships or discover customer acquisition strategies. Proxy feedback has lower coordination costs than real feedback. Proxy feedback was used to refine ventures' strategies and the effective communication of those strategies. In contrast to mentors who assisted ventures with learning the business landscape, or exploration (March, 1991), directors assisted ventures with iterative learning around the chosen strategy, or local search (Levinthal, 1997; March, 1991; Stuart \& Podolny, 1996).

Overall, directors focused learning for ventures. Beginning with the accelerator program application, which focused learning on answering application questions, and continuing through the program structure, which directed venture activities throughout the program, directors directed what and when ventures learned. Ventures that followed the 
temporal structure provided by the accelerator directors knew what to work on, how long to spend on each phase of development, and what not to work on. Directors also helped venture founders select the most promising strategies, either by providing direct feedback or by teaching ventures how to validate strategies with customers. Finally, like sculptors, directors chiseled away at a venture's pitch until only the core, the most important strategic points, were left, creating a poignant and concise pitch. 
Table 11: Director Experts

\begin{tabular}{|c|c|c|c|c|}
\hline Accelerator & Experience; alumni size & Level of Structure & Shaping/ Frequency of pitch & Learn MD \\
\hline \multirow[t]{2}{*}{ Chestnut } & $<25$ & None & 12, no score & 4.33 \\
\hline & $\begin{array}{l}\text { "Had three companies" } \\
\text { "It all depends" }\end{array}$ & $\begin{array}{l}\text { "It really depends on who is available and } \\
\text { when." } \\
\text { "The vertical focus of it was sort of the key." }\end{array}$ & $\begin{array}{l}\text { "Interns that would give feedback, Owen } \\
\text { would give feedback, we have judges } \\
\text { sometimes-almost all the time actually, } \\
\text { the other companies would give } \\
\text { feedback." }\end{array}$ & \\
\hline \multirow[t]{2}{*}{ Birch } & $25-100$ & Monthly & $20-30$, no score & 5.83 \\
\hline & $\begin{array}{l}\text { "I have been VC for a dozen years. I have } \\
\text { seen a lot of pitches" } \\
\text { "We are cognizant ... what their fatal } \\
\text { flaw might be." } \\
\text { "They ran a lunch session with examples } \\
\text { of other people's pitches." }\end{array}$ & $\begin{array}{l}\text { "It was pretty structured. So the first month } \\
\text { mentors are more product focused whereas the } \\
\text { second month their giving you marketing } \\
\text { distribution strategy and then its meeting a lot of } \\
\text { investors." } \\
\text { "When you start off, you don't know what you } \\
\text { don't know." }\end{array}$ & $\begin{array}{l}\text { "You'd never walk out of a meeting } \\
\text { [with the finance guy] feeling good about } \\
\text { it; he'll always rip you apart. The tech } \\
\text { guy would always tell you you're doing } \\
\text { great and then the CEO guy would be } \\
\text { like the pragmatic optimist." } \\
\text { "It makes you stronger." }\end{array}$ & \\
\hline \multirow[t]{2}{*}{ Oak } & $>200$ & Monthly, flexible & 0, as requested & 3.83 \\
\hline & $\begin{array}{l}\text { "It's not like we had a great a great } \\
\text { background." } \\
\text { "We try and work with one hundred and } \\
\text { twenty-five companies but our model is } \\
\text { more along the lines of the connector } \\
\text { model." }\end{array}$ & $\begin{array}{l}\text { "The first month is all about getting settled, work } \\
\text { with your mentors to define your goals, what you } \\
\text { want out of it and get to know the mentors and } \\
\text { all the resources or do education sessions. Then, } \\
\text { it's time to just work on your business whether } \\
\text { it's with your mentor, whether it's educational. } \\
\text { As we get toward the final September period ... } \\
\text { getting prepared for more on the pitching side, } \\
\text { make sure you can present you ideas in coherent } \\
\text { fashion." }\end{array}$ & $\begin{array}{l}\text { "The offer's open, they can sit down with } \\
\text { us but again, we don't want to be the } \\
\text { bottleneck for the whole } 125 \text { companies, } \\
\text { right. So what we tell them is, practice } \\
\text { with their mentors." }\end{array}$ & \\
\hline \multirow[t]{2}{*}{ Ash } & $<25$ & None & 12 & 5 \\
\hline & $\begin{array}{l}\text { "I started angel investing before I ever } \\
\text { taken any investment." } \\
\text { "Over time a mentor can teach you } \\
\text { wisdom, in the short term a mentor gives } \\
\text { you shortcuts." }\end{array}$ & $\begin{array}{l}\text { "It's not formally broken up." } \\
\text { "Every company is different, so what they need } \\
\text { is different." }\end{array}$ & $\begin{array}{l}\text { "boiling it down with the essence of their } \\
\text { company" } \\
\text { "hazing ritual" }\end{array}$ & \\
\hline \multirow[t]{2}{*}{ Hickory } & $25-100$ & Monthly & 100+, scored & 6.2 \\
\hline & $\begin{array}{l}\text { "I have seen this movie before; it is going } \\
\text { to fail because customer acquisition is too } \\
\text { expensive" } \\
\text { "One of the companies, we had to do an } \\
\text { intervention of sorts but I recognized what } \\
\text { was going on earlier." }\end{array}$ & $\begin{array}{l}\text { "Because they told us [when to prep for Demo } \\
\text { Day]." } \\
\text { "When filling out the application-I did not even } \\
\text { know what I didn't know!" } \\
\text { "Generally the format is: if you believe these } \\
\text { three things, you're going to invest." }\end{array}$ & $\begin{array}{l}\text { "We don't sugarcoat it at all" } \\
\text { "That was the worst pitch I've ever seen } \\
\text { in my life ... here is what you need to } \\
\text { change." } \\
\text { "I kept getting all this negative feedback; } \\
\text { I got a score of one." }\end{array}$ & \\
\hline
\end{tabular}




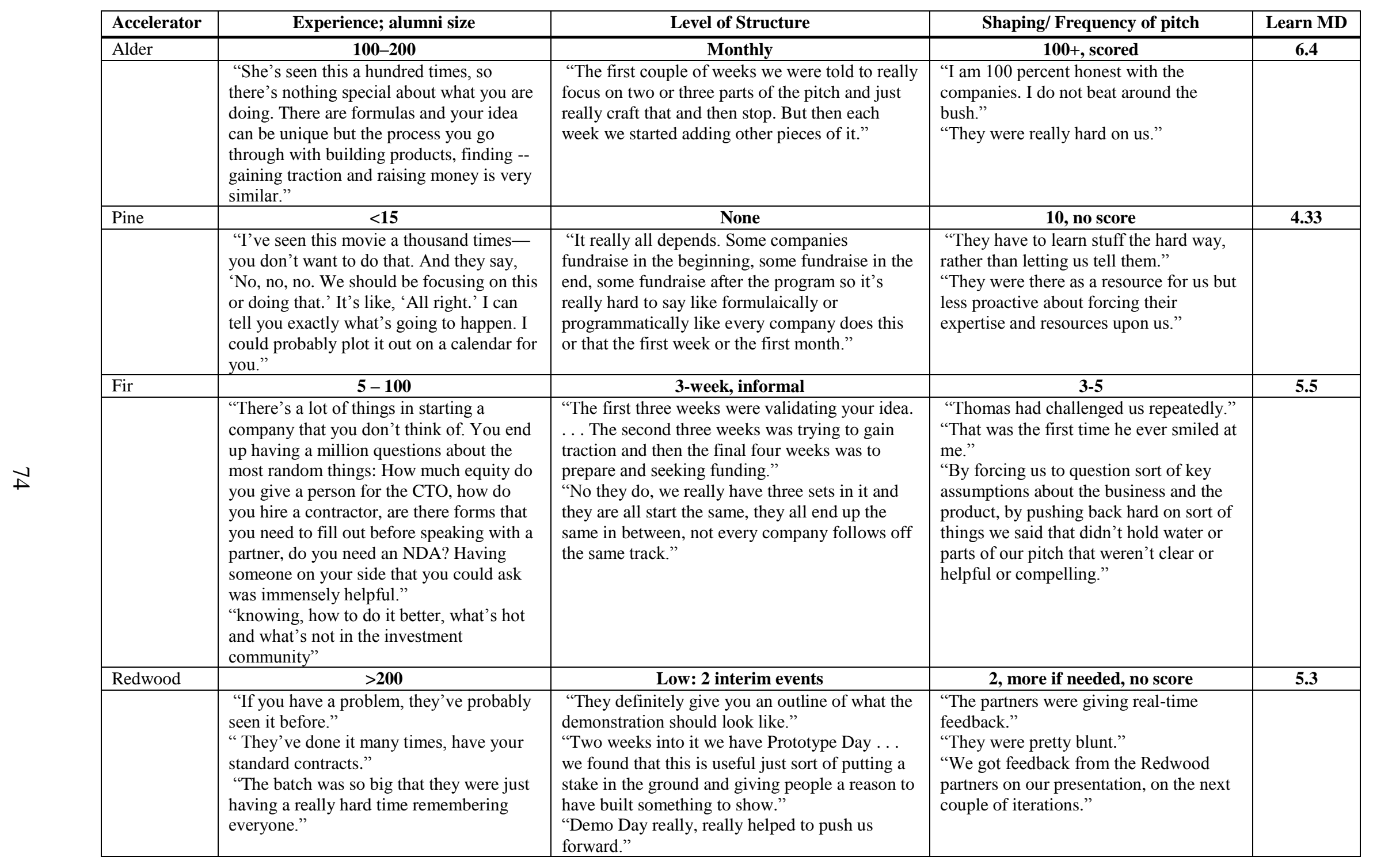




\subsection{Divided Teams}

Prior work suggests teams that work together on each experience accelerate learning (Pisano et al., 2001; Wheelwright \& Clark, 1994). For example, surgical teams that trained together and whose membership remained stable learned a new cardiac surgical procedure more quickly than teams that had more fluid membership (Pisano et al., 2001). In contrast, this study found that teams accelerated learning by working independently, rather than together on each experience. I define divided teams as teams that do not work together on each experience. Table 12 summarizes evidence on divided teams. I assessed divided teams by averaging the team size and evaluating the extent to which teams did not work together on each experience. The concept of trust repeatedly emerged from the data. Thus, I also assessed the level of trust within the team.

Birch provides an example of divided teams. All of the Birch teams began the program working together. For example, cofounders usually began by attended the mentor meetings together. When they worked together, teams developed a shared vision for their venture and routines for collaborating. Eventually, all of the Birch teams divided work. Founders explained that they divided their efforts in response to extreme time pressure and demanding schedules required by the accelerator program. Division enabled them to work in parallel. One founder explained, "It would be impossible for us both to participate in at least the business side, mentor and investor meetings just because there isn't enough time in the day."

Several founders explained how they divided work. Commonly, one founder, usually the Chief Technology Officer, focused on building the product while the other founder, usually the Chief Executive Officer, focused on meeting with mentors. One founder 
explained, "J worked on building product and I worked on improving the pitch and meeting with mentors to get product advice." Cofounders who divided spread learning across the team. For example, chief technology officers started implementation and learning-by-doing while CEOs refined learning about the business model. One founder described his relationship with his cofounder,

We're in constant dialogue. Yesterday we were doing some user experience updates and walking through it and we've worked together so long at this point that we finish each other's ideas and sentences. We know how each other think and I know how he likes to work, so I mapped it out in Photoshop and I then ask him his ideas.

At the same time, teams learned how to integrate independent learning. Some teams relied on the CEO to filter and direct knowledge. A CEO said, "I filter ... I take all the things that I think are appropriate like product feedback and I iterate that so if I sit in a meeting for half an hour I try to sum it up for him in a minute or two." Another founder described how his team balances working together and apart. At first he said, "We divide and conquer executionally. We solve problems either organically in terms of you solve it if you discover the problem or if it's related to something in your purview or it comes top down from me... It's pretty rare that five of us sit around the room an try to think of solutions to problem." Yet that founder also said, "When it comes to actually running the business we're pretty collaborative." Thus some teams developed rather complex working relationships that included both division and collaboration.

Fir provides another example of divided teams. Fir's program was two weeks shorter than most programs. This additional time pressure made it even more difficult for founders to be ready for Demo Day. Seventy-five percent of the founders at Fir reported dividing. One venture founder explained, "We started trying to solve them together and we realized that the divide and conquer is much better for us." Another founder concurred, "One of us was really 
focused on the product and the other started really figuring out the company." Another founder's story confirms that founders divide to learn in parallel, "It's more trust when we come from our areas of expertise. So, I'd say it increased our team productivity pretty dramatically as we divide and conquer." By dividing, each founder built expertise and legitimacy in their domain, thus engendering trust from the rest of the team.

Ventures at Fir reported that the technical experts coded while the business leaders continued to meet with mentors and customers, hired new staff, and spoke to the press. Toward the end of the program, the business person focused on developing and refining the pitch. A founder said,

[My cofounder] was coding all the time ... during the first phase of the program, I actually went and did some more site visits and some more interviews to kind of check to see if we were going in the right direction. During the middle part of the program, I did more product work, so UI design and working with contractors to fill holes in our technical skillset. And then during toward the end of the program, I definitely was focusing on the pitch.

Division evolved during the program as teams discovered trade-offs between learning together and dividing. As a venture founder explained, "We started trying to do everything together and we realized that the debates and the ways of trying to refine the ideas was making our ideas a little bit better but taking a lot longer ... but when we divided and conquered, everything has been executed much more quickly." Rather than squeeze every bit of learning from each experience, ventures that divided learning accelerated learning by learning more efficiently.

When does dividing happen? One founder at Alder explained that they divided "once the problem is understood together."Another founder at Alder said that time pressure translated to division for her team, "We started to understand more of what defined our role as we got busier." A founder at Alder described how her team changed over the course of the 
program, "We started to understand more of what defined our role as we got busier. Because, it would have been really hard for us to be at all the same meetings but we really realized that even in the first few weeks. So, learning about roles, trusting the cofounders to take care of their departments."

Founding teams that had or developed trust were able to overcome stress and challenges. A founder at Alder said, "There were a couple of times where we got into huge fights because Alex felt we had to do one thing and I thought we had to do a different thing and we just couldn't just see eye to eye. But in the end, Alder really helped us figure out conflict resolution because at the end of the day, we had to make a decision and we had to be a team about it." This team developed a collective vision and compromised individual differences for the benefit of the team. Another Alder team that not develop a collective vision broke up after the program. The remaining cofounder said,

I actually ended up firing my co-founder at the end of the program about three days after Alder. It was really unfortunate. One of the big things that he came into Alder with was tension around working in education versus corporations and he was very not interested in working for corporations. He wanted to make it work for higher education and the deal we made was if he could get seven more higher education institutions with the current platform, that would be attractive to go to VCs and say look here is the corporate direction, here is a higher education. We couldn't go into a funding round where a spread sheet really was not profitable. And so he took responsibility for that and then when he was unable to do it that he said I don't want to go into corporations.

Thus trust may be a prerequisite for successful division.

Collective vision may also be a prerequisite for successful division. Through the process of jointly attending mentor meetings, cofounders developed collective cognition (Lant, Milliken, \& Batra, 1992). Teams that developed individual rather than collective cognitions broke down later. For example, one founder at Fir described his teams' work style as, "divide and conquer that didn't work." He continued, "Ultimately, the product that he built was different than the vision that I was selling." The team "butted heads a lot" and 
ended up disbanding after the program. Interestingly, the cofounders were introduced shortly before the accelerator program, as compared to many teams that had previously established working relationships. The split was not due to the lack of a business opportunity. After the split, one of the cofounders rebuilt and rebranded the company using the same core strategy. The new company raised $\$ 1.6 \mathrm{M}$ in investment capital from a top-tier venture capitalist,

The closer teams grew, the more collective their vision and cognition also became. This shared trust and vision enabled teams to successfully divide implementation and related learning. In teams that did not develop trust, division led to unproductive bifurcation rather than cohesive parallel learning.

How did divided teams accelerate learning? Dividing learning optimized internal capabilities across team and built transactional memory systems (Argote \& Ren, 2012; Gibson \& Vermeulen, 2003; Wegner, 1987), which enabled team members to learn in parallel. Dividing helped teams learn who is good at what, and who knows what. For example, a founder at Hickory described how she and her cofounder learned about each other by dividing work, "I know his strengths he knows mine, and we both, of course, had to do things that we don't always like, but we divide it pretty evenly." It was through dividing that this founder and her cofounder discovered each other's talents.

When teams divided, team members simultaneously employed different modes and different areas of learning. Dividing increased functional diversity because team members typically divided work according to function; for example, technical cofounders coded while sales and marketing team members met with potential clients. Yet teams also needed to integrate some of what they learned. Integrating learning enhanced learning comprehension because founders needed to synthesize what they learned to share it with their team. A team 
at Redwood explained how they came together after dividing, "So we usually try to like separate, think about it on our own and then come together so we benefit from both, solo path and then the group thoughts."

Dividing teams also improved organizational communication by reducing the assumption of shared experience (Stasser \& Titus, 1987) and producing constructive dialog, which led to deeper learning (Haunschild \& Sullivan, 2002). A founder from Hickory explained, "I prepared for meetings, I do meetings all day. Ezra would code it all day, and then from probably like 7:00 to 8:30 at 9:00 we brief each other. I do all of my follow up and then leave around midnight, and then we start all over again, and that was the-it was helpful in that, and we both knew what the other was doing." A founder at Redwood explained how dividing and then coming together expanded learning, "Usually somebody on the team will own the problem and spearhead or propose a solution. As a full team, we'll give feedback on whether or not we believe that solution is the right solution." Another founder at Redwood explained how his team usually divided, but when they had a larger problem, they came together, "When problems straddle our skill sets, when it's a future decision that really is going to affect schools, $R$ and I sit down and talk about it and think it through." A founder at Pine similarly said "Mostly we divide and conquer; big things, we'd do together; We get together and work it out. You know, price point was a great one. We duked it out for six hours and I mean there were some strong opinions on every side of it. But when we left, we had a new price point and everybody was good with it."

Divided cofounders synthesized learning when they communicated key concepts and concerns with each other. They further extended learning by asking their cofounders questions about what they have learned and what still needs to be learned. Divided teams 
built internal communication cadence, such as daily or weekly meetings, which further enhanced learning (Bingham \& Haleblian, 2012). 


\section{Table 12: Divided Teams}

\begin{tabular}{|c|c|c|c|}
\hline Accelerator & \# Founders & Did division emerge? & Did trust emerge? \\
\hline Chestnut & 2.2 & $\begin{array}{l}\text { Yes "I just started going to the meetings and filtering the feedback to my team . } \\
\text {. my team focused on doing the work instead of thinking holistically and } \\
\text { strategically." } \\
\text { Complex "We have always divided our work." Yet "We all went to mentorship } \\
\text { meetings." } \\
\text { Yes "In the beginning we would all go to those meetings together for those } \\
\text { meetings but it was to the point where my technical co-founder didn't want any } \\
\text { distractions and just get in the zone." }\end{array}$ & Yes "We think pretty much alike." \\
\hline Birch & 1.67 & $\begin{array}{l}\text { Yes "Initially we did them together. After a while I took all of them." } \\
\text { Yes "It made sense one of us cover almost every meeting." } \\
\text { Yes "We decided early on that it would be impossible for us both to participate } \\
\text { in at least the business side, mentor and investor meetings just because there } \\
\text { isn't enough time in the day." } \\
\text { Yes "C was still heads down developing and now I was doing a ton of } \\
\text { meetings." }\end{array}$ & $\begin{array}{l}\text { Yes "It's been a good bonding experience." } \\
\text { Yes "We came and actually we got closer. We'd known } \\
\text { each other in San Francisco; we'd been working together } \\
\text { for a bit but moving together and spending full time } \\
\text { together in the office definitely helped that." }\end{array}$ \\
\hline Oak & 2 & $\begin{array}{l}\text { Yes "Then as new projects and things come up we ask who on the team wants to } \\
\text { be part of them and then we delegate and then we divide and conquer." }\end{array}$ & $\begin{array}{l}\text { Yes "We're still all really good friends. ... In our } \\
\text { situation, because we are all so passionate, we live, } \\
\text { breathe and eat our social mission." }\end{array}$ \\
\hline Ash & 2 & $\begin{array}{l}\text { No "We solve problems together, because we have very different backgrounds } \\
\text {. no matter whose problem it is, we will attack it and we can ask quite some } \\
\text { unexpected questions of each other, which helps brings out, you know, issues } \\
\text { and problems, or a solution." }\end{array}$ & $\begin{array}{l}\text { No "Things came to a head, and one of our mentors was } \\
\text { like, what are you doing? You know, why aren't you } \\
\text { charging for this? (excitement) I don't understand why } \\
\text { you are not charging for this! And guys are like } \\
\text { pounding on us, why aren't you charging for this, you } \\
\text { are not going know if anybody going ... and that's what } \\
\text { my partner and I argued about, and we didn't have a } \\
\text { good way to break the impasse, and that was the biggest } \\
\text { thing." }\end{array}$ \\
\hline Hickory & 2.4 & $\begin{array}{l}\text { Yes "Ely and I had a strict division of labor, so I did every single mentor } \\
\text { meeting, and he did nothing but write code." } \\
\text { Yes "He was really great about managing all the mentor relationships, and then } \\
\text { I have been always the numbers and presentation person or the analysis person, } \\
\text { so we were able to more evenly divide our responsibilities." }\end{array}$ & $\begin{array}{l}\text { Yes "like a brother and sister relationship" } \\
\text { Yes "Figured out how to work as a team." }\end{array}$ \\
\hline
\end{tabular}




\begin{tabular}{|c|c|c|c|}
\hline Accelerator & \# Founders & Did division emerge? & Did trust emerge? \\
\hline Alder & 2.4 & $\begin{array}{l}\text { Yes "We've laid out clearer goals because we knew that we would have to take } \\
\text { on a lot of responsibility individually as we collaborated together." } \\
\text { No "We come together to solve problems." } \\
\text { Yes "So we both went to all of the meetings and eventually-after we picked } \\
\text { our lead mentor, so probably in Week Four or Five-we started figuring out } \\
\text { which meetings I should go to versus which meetings Alex should go to alone." } \\
\text { Yes "Depended; at the beginning, the three founders went the meetings and then } \\
\text { over time it really depended on peoples' expertise and what mentor meetings } \\
\text { were like" } \\
\text { Yes "It would have been really hard for us to be at all the same meeting. We } \\
\text { really realized that even in the first few weeks." }\end{array}$ & $\begin{array}{l}\text { No "He was very not interested in working for } \\
\text { corporations, wanted to make it work for higher } \\
\text { education and the deal we made was if he could get } \\
\text { seven more higher education institutions with the current } \\
\text { platform, that would be attractive to go to VCs. . . And } \\
\text { so he took responsibility for that and then when he was } \\
\text { unable to do it that was that and he said I don't want to } \\
\text { pivot into corporations" } \\
\text { Yes "Learning about roles, trusting the cofounders to } \\
\text { take care of their departments, so to speak." }\end{array}$ \\
\hline Pine & 2 & $\begin{array}{l}\text { Complex "Mostly divide and conquer; big things, we'd do together. We'd get } \\
\text { together and work it out. You know, price point was a great one. We duked it } \\
\text { out for six hours and I mean there were some strong opinions on every side of it. } \\
\text { But when we left, we had a new price point and everybody was good with it." }\end{array}$ & $\begin{array}{l}\text { Yes "You know, we began to learn to trust one another } \\
\text { in new ways and we were moving so fast that sometimes } \\
\text { you had to go blind." } \\
\text { Yes "We sort of learned to trust one another making } \\
\text { those decisions and we couldn't all fit in the strategic } \\
\text { position and have all the information at all times." }\end{array}$ \\
\hline Fir & 2.2 & $\begin{array}{l}\text { Yes "My cofounder would defer." } \\
\text { Yes "So, one of us was really focused on the product and the other started really } \\
\text { figuring out the company." } \\
\text { Yes "We started trying to do everything together and we realized that the } \\
\text { debates and the ways of trying to refine our ideas was making our ideas a little } \\
\text { bit better but taking a lot longer. But when we divided and conquered } \\
\text { everything has been executed much more quickly." }\end{array}$ & $\begin{array}{l}\text { No "The program was stressful. It placed stress on our } \\
\text { relationship." } \\
\text { No "We butted heads a lot and ended up having different } \\
\text { areas of the company . . my cofounder is my ex- } \\
\text { cofounder" } \\
\text { Yes "When people gel, they move a lot faster with three } \\
\text { cofounders, but at the same time, it increases the } \\
\text { likelihood of tension." }\end{array}$ \\
\hline Redwood & 2.5 & $\begin{array}{l}\text { Complex "It depends on the nature of the problem. Usually somebody on the } \\
\text { team will own the problem and spearhead or propose a solution. As a full team, } \\
\text { we'll give feedback on like whether or not we believe that solution is kind of the } \\
\text { right solution." } \\
\text { Yes "It was probably five companies that I talked to every week at dinners and } \\
\text { my cofounders each had their own five and there wasn't that much overlap." } \\
\text { Yes "It's really clear who owns what and so Tom gets to make the final call } \\
\text { when it comes to business development and that's great and I respect his } \\
\text { decision and I'll push on him. But, when I have a different opinion but it's like, } \\
\text { you know, it's just you're trying to add input and help him make a better } \\
\text { decision, so, yeah, we do that all the time but it's never like we've ever fought. } \\
\text { But we discuss directions all the time." } \\
\text { Yes "We have our areas that we just take care of ourselves and also areas where } \\
\text { we come together and solve together." }\end{array}$ & $\begin{array}{l}\text { Yes "It's changed since we've been living together and } \\
\text { working together and spending tons of time together. } \\
\text { We're still really, really good friends who can just be } \\
\text { friends and also really good co-founders who can be } \\
\text { good co-founders." }\end{array}$ \\
\hline
\end{tabular}




\subsection{Cohort Peers}

Given that ventures in accelerator programs are under extreme time pressure and perceive that they are in direct as well as indirect competition for resources such as external funding, mentorship, and director attention, prior literature suggests knowledge flow between ventures should be limited (Messick \& Mackie, 1989). The ventures within accelerator cohorts were rivals and openly competed with one another. Surprisingly, my data suggest that ventures also shared significant amounts of knowledge with each other through a construct that emerged from the data: cohort peers. Cohort peers is defined as related ventures that influence peer aspirations and self-performance evaluations but also help close each others' performance gaps. Unlike industry peers, which have been the focus of extant research (e.g., Hu, Blettner, \& Bettis, 2011; Kim \& Miner, 2007; Zuckerman \& Sgourev, 2006), cohort peers need not be in the same industry.

Table 13 summarizes this study's evidence on cohort peers. I assessed cohort peers by examining both rival and supportive behavior. I assessed rivalry three ways: (1) the degree of openness at the accelerator's space; (2) the number of days from the start of the program until ventures first pitched to the rest of their cohort; (3) the proportion of ventures that reported being part of a cohort drove them to work harder. I assessed supportive behavior by calculating the percentage of ventures that reported giving or receiving help from another cohort member and the average response to the closed ended question, "During the time you were in the accelerator, rate the amount your firm learned from your cohort." Ratings were provided on a seven-point Likert scale.

Alder provides an example of cohort peers that accelerated learning. Each Alder cohort included ten to twelve ventures. All of the Alder teams reported working harder 
because of the rivalry with other ventures in their cohort and founders described the program as having "a lot of peer pressure" and "intense." One founder commented that "the group of people around you [...] drive you to do more." A mentor said, "Some of the teams were jealous of some of the others."

The managing director at Alder fostered rivalry to motivate ventures to work harder. She explained, "Because if you see somebody else doing really, really well and working really hard and cranking and making tons of progress, you have social pressure to do that too." Rivalry was intentionally constructed - the accelerator was structured to "expose progress" made by the ventures. For example, every week, firms identified what they needed to accomplish during the following week to "move their company forward." The next week, firms reported their progress to the group and identified their next challenge. Regular updates to metrics displayed on a public board further revealed venture progress and fostered rivalry as teams competed to show the most progress. Actions that might be considered bragging in other contexts were acceptable, even encouraged, at Alder. Alder's director explained, “We publicly surface progress that will put pressure on other teams to execute too." Even the office space was designed to increase pressure. Alder's office space was cramped and teams worked beside each other at long tables. They worked so close together that it was hard to distinguish between the teams but easy for teams to monitor each other's progress.

Progress was also exposed through weekly pitch practice. Ventures saw each other's pitches develop over the program. They also heard feedback directed toward other ventures and provided feedback to each other. Alder's director said that pitching each other "takes a ton of time" but was "very necessary." She explained, "A lot of the learning comes from listening because the same piece offeedbackfor this company might be the same piece of 
feedback that you'll get - and you may hear it a couple of times. As you see it in different instances it really starts to hammer home." Teams not only saw each other's progress but also compared their progress to that of their cohort peers. One founder said, "Depending on what stage the companies are in, they're already raising more money than a lot of us, they have more employees than us. So, depending on the stage, there's definitely some comparison." Ventures compared themselves and raised aspiration levels to match the top performers in the cohort.

Cohort peer relationships were complex. On one hand, firms competed with one another and compared their progress, which fostered rivalry and imitative learning. As a director at Alder shared, "They see each other's pitches so they get some ideas on how to do things differently than what they're doing." In some instances, ventures simply observed how cohort peers achieved success. Alder's director explained, “They lean over each other's shoulders, they give each other tips and advice, they share resources." Because ventures worked in close proximity causal ambiguity was reduced. On the other hand, cohort peers also actively helped one another. Alder's director explained, "They come in thinking that it's competitive and they find out it's cooperative and they find out they love each other because they're all going through the same stuff. They learn as much from each other as from us." A venture founder explained,

The vibe is 'help everyone at all cost' ... I received help from so many different people ... they would stop what they were doing, working on their dream idea and talk to us ... certain people in the program had expertise in pricing, certain people had expertise in software development. They would stop and talk to us at length about that and then we would do the same with others in our areas of expertise.

Akin to pacers in a triathlon race, where leaders set the pace for each event, ventures that excelled in different matters set the pace for the cohort. A founder explained, "So certain 
teams make progress in certain areas faster than others. For us, for example, it was fundraising." The leaders then helped other others in their cohort catch up. Another Alder founder explained, "Some companies were really well-prepared for Demo Day and you started to see people giving other teams help and advice and even sitting down and working their pitch with them."

More generally, ventures asked for and received feedback from cohort peers. "We would all use each other's early versions of the software, so you had the built-in feedback loop of 50 people in the same room as you." Feedback from cohort peers was obtained quickly and more completely than feedback could normally be obtained from the external environment.

Redwood provides another example of cohort peers. Redwood was a large accelerator, with over 80 firms in their last cohort. Redwood's ventures did not work in shared office space. Instead, they frequently lived and worked with their cofounders, sometimes alongside founders of other ventures. A founder at Redwood said that " $a$ lot of the interaction happened on Facebook." Even though they did not collocate during the program, all of Redwood ventures reported working harder because they were part of a cohort. Eighty percent reported giving or receiving help from another venture in their cohort.

Like Alder, Redwood encouraged rivalry by exposing venture progress. The second week of Redwood's program, venture founders showcased their idea or prototype to their cohort. Seeing other venture's prototypes decreased ventures' self-performance evaluations. As one of Redwood's directors shared, "People who might come into the program thinking, 'Oh, we're so far along. We're a little bit more advanced than most people that you fund.' Once they start seeing what the other people are building, they're kind of like, 'Oh wait, I'm 
not as far along as I thought." Seeing the other teams' progress also raised and broadened ventures' aspiration levels. The director continued, “"This group's pumping out all these new features, I better do the same." Another Redwood venture explained the complex cohort relationship, "You are really openly competing and also helping each other, it's very weird, it's a kind of a funny, interesting dynamic. You contribute to the network and when you need something from the network, it will contribute back to you."

Weekly gatherings offered a regular opportunity to expose progress. As one venture founder said, "You want them to do really well but when they do really well, it will make you work a little bit harder as well." Weekly dinners featured extremely distinguished guest speakers. Yet several founders commented that the most valuable part of "dinners was talking to the other companies." Normally, entrepreneurship can be lonely. Weekly dinners with the accelerator cohort made entrepreneurship more social. A founder explained, "It can be very, very lonely and I think just being a part of a group of people that are all doing the same thing and going through the same ups and downs. It's just really like a stabilizing force."

A week before Demo Day, a dress rehearsal provided another opportunity for social calibration and peer learning. Ventures pitched in front of and received feedback from their cohort and the program's directors. Ventures learned from watching each other's pitches and listening to critiques, as a founder told me, "We saw presentations from other companies and we saw things that we really liked from those." Ventures also competed for the coveted first and last spot of the Demo Day program. Based on the performance at Rehearsal Day, the director bestowed the coveted first and last spots in the Demo Day program on the two best ventures. 
Although Redwood founders described how they learned from cohort peers, many founders had difficulty comparing their venture to the rest of their cohort. For example, founders answered comparison questions with answers such as, "They are very hard to compare, there's so many different types of companies." Another founder explained that she did make comparisons, but they were specific,

When you compare something, you're not comparing your overall company. You're comparing like specific stuff. Like what's the email you're sending when someone signs up for your product? Oh here's what ours is. And try to like compare and make it better. It's not really like; you don't expect that very much and be like what's better than half of the companies in the batch or something.

The lack of collocation or extremely large cohort size may have attenuated the effect of cohort peers.

Oak is an example of an accelerator where cohort peers did not emerge. Oak was also a large accelerator, with over 100 ventures in each cohort. The last cohort was divided into four smaller communities, each located in a corner of a vast open office. Ventures in Oak chose whether to attend practice pitch sessions, though only one of the ventures in this study chose to attend. The other ventures never saw their cohort peer's pitches during the program. Two-thirds of the ventures at Oak reported giving or receiving help from a member of their cohort.

Ventures at Oak reported feeling cooperative with the other ventures. An Oak expected to feel competitive with her cohort, "Coming into the program, I always felt that all the different teams who were accepted might feel a little bit competitive." Instead, she found the environment not to be competitive. She said, "It was kind of surprising how helpful it was to actually have similar teams." 
Not only were the teams at Oak less competitive with their cohort peers but they also learned less from their cohort peers. A founder commented that "people are supportive but because everyone else also has their own business, they're not as concerned about supporting others." When asked about learning from her cohort, another Oak founder simply replied, "I wish I had."

In summary, cohort relationships are complex. Cohort peers simultaneously motivated and helped ventures to achieve more. Several informants commented on the importance of cohort peers. One venture founder said, "Being part of a [cohort] is hard to separate from being part of Redwood." Several accelerator directors agreed. One explained, "The most valuable thing of any program I would argue is the cohort working together."

At the same time, cohort peer learning was difficult to achieve. Recall that Redwood ventures did not work in communal office space. Given their limited contact, it is surprising that they learned so much from cohort peers. On the other hand, ventures of Oak learned less from cohort peers despite the fact that they shared office space. Simple collocation was not sufficient to foster accelerated learning from cohort peers. Neither was collation required.

How do cohort peers accelerate learning? Regular public updates reduced learning coordination costs. Exposing progress through public updates facilitated knowledge spillovers between teams, and teams imitated successful strategies. Public updates reduced learning-coordination costs by extending transactional memory beyond firm boundaries. Ventures knew which firms or founders in the cohort knew what. Thus, when ventures needed expertise, they could find it quickly within the cohort.

Public updates also created rivalry, which motivated ventures because they aspired to perform as well as all of the cohort peers. Rather than with industry peers, as prior literature 
suggests (Greve, 2003), ventures created social reference groups with their accelerator cohort. Calibrating against the best firms in their cohort, ventures concurrently downwardly adjusted self-assessments and raised aspirations. Also, rather than aspiring along a single performance metric, such as accident rates (Baum \& Dahlin, 2007) or market share (Greve, 2003), accelerator ventures compared themselves to multiple ventures on plural performance dimensions. In fact, some accelerators selected "pacers" along multiple dimensions to raise plural aspiration levels for participating ventures.

Moreover, rather than attempting to imitate firm-level strategies by observing others from a distance, which can lead to incomplete learning (Denrell, 2003), firms in accelerators observed the source of their peer's success, which showed ventures how to achieve similar success. Ventures within a cohort had frequent contact, so they observed "how" other firms achieve success, including failed strategies that they could then avoid. In some cases, ventures simply imitated successful peer strategies. Cohort peers also actively helped ventures close performance gaps. Why did cohort peers help each other despite being timepressured for their own venture's progress? It might be because venture founders became incredibly close with one another. A mentor from Alder explained,

It creates a bond, right? It's like fraternity brothers, maybe it's like military people in a company at war, because of the pressure and the intensity. I just think that there's a pride, there's an acknowledgement of having gone through that together. Definitely it concentrates itself on the people you went through with. But then there's the fraternity of others who have gone through the same program.

Ventures may also have helped to improve their own reputation. As one venture founder explained, "You become known for what you can do and help with." Regardless of the motivation, helping solidified ventures' own leaning. 
In sum, cohort peers accelerated learning in several ways. Ventures used cohort peers as aspriational reference groups. They upwardly adjusted aspiration levels and downwardly adjusted self-evaluation, which expanded performance gaps. Cohort peers also helped each other close performance gaps, both by knowledge spillovers and through active helping. 
Table 13: Cohort Peers

\begin{tabular}{|c|c|c|c|c|c|c|c|}
\hline & \multicolumn{4}{|r|}{ Rivalry } & \multicolumn{3}{|r|}{ Support } \\
\hline Accelerator & $\begin{array}{l}\text { Shared } \\
\text { space }\end{array}$ & $\begin{array}{l}\text { st }^{\text {st }} \\
\text { Pitch } \\
\text { cohort }\end{array}$ & $\begin{array}{l}\text { Work } \\
\text { harder }\end{array}$ & Representative quotes & $\begin{array}{l}\text { Give or } \\
\text { receive } \\
\text { help }\end{array}$ & $\begin{array}{l}\text { learn } \\
\text { cohort }\end{array}$ & Representative quotes \\
\hline Chestnut & $\begin{array}{l}\text { Yes, but } \\
\text { individual } \\
\text { offices }\end{array}$ & $1^{\text {st }}$ day & $100 \%$ & $\begin{array}{l}\text { Yes "You see all other people in a way really } \\
\text { hard and obviously puts some peer pressure on } \\
\text { you." } \\
\text { Yes "If you're surrounding yourself with } \\
\text { really smart people who are willing to put } \\
\text { down } 90 \text { or } 100 \text { hours a week to run your } \\
\text { company-it's not an exaggeration-then you } \\
\text { do it too." }\end{array}$ & $66 \%$ & 5.33 & $\begin{array}{l}\text { No "The blind leading the blind" } \\
\text { No "We were all working in these little silos ... you had to make } \\
\text { an effort to be social." } \\
\text { No "We were all competing with each other." } \\
\text { No "We weren't necessarily able to ask questions." [about other } \\
\text { teams pitches] }\end{array}$ \\
\hline Birch & $\begin{array}{l}\text { Yes, but } \\
\text { individual } \\
\text { offices }\end{array}$ & $1^{\text {st }}$ day & $100 \%$ & $\begin{array}{l}\text { Yes "You are here at midnight and you're not } \\
\text { by yourself." } \\
\text { Yes "It was somewhat of a competitive } \\
\text { dynamic." } \\
\text { Yes "Behind the scenes, kind of sizing each } \\
\text { other up" }\end{array}$ & $66 \%$ & 4 & $\begin{array}{l}\text { Yes "All the CTOs would meet once a week and have a CTO } \\
\text { roundtable where they could discuss various issues." } \\
\text { Yes "I was like, 'OK, how did you guys run this?' And then they } \\
\text { pulled up in their Facebook ad planner and showed me." } \\
\text { Yes "The peer group is where you could actually exchange best } \\
\text { practices in real-time." }\end{array}$ \\
\hline Oak & Yes & Never & $0 \%$ & $\begin{array}{l}\text { No "I don't know if it affected our pace so } \\
\text { much." } \\
\text { No "I guess it was kind of surprising how } \\
\text { helpful it was to actually have similar teams. } \\
\text { Like, coming into the program, I always felt } \\
\text { that all the different teams who were accepted } \\
\text { might feel a little bit competitive." }\end{array}$ & $67 \%$ & 3.67 & $\begin{array}{l}\text { No "I never saw everybody else's pitch." } \\
\text { No "I wish I had." [learnt something from my cohort] } \\
\text { No "People are supportive but because everyone else also has their } \\
\text { own business, they're not as concerned about supporting others." } \\
\text { Yes "Walk over to someone's desk and say 'hey can you take a } \\
\text { look at this' .. you need to take the initiative to foster it." }\end{array}$ \\
\hline Ash & Yes & 1 & Yes & $\begin{array}{l}\text { Yes "It helps you stay up a little later or try to } \\
\text { work a little smarter." } \\
\text { Yes "Comparing yourself the whole time" } \\
\text { Yes “"One of the other companies made a } \\
\text { sale!' and everyone is jumping up and down. } \\
\text { And then you go back to your office and you } \\
\text { are like damn I got to beat that." }\end{array}$ & Yes & 4 & $\begin{array}{l}\text { Yes "We saw each other make mistakes and we saw each other } \\
\text { succeed and so there was a lot of, 'How do you guys do that?"” }\end{array}$ \\
\hline Hickory & Yes & 1 & $80 \%$ & $\begin{array}{l}\text { Yes "Seeing someone else in the office would } \\
\text { definitely help me push me to stay." } \\
\text { Yes "Competitors for capital for us" } \\
\text { Yes "We saw things getting done really } \\
\text { quickly, and we had to do it as well." } \\
\text { Yes "There is pressure to move fast in like a } \\
\text { group environment." } \\
\text { Yes "Made us step it up you know some of the } \\
\text { companies were really amazing." }\end{array}$ & $100 \%$ & 5.4 & $\begin{array}{l}\text { Yes "You have nine other teams that may have been through it or at } \\
\text { least can give you impartial advice." } \\
\text { Yes "Having people here with all kinds of experience and } \\
\text { backgrounds... We have a room of } 40 \text { people; someone knows the } \\
\text { answer." } \\
\text { Yes "We saw how hard it was for them to break into that sector- } \\
\text { we are like we are not touching that with a ten foot pole." } \\
\text { Yes "Sal taught me a lot about how to raise money ... I learned a } \\
\text { lot about technology development from Jim." } \\
\text { Yes "People asked us a lot of questions, a lot of technology } \\
\text { questions." }\end{array}$ \\
\hline
\end{tabular}




\begin{tabular}{|c|c|c|c|c|c|c|c|}
\hline & \multicolumn{4}{|r|}{ Rivalry } & \multicolumn{3}{|r|}{ Support } \\
\hline Accelerator & $\begin{array}{l}\text { Shared } \\
\text { space }\end{array}$ & $\begin{array}{l}1^{\text {st }} \\
\text { Pitch } \\
\text { cohort }\end{array}$ & $\begin{array}{l}\text { Work } \\
\text { harder }\end{array}$ & Representative quotes & $\begin{array}{l}\text { Give or } \\
\text { receive } \\
\text { help }\end{array}$ & $\begin{array}{l}\text { learn } \\
\text { cohort }\end{array}$ & Representative quotes \\
\hline Pine & Yes & 1 & $33 \%$ & $\begin{array}{l}\text { Yes "When you see how hard other people are } \\
\text { working, a bunch of smart people in the room, } \\
\text { caused us to perform a lot-caused us to } \\
\text { perform at a higher level." } \\
\text { Yes "I mean that sense of competitive just in } \\
\text { terms of volume but it's not competitive in } \\
\text { terms of worrying about someone's going to } \\
\text { steal your customers." } \\
\text { Yes "Because there is a natural sense of what } \\
\text { are other people doing and, you know, } \\
\text { therefore, you what can you get done." }\end{array}$ & $100 \%$ & 5.67 & $\begin{array}{l}\text { Yes "Whenever I make a technology hire, I send them to A." } \\
\text { Yes "I'd do anything for those guys. I think they would also for } \\
\text { me." } \\
\text { Yes "So we tend to learn from other people what they do process- } \\
\text { wise." } \\
\text { Yes "You develop relationships with the people who are going } \\
\text { through all of the exact same problems you are. They can help you, } \\
\text { they can commiserate with you, and because everyone is doing } \\
\text { fundamentally different stuff, there is no competition or conflict." } \\
\text { Yes "I didn't realize how much companies would get from each } \\
\text { other-all of the different stages and how much value that brings- } \\
\text { some people are further along or have had different businesses } \\
\text { themselves. They really teach you a lot." }\end{array}$ \\
\hline Fir & Yes & 1 & $60 \%$ & $\begin{array}{l}\text { Yes "There was a huge competitive aspect." } \\
\text { Yes "Caused us to perform at a higher level" } \\
\text { Yes "It was hard to go slow with everybody } \\
\text { going fast." } \\
\text { Yes "Pressure that was mutually reinforcing", } \\
\text { No "The teams in the cohort were at radically } \\
\text { different stages of their companies." }\end{array}$ & $100 \%$ & 6 & $\begin{array}{l}\text { Yes "People we can tap into for different things .... got us } \\
\text { connected to the right people on the Android team." } \\
\text { Yes "This person sat down with me at a Chipotle one night in } \\
\text { October and we figured out how to do this." } \\
\text { Yes "We had } 40 \text { extremely smart individuals that we would bounce } \\
\text { ideas off of } 24 / 7 . " \\
\text { Yes "Consult them on a business or a market that they had more } \\
\text { expertise, mostly informally." }\end{array}$ \\
\hline Alder & Yes & $1^{\text {st }}$ day & $100 \%$ & $\begin{array}{l}\text { Yes "There's a lot of peer pressure that's } \\
\text { inherent with a program like this. You have a } \\
\text { lot of motivated people, a fixed timeframe and } \\
\text { a lot at stake." } \\
\text { Yes "You feel like everyone else is working } \\
\text { harder than you, even though you're working } \\
\text { around the clock." } \\
\text { Yes "It was a very good friendly competition." } \\
\text { Yes "If everyone else was pulling a late night, } \\
\text { you feel like, 'Oh, I want to pull a late night, } \\
\text { too."" }\end{array}$ & $100 \%$ & 5 & $\begin{array}{l}\text { Yes "We would all use each other's early versions of the software, } \\
\text { so you had the built-in feedback loop of } 50 \text { people in the same room } \\
\text { as you." } \\
\text { Yes "So certain teams make progress in certain areas faster than } \\
\text { others. For us, for example, it was fundraising." } \\
\text { Yes "You also saw that some companies that were really well- } \\
\text { prepared for Demo Day giving other teams help and advice and } \\
\text { even sitting down and working their pitch with them." } \\
\text { Yes "The vibe is "help everyone at all cost."” } \\
\text { Yes "If it's a technical problem, I can email three of the other } \\
\text { CTOs." }\end{array}$ \\
\hline Redwood & $\begin{array}{l}\text { No } \\
\text { "A lot of } \\
\text { the inter- } \\
\text { action } \\
\text { happened } \\
\text { on } \\
\text { Facebook. } \\
\text { " }\end{array}$ & Week 2 & $100 \%$ & $\begin{array}{l}\text { Yes "There was a certain amount of } \\
\text { competition, comparing yourself to your peers } \\
\text { and you certainly don't want to be in the last } \\
\text { company to launch." } \\
\text { Yes "Someone shows you a prototype at the } \\
\text { Redwood dinner on a Tuesday and then the } \\
\text { next week it's a working product and they've } \\
\text { already got } 500 \text { users. It doesn't get much } \\
\text { more motivational than that." } \\
\text { Yes "You want them to admire what you've } \\
\text { done." } \\
\text { Yes "You're just competing in like a tiny little } \\
\text { bubble that's been created for you." } \\
\text { Yes "It's a very positive sense of competition." }\end{array}$ & $80 \%$ & 5.0 & $\begin{array}{l}\text { Yes "All of a sudden you have a peer group of about } 100 \text { people } \\
\text { and they are all geniuses, no matter what problem I face there's } \\
\text { someone in that group who's faced it before and can help me with } \\
\text { some advice." } \\
\text { No "We didn't really consult other people in our cohort." } \\
\text { Yes "We have some weird bug with Internet Explorer } 7 \text { our batch } \\
\text { helped us out with it from our batch mates." } \\
\text { Yes "We got blocked on Facebook earlier on because we didn't } \\
\text { really understand some of the policies and we were able to get help } \\
\text { figuring out how we can get unblocked." } \\
\text { Yes "We saw presentations from other companies and we saw } \\
\text { things that we really liked from those." }\end{array}$ \\
\hline
\end{tabular}




\section{CHAPTER 5}

\section{DISCUSSION}

This study contributes to organizational theory, strategy, and entrepreneurship by suggesting how firms accelerate learning. Prior research establishes that firms learn at different rates (Argote \& Epple, 1990; Argote, 1999; Darr et al., 1995; Dutton \& Thomas, 1984; Lieberman, 1984; Pisano et al., 2001; Reagans et al., 2005), explores which learning modes might be faster (Eisenhardt \& Tabrizi, 1995; Pisano, 1994), and suggests how organizations might accelerate production-related learning (e.g, Darr et al., 1995; Ittner et al., 2001; Lapré \& Van Wassenhove, 2001). Nonetheless, prior work leaves unanswered questions about how to accelerate learning, especially learning unrelated to production and in nascent organizations. Leveraging a novel context — accelerators, which accelerate organizational learning during gestation - this study addresses this gap. The research setting is ventures participating in nine U.S. accelerator programs. Programs span the United States and vary in cohort size. Ventures are primarily technology firms and implementation is most often software development.

\subsection{Framework: Accelerated Learning}

A primary contribution of this research is the emergent framework for how to accelerate learning. First, firms partake in mentor overload, time-compressed engagement with external advisors who give conflicting feedback while implementation is delayed. Mentor overload accelerates learning by reducing learning-coordination costs, which enables ventures to temporally compress learning from numerous external advisors. Accelerators that 
arranged meetings and brought mentors to the ventures absorbed learning-coordination costs for the venture. Indeed, on average, when accelerators scheduled meetings for the ventures, ventures had 55 more mentor meetings than when the venture scheduled meetings for themselves. When learning-coordination costs are reduced, not only can ventures learn more quickly but they may also learn more completely (Stigler, 1961) because time not spent on coordination can be redirected toward learning. By the conclusion of mentor overload, ventures commit to a strategy (Porter, 1996) and avoid pivoting during implementation (Lynn et al., 1999). This contrasts with popular business rhetoric (Ries, 2011), which focuses entrepreneurial attention on pivoting rather than committing to strategies. The ventures at the top-performing accelerators in this study rarely made significant pivots after mentor overload. Instead, most refined existing business ideas by expanding or contracting scope. Jointly, mentors provide heterogeneous feedback, which accelerates learning "the business environment." Overall, mentors expand what ventures learn.

Second, director experts cumulate and then transfer expertise to ventures by predicting, synchronizing, and shaping learning. Prior research demonstrates the challenges of transferring knowledge (Von Hippel, 1994; Polanyi, 1966) to nascent firms that lack the organizational routines, foundational knowledge, and problem-solving experience required to absorb learning (Cohen \& Levinthal, 1990). Director experts do just that, though. How? First, director experts who have "seen it many times" project future outcomes for ventures. When projections are unsatisfactory, ventures change course. Thus director experts help firms "look forward" (Gavetti \& Levinthal, 2000) to temporally advance learning. Director experts also synchronize learning through templates that they develop based on their direct experience as entrepreneurs and indirect experience helping ventures in prior accelerator cohorts. The 
broadest template is the program structure itself. Programs are divided into sections and venture learning is prescribed for each period. Temporal structure maintains forward momentum as firms commit to learning from one stage prior to progressing to the next. Last, directors shape learning using frequent "intellectually honest" feedback that proxies for external stakeholder feedback. Director feedback is more accessible than feedback from external stakeholders, such as investors and customers. Much prior work proclaims the merits of positive feedback. However, director feedback is often negative. Directors' honest feedback might be less ambiguous and interpreted more quickly than feedback that is strictly positive. Further, positive feedback requires the assessor to wait to observe the desired behavior, which can be time-consuming, while honest feedback can be delivered anytime. Overall, director experts help ventures focus learning.

Ventures also accelerated learning by dividing teams. Prior work suggests that teams accelerate learning by working together as they cumulate expertise (Pisano et al., 2001). This study's data suggests that nascent teams learning novel knowledge accelerate by dividing experiences. Some teams began with team members working together. However, when strategy stabilized and team members developed shared cognition and trust in one another, they divided experiences. For example, technologists began developing products while business executives conducted customer interviews, developed customer acquisition strategies, and refined business models. Dividing experience rather than sharing it enables team-members to learn in parallel, which not only distributes learning across team members but also optimizes learning because team members focus on learning related to their area of expertise (Gibson \& Vermeulen, 2003). Each team member specializes their learning, which leads to functional diversity. Functional diversity decreases the assumption of shared 
experience, which stimulates conversation and crystallizes learning (Stasser \& Titus, 1987).

It also builds an internal communication cadence that enhances learning (Bingham \& Haleblian, 2012). In sum, dividing learning accelerates learning because team members specialize in their area of expertise, which develops diversity and fosters communication.

Finally, ventures accelerated learning by relating to cohort peers, peer ventures who are concurrently rivals and helpers. Although cohort peers are rarely direct competitors, they perceive themselves to be in competition for capital, director attention, and reputation. Rivalry among cohort peers motivates firms. Although prior work has established the importance of performance gaps relative to peers it has focused on industry peer groups and has examined performance along one dimension (Cyert \& March, 1963; Greve, 1998). This study suggests that ventures form aspirational peer groups with their cohort-peers, who compete in different industries. Ventures in cohorts adjust their aspirations in three ways that accelerate learning: (1) Ventures downwardly adjust their self- performance assessment by calibrating against cohort peers. Like other entrepreneurs (Hayward, Shepherd, \& Griffin, 2006), ventures frequently begin the program with hubris; after all, they were recently selected to participate in the accelerator. Calibrating against cohort peers attenuates hubris. (2) When ventures see the extreme performance of cohort peers they raise their aspiration levels. (3) Rather than creating aspirations along a single performance dimension, ventures in accelerators create plural aspirations, affiliated with plural cohort peers.

Given the high level of rivalry among firms, prior work suggests that knowledge flow between ventures should be limited (Messick \& Mackie, 1989), but cohort peers routinely helped lagging cohort members close performance gaps. Accelerator routines that "expose progress," including weekly public updates, reduce learning-coordination costs between 
ventures and thus increase spillovers between firms. Cohort peers also actively help their peers. In some cases, ventures test products for each other, closing feedback loops. In other cases, ventures explicitly share learning. As a venture founder at Birch explained, "The peer group is where you could actually exchange best practices in real-time." Cohort peers accelerate learning by instilling rivalry, facilitating for imitation, and actively helping one another.

\subsection{Organization Theory}

This study's primary contribution is to organizational theory. Accelerators accelerate learning by minimizing learning-coordination costs associated with learning. Although minimizing coordination costs is central to accelerators, it has been largely ignored by extant literature. For example, learning curve studies typically begin, at earliest, with the first unit of production (e.g., Argote \& Epple, 1990; Argote, 1996, 1996; Benkard, 2000; Pisano et al., 2001; Rapping, 1965). They omit learning and related learning coordination that occurs prior to producing the first unit. These antecedents to learning might include scheduling meetings, determining factory floor plans, building relationships to solicit feedback, and locating close enough to absorb spillovers. Similarly, studies that examine learning during internationalization (Bingham et al., 2007; Bingham \& Eisenhardt, 2011; Vermeulen \& Barkema, 2002) begin with the first entry, assume country entries are readily available to provide learning, and omit coordination costs, which might include deciding which countries to enter, learning about local customs, selecting partners, or even travel prior to entry. Studies on alliances likewise begin with an alliance formation (e. g., Hamel, 1991; Khanna et al., 1998; Ozcan \& Eisenhardt, 2009) and then assess learning without regard to the costs 
associated with setting up alliances, including learning associated with deciding whether or not to enter an alliance at all.

Accelerators reduce learning-coordination costs in several ways. Mentor interactions are set up by the accelerator, which reduces the amount of time the venture needs to spend on networking to meet potential advisors, scheduling meetings, and traveling to and from meetings. As a director at Birch said, "We have those people come to you as opposed to you going to them. So just travel time across the city is, is a meaningful acceleration." Directors also reduce learning-coordination costs by providing proxy feedback for investors or customers. Proxy feedback is faster than learning from direct experience. They also answer a wide array of questions or quickly "route" ventures to experts who can answer questions. The director at Alder even calls herself a "massive router."

Cohort peers also reduce learning costs. Unlike spillovers, which inadvertently leak to other ventures via inventor mobility or geographic proximity (Agarwal, Ganco, \& Ziedonis, 2009; Almeida \& Kogut, 1999; Jaffe, Trajtenberg, \& Fogarty, 2000; Jaffe, Trajtenberg, \& Henderson, 1993), accelerators encourage spillovers. Frequent interaction and public updates announce learning, which can then imitated by cohort peers. Problems are efficiently broadcast to a large group of ventures working on similar problems. Ventures quickly identify solutions that have worked for cohort peer ventures. Overall, accelerators "reduce friction" related to learning and "have all the resources come to them as opposed to knocking on every door possible."

I also contribute to organization theory by extending work on learning from others (e.g., Baum et al., 2000; Bingham \& Haleblian, 2012; Haunschild \& Miner, 1997). Prior work has focused on the firm that is doing the learning. I find that the sources of learning are 
also important. Ventures in accelerators begin by learning from a diverse group of mentors who provide heterogeneous feedback while implementation is delayed. They also learn from experienced director experts who transfer cumulated experience to the ventures to jump-start learning. Additionally, they learn from cohort peers whose distributed experience helps solve tactical problems. Juxtaposing learning from mentors, directors, and cohort peers, a framework of learning from others emerges (see Table 14). When conducting lower-order learning (Fiol \& Lyles, 1985), including learning a business landscape, learning from a large and diverse group with some relevant experience is preferred. This group does not need to have true experts. However, to conduct higher-order learning (Fiol \& Lyles, 1985), such as how to start a business, interacting with a single or small group of extreme experts is preferred. Extreme experts cumulate thousands of hours of purposeful experience and then transfer learning to nascent ventures. Finally, when solving problems for which there is a known solution, such as technical problems, broadcasting the problem to a large group of peers and dividing team experience expedites learning.

Table 14: Learning from Others' Experience

\begin{tabular}{c|cc} 
& External Advisors & Peers \\
\hline Distributed expertise & Mentors & Cohorts \\
& Expand options & Simultaneous options \\
Concentrated expertise & Advisors & Divided teams \\
& Narrow options & Commit to options
\end{tabular}

This study further contributes to organization theory by expanding the social learning and aspiration literatures (Cyert \& March, 1963; Greve, 2003). First, it introduces cohort peers to the literature. Although prior work suggests that organizations compare themselves to industry peers (Zuckerman \& Sgourev, 2006; Kim \& Miner, 2007), this study suggests 
they also compare themselves to cohort peers. Moreover, this study draws a more nuanced picture of aspirations, expanding the emerging but scarce literature that suggests that firms form multiple apparitional goals (Hu, 2012). Firms learn from cohort peers both by passive observation and by active knowledge exchange. This knowledge transfer efficiently closes performance gaps.

Figure 1: Framework for Accelerated Learning

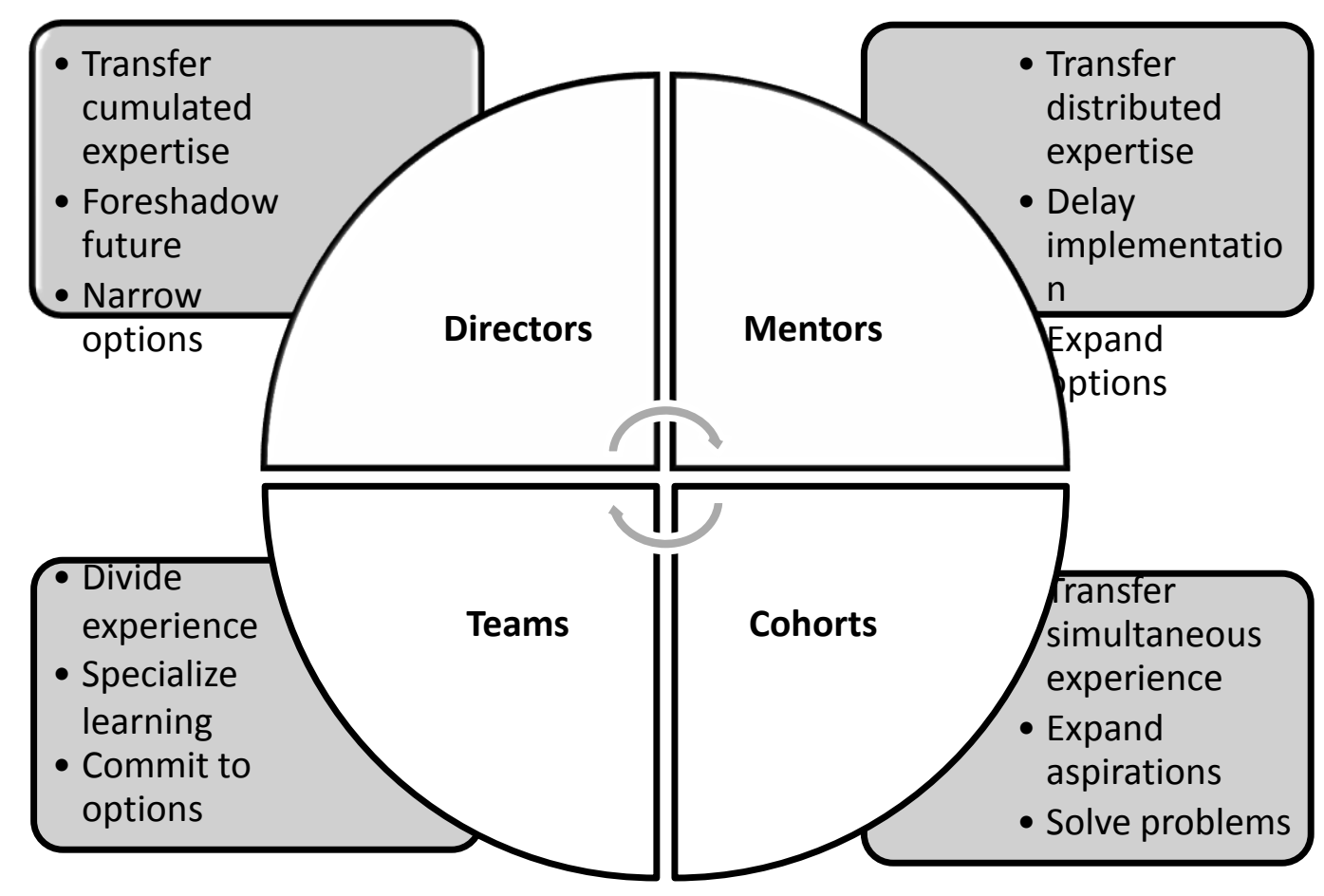

\subsection{Strategy}

This study also contributes to strategic management. Although learning theorists purport that learning is diminished when it is temporally compressed (Dierickx \& Cool, 1989; Levinthal \& March, 1981), this study finds the opposite: Learning is enhanced when it 
is temporally compressed. Temporally compressing learning reduces small-sample biases (Levinthal \& March, 1993). Moreover, ventures that collect substantial amounts of feedback are more likely to learn a broader range of the distribution of feedback. Not only will they be able to identify the mean feedback but they will also know the variance of feedback. Perhaps more important in an entrepreneurial context, increasing feedback also increases the probability of identifying outlying feedback, which may lead to extreme performance.

This study also contributes to strategy by suggesting that firms delay learning-bydoing rather than beginning with learning-by-doing, as prior work prescribes (Eisenhardt \& Tabrizi, 1995; Pisano, 1994). Ventures engaging in mentor overload decelerate learning-bydoing because ventures' time and attention (Ocasio, 1997) is consumed with mentor meetings. One reason for this discrepancy might be that prior research is left truncated (Argote, 1999; Yang \& Aldrich, 2012), thus may fail to observe delayed implementation that happens prior to the study period. Rather than trying alternatives sequentially (Van de Ven \& Polley, 1992), firms that delay and temporally compress learning decide between a group of alternatives, which reduces the negative effects of escalation of commitment to failing strategies (Staw, 1981) and experience bias (Levinthal \& March, 1993). Venture founders receive copious feedback prior to implementation and are able to make foundational strategic decisions (Stinchcombe, 1965) based on more knowledge than they would if learning was not temporally compressed. Moreover, firms that hear similar messages in a short period of time are more likely to act on those messages than firms that hear similar feedback over a longer period of time because firms are more likely to forget over time (Argote, 1999). Thus, compressing learning avoids forgetting and amplifies learning. 
Evidence of time-compression economies is important because prior literature suggests that time-compression diseconomies provide sustainable advantages to firms with more knowledge - competitors cannot compress learning to "catch up" to knowledge leaders (Dierickx \& Cool, 1989; March, 1991). If there are also time-compression economies to learning, then knowledge stocks might provide long-term advantages only to those firms that continue to learn faster than their competitors.

\subsection{Entrepreneurship}

This study makes several contributions to the entrepreneurship literature. It contributes to the understanding the origins of absorptive capacity in nascent ventures. Research shows that those firms with higher internal R\&D capacities developed through direct experience (Zahra \& George, 2002), are able to retain more external knowledge (Cohen \& Levinthal, 1989, 1990). The premise of this research is that firms need basic technical understanding before they can absorb more complex technical information garnered from external sources such as alliance partners. This study suggests that absorptive capacity may begin by reducing unknown unknowns to unknowns that can then be solved. An organization might accelerate its initial accumulation of absorptive capacity by following templates that structure learning. Prior work on templates highlights the role they play in intra-firm transfer, including between franchisers and franchisees (Winter et al., 2012). This study shows that templates can also transfer across firm boundaries from experts to nascent firms. Templates might seed absorptive capacity by providing initial foundation and structure, which accelerates learning in nascent organizations.

I also contribute to the discussion on lean startups. Discourse on entrepreneurship has focused on how firms pivot, or change during gestation (Ries, 2011). However, my data 
suggest that pivoting might not be as important as this discourse seems to suggest. I found evidence that ventures accelerate learning by stabilizing strategy prior to implementation rather than pivoting strategy during implementation. Entrepreneurs may want to shift their attention away from pivoting toward making strategic commitments.

This study also extends prior work on learning by entrepreneurial teams (Bingham \& Davis, 2012), which suggests that entrepreneurial ventures begin learning by observing others. More specifically, this study extends prior work by suggesting not only that nascent ventures begin by learning vicariously but also that they begin by learning vicariously from a large group of heterogeneous external advisors. The large size and diversity of the group enhances vicarious learning. Ventures also learn from smaller groups of experts who transfer templates, refine learning, and forecast future outcomes. The concentration of expertise is particularly important and related to what is learned. Distributed expertise enables heterogeneous lower-level learning while concentrated expertise enables homogeneous higher-level learning.

This study also contributes to our understanding of what accelerators are and what they do. More broadly, this study contributes to the literature on incubators (Barbero, Casillas, Ramos, \& Guitar, 2012; Bruneel, Ratinho, Clarysse, \& Groen, 2012; Rothaermel \& Thursby, 2005a, 2005b; Smilor, 1987) and angel investors (Hochberg et al., 2007; Hochberg, Ljungqvist, \& Lu, 2010; Hsu, 2007) by explaining the differences between the three forms. The defining feature of accelerators is their limited duration, which creates cohorts of ventures who start and end programs together. Moreover, accelerators expand social interactions for entrepreneurs, enhancing opportunities to learn vicariously. 
Finally, the findings in this study might help explain serial entrepreneurs' superior performance (Hsu, 2007). Prior work finds that serial entrepreneurs benefit from superior networking and social capital. This study might explain how entrepreneurial firms with serial founders learn faster. Like director experts, serial entrepreneurs may be better at predicting future outcomes, which triggers search when outcomes are below aspirations, creating templates to focus initial learning and using temporal structure to maintain forward momentum. 


\section{CHAPTER 6}

\section{CONCLUSION}

Conceptually, there are two types of learning: learning what to produce and learning how to produce it efficiently (Argote, 1999), yet prior work on how to accelerate learning focuses narrowly on how to accelerate learning related to production efficiency (Adler \& Clark, 1991; Argote \& Epple, 1990; Benkard, 2000; Ittner et al., 2001; Levin, 2000), leaving many unanswered questions about how to accelerate learning. The purpose of this study is to suggest how firms accelerate learning. Using an inductive, multiple-case methodology, I explored how nascent firms participating in nine U.S. accelerator programs accelerated learning.

The theoretical framework for accelerated learning that emerged from the data suggests that learning was accelerated through four constructs: (1) mentor overload - time compressed interactions with external advisors that delays implementation; (2) director experts who develop and transfer expertise nascent ventures; (3) divided teams-founding team members who split up rather than band together during experience accumulation; and (4) cohort peers - peer ventures who are concurrently both rivals and supporters.

This dissertation makes several important contributions. First, it highlights the importance of learning-coordination costs, which occur prior to learning engagements. Prior work has largely neglected the period prior to learning interactions. Attention to what happens prior to learning interactions brings to light the importance of learning-coordination costs. Minimizing learning-coordination costs enables learning to be accelerated and 
temporally compressed. Interestingly, contrary to theoretical predictions that warn against time-compressed learning (Dierickx \& Cool, 1989; Levitt \& March, 1988), this study’s data suggest that time compression enhances learning. Under time pressure, ventures compared strategies simultaneously rather than sequentially, which reduced experience biases. Time compression also enabled ventures to learn more, which reduced small-sample biases.

Second, unlike prior work that suggests that firms begin with "doing" (Eisenhardt \& Tabrizi, 1995; Pisano, 1994), data from this study suggest that firms delay "doing" until strategy emerges and begins to stabilize. Also, although prior work suggests that teams stick together as they cumulate experience (Pisano et al., 2001), venture teams in this study divided when they learned by “doing." Dividing experience enabled teams to accelerate learning by spreading learning across the team. Each member created specialized knowledge in their area of expertise and learned in parallel. Dividing also reduced the assumption of shared knowledge (Stasser \& Titus, 1987), which enhanced team communication. One reason for the contradiction with prior work might be differences in joint team tenure. Prior studies examine well-established teams in incumbent firms (Eisenhardt \& Tabrizi, 1995; Pisano, 1994), whereas this study examines nascent teams. Established teams may have divided earlier in their tenure and may already have developed specialized knowledge (Levinthal \& March, 1993), thus they might benefit more from coming together while nascent teams might benefit more from specialization enabled through division. More research is needed to understand how and when teams should learn together and when they should divide.

Third, this study extends work on social learning (Cyert \& March, 1963; Greve, 1998). Prior work has found that firms form social reference groups with peer firms in the same industry (Zuckerman \& Sgourev, 2006). This study suggests that organizations need 
not be in the same industry to form reference groups. Ventures in the same cohort formed aspirational peer groups, even if they were in different industries. Moreover, rather than single goals, ventures created portfolios of aspirations. This study also extends work on transactional memory systems. Prior work on describes transactive memory systems within firm boundaries (Argote \& Ren, 2012; Wegner, 1987). Ventures in this study extended capabilities and knowledge beyond firm boundaries to the broader cohort. Many ventures interviewed employees for each other. Others relied on each other's specific knowledge. For example, a founder at Fir recalled consulting cohort peers, "On a business or a market that they had more expertise."

Fourth, this dissertation also expands our understanding of vicarious learning and the foundations of absorptive capacity. This study suggests that the concentration of expertise among focal firms matters. In particular, distributed expertise accelerates lower-order learning while concentrated expertise accelerates higher-order learning. In particular, directors who cumulated expertise on organizational gestation period were able to transfer knowledge to nascent ventures despite the presumably low absorptive capacity of those ventures. At accelerators, where the directors had less cumulated expertise, the ventures learned more slowly. This study extends prior work that explains the attributes of experts to suggest that experts can transfer learning to other organizations-even nascent firms. Directors seeded venture learning and absorptive capacity using templates that directed learning. Templates communicated what, when, and how to learn.

Accelerators are quickly proliferating across the globe. This study might have implications for accelerators as well as the ventures that participate in them. This study explains what accelerators do and compares the relative effectiveness of program 
components. It also draws comparisons to incubators and angel investors. Unlike incubator programs, accelerators are limited in duration and cohorts of firms enter, progress, and exit together. Unlike angel investors, accelerators invest in cohorts of firms, which might be a better way to invest in early-stage ventures. More research is needed to determine the effectiveness of accelerators as an investment vehicle.

Nevertheless, like others, this study has limitations. Data collection relied on retrospective information and assessment provided by informants. Ideally, future work might ethnographically observe firms as they participate in an accelerator program. However, this study takes a first step in addressing how firms accelerate learning. It is also part of a broader stream of research on accelerated learning that deductively examines the framework proposed herein. The ventures in this study are primarily technology ventures with short development times. Future work is required to test the boundary conditions. For example, what adjustments, if any, might firms with longer development times require?

This study may also have implications for managers in both entrepreneurial and established firms who want to accelerate learning. For example, new product development managers may consider how to mimic mentor overload in a corporate setting. Customers and suppliers might serve as mentors for one another, or managers from different divisions of a multi-division firm might serve as mentors. Moreover, larger firms might consider how to achieve the benefits of cohort peer relationships amongst internal or external new product development teams. One idea might be having teams apply to an internal accelerator program, with start and graduation dates. Or, firms might form accelerators with related, noncompetitive firms. 
Additionally, this study contributes to the field of education. First, it suggests that temporally compressed educational programs, such as one-year MBA programs, may want to consider structuring the program in temporal sequences that synchronize learning across cohorts. Moreover, this study suggests that routines that expose progress among student cohorts may enhance learning. For example, asking student teams to publically update the rest of the class on the progress of final projects might accelerate learning for all teams.

More specifically, this study is relevant to entrepreneurship educators in universities, incubators, and other institutions. Prior work has asked the question, "Can entrepreneurship be taught?" Perhaps a better question is, "How can entrepreneurship be taught?" This study suggests that the format of entrepreneurship education is particularly important. Highly engaged, hands-on development of student businesses that follows a template and leverages cohort peers might be an effective means to teach entrepreneurship. Although collocation was neither necessary nor required to develop productive cohort peer relationships, regular updates that expose progress are essential. Entrepreneurship education might benefit from lab sessions where student teams take significant time to update classmates and help each other. 


\section{APPENDECES}

\section{APPENDIX 1-ACCELERATOR DIRECTOR INTERVIEW GUIDE}

Date:

Researcher 1:

Researcher 2:
Respondent:

Title:

Company:

\section{INTRODUCTION (5 Minutes)}

A. Provide background of researcher

B. Identify the purpose of the research: To understand how accelerators work with young firms, and understand what makes some accelerators more effective than others.

C. Describe research involvement:

- Interview (60-90 minutes)

- Follow-up emails or phone conversations (if needed)

- Applicable internal reports or documents

D. Discuss information privacy: All information will remain confidential. Information gained from respondents at one interview will not be shared with respondents at another. Further, in the write-up, all corporate and individual names will be changed to mask identities.

E. Ask permission to begin recording the interview and have informant sign consent form agreeing to participate in the study.

- I'd like to record our conversation so I don't have to take notes and so I can come back to accurately recall our conversation in the future.

F. Outline the flow of the interview. The interview uses both open- and closed-ended questions.

- In the first section, I will ask you short-answer questions about your background and your accelerator's history

- In the second section, I will ask you to describe the accelerator program. The questions are mainly open-ended and will take up the majority of the interview.

- In the final section, I will ask you a few short answer questions

Depending on your level of involvement with the accelerator, you may not be able to answer every question - this is fine. 


\section{SECTION ONE - OVERVIEW (5 Minutes)}

I'd like to start by asking you a few questions about your background and your accelerator's background.

1.1 Can you briefly tell me the history of your accelerator? (When/why founded (goals), changes along the way)

1.2 Can you briefly tell me about your background? Why did you start the accelerator?

1.3 How is your accelerator different from Venture Capital or seed fund?

1.4 How do you measure success?

SECTION TWO-ACCELERATION PROGRAM (45 Minutes)

\section{PROGRAM}

2 Can you describe your program from application to Demo Day?

- Can you elaborate on what happens for the each part of the program? (each month or phase)

- Has your program always worked like this? Why/why not? What is the rational for running your program this way? What has changed?

- Is there anything about how your program works that surprised you? What?

2.2 Can you tell me more about the common educational piece of the program? That is, educational opportunities for the whole cohort. (if needed ... dinners, lectures, manuals, etc.) Why do you include them when you do?

2.3 How do you think the length of the program affects what firms get out of the program? Why? Can you provide an example?

2.4 Compared to firms you have been involved with outside of the accelerator, what get's "accelerated" for firms in the accelerator? Does anything go slower?

2.5 Founders have limited time, no doubt, what should they focus on first? Why?

2.6 In general, how committed are venture founders to their idea when they start? 
- Do you try getting them to consider alternative ideas?

- How does that usually happen?

- In your experience, what's the most common reason firms decide to pivot? Why do some fail to pivot?

\section{COHORT}

2.7 Can you tell me about having firms enter and exit in cohorts?

a. How do firms interact with their cohort?

b. How do they benefit from their cohort?

c. How else does the cohort affect ventures?

d. Why did you decide to have \# firms in a cohort?

e. What advice might you give to firms about the "cohort" effect?

f. Did you observe anything interesting or unexpected about firms when they are part of a cohort?

\section{VENTURES}

2.8 Tell me more about venture teams.

a. How do you assess teams?

b. Do you think team dynamics change - for better or for worse - during the program? Why?

c. When do team dynamics delay a firm?

d. When do they help speed-up a firm?

e. In your experience, what do the venture founders think they will get out of your program - that is, at a high-level, what are their expectations?

f. How accurate do you think firms are at self-evaluating the potential of their idea? How does their self-evaluation change during the program? How does that change during the program? (Note time markers of changes)

g. Is there an ideal stage of company? What are the pros/cons of being very early stage? How about being further along?

h. In general, how committed are venture founders to their idea when they start?

- Do you try get them to consider alternative ideas?

- How does that usually happen?)

i. Anything surprise you about how teams perform?

2.9 What commitments do firms make during the program? (e.g. Do firms typically hire people during the program? Buy equipment? Plan for after the program (like sign a lease)?

\section{MENTORS}

2.10 Let's talk about mentors for a few minutes.

2.10.1 What do you look for when selecting mentors? 
2.10.2 How many mentors does each venture have? Why?

2.10.3 How do interactions between founders and mentors happen; are they scheduled regularly or ad-hoc?

2.10.4 Are there particular combinations of mentors that seem to work best? (e.g. venture capitalist and entrepreneur, mentors that have worked together in the past)

2.10.5 What, if any guidance do you give to mentors? When do you give that advice? Do you give any other advice?

2.10.6 Is there anything about the mentorship part of your program that surprised you?

2.11 Tell me more about your personal involvement, along that of your co-founders and DMs. Can you provide a few examples of how you help firms? What are the most common types of problems you see, and how do you solve them? How do firms meet with you - do you schedule in advance, hold open office hours?

2.12 How do firms incorporate customer feedback? Is this different for accelerated firms than non accelerated firms? Anything surprise you about how firms have incorporated customer feedback?

2.13 If convertible note: What, if anything, changed for firms when you started providing a convertible note? (Amount of note:

\section{SECTION THREE - Overall Questions}

3.1 Overall, what do you hope firms learn by participating in the accelerator? When does this happen? What prevents it from happening?

3.2 Think of a successful and less successful firm, how did they differ with regards to what they get out of the program?

- Was the timing of when they honed in on their business model and product different?

- Timing of first sale?

- Did either pivot? When?

- Describe both CEOs in a few words?

3.3 Choose a successful firm that participated in your program. How did their product or service change during the program? Describe their CEO in $3-5$ words. Who were there mentors? How did the team work together?

3.4 IF TECHSTARS: What does the TechStar Network provide to you? 
3.5 What is the source of your investment funds - the money that you use to invest in ventures and for operations?

3.6 Overall, do you think your accelerator selects good firms, or builds good firms? Can you back that up with any evidence?

3.7 Is there anything else that you would like to tell me?

3.8 In order to get a rough idea of your accelerator's history, can you tell me about your previous cohorts?? (entry interview only)

\begin{tabular}{|c|c|c|c|c|c|}
\hline \multirow[b]{2}{*}{ Year } & \multirow[b]{2}{*}{ Number of firms } & \multirow{2}{*}{$\begin{array}{l}\text { Number } \\
\text { Funded }\end{array}$} & \multicolumn{2}{|c|}{$\begin{array}{l}\text { Number of positive } \\
\text { exits }\end{array}$} & \multirow{2}{*}{$\begin{array}{c}\text { Number } \\
\text { Disbanded or } \\
\text { comatose }\end{array}$} \\
\hline & & & Acquisition & IPO & \\
\hline & & & & & \\
\hline & & & & & \\
\hline & & & & & \\
\hline & & & & & \\
\hline
\end{tabular}

I would like to speak to a few firms that participated in your program. Our conversation should last $45-60$ minutes.

- Can you introduce me to 3 firms that participated in your last cohort that learned a lot from the program?

- Can you introduce me to 3 firms that participated in your last cohort that learned only a little from the program?

Can you introduce me to a few mentors that worked with these firms?

Thank you. 


\section{APPENDIX 2-VENTURE FOUNDER INTERVIEW GUIDE}

\section{INTERVIEW GUIDE}

Date:

Researcher 1:

Researcher 2:
Respondent:

Title:

Company:

\section{INTRODUCTION (5 Minutes)}

A. Provide background of researcher

B. Identify the purpose of the research: To understand how accelerators work with young firms.

C. Describe research involvement:

- Interview (45-60 minutes)

- Follow-up emails or phone conversations (if needed)

- Applicable internal reports or documents

D. Discuss information privacy: All information will remain confidential. Information gained from respondents at one interview will not be shared with respondents at another. Further, in the write-up, all corporate and individual names will be changed to mask identities.

E. Ask permission to begin recording the interview and have informant sign Human Subject's consent form agreeing to participate in the study.

F. Outline the flow of the interview. The interview has three sections and uses both open and closed-ended questions.

- In the first section, I will ask you short-answer questions about your background and your firm's history

- In the second section, I will ask you to describe the accelerator program. The questions are mainly open-ended and will take up the majority of the interview.

- In the final section, I will ask you a few short answer questions

- On some questions I will ask you to be brief, while on others I will ask you to be detailed.

Depending on your level of involvement with the accelerator, you may not be able to answer every question - this is fine. 


\section{SECTION ONE - OVERVIEW (5 Minutes)}

1 I'd like to start by asking you a few questions about the background of your company and its founders. Please answer briefly as this section should take 5 minutes.

Please state your name, the name of your business and your cofounder's names.

A. What is your title/role?

You

Founder 2

Founder 3

B. Gender

C. Age

D. Highest educational level/area

E. Functional expertise

F. Have you ever started a company before?

If so, how was it financed?

What was your role?

Did it exit? How? (acquired, failed, still going)

G. Did you move to STATE for the program?

H. If yc:

I. If not $\mathrm{YC}$

i. Where did you work during the program?

i. Did you work at the accelerator's space?

ii. For how long?

1.1 Why did you apply to an accelerator? Why did you choose this one?

1.2 Did you consider going directly to an angel or VC? How about an incubator? Why didn't you?

1.3 Think back to when you started the program. On a scale of $1-7$, where 7 is the most developed, where did you think your business was at the beginning of the accelerator program? Knowing what you know now, where do you think it was at the beginning of the program? Where do you think it was at the end of the program?

\section{SECTION TWO_ACCELERATION PROGRAM (45 Minutes)}

2 Let's slow down now. Tell me about ACCELERATOR program, starting with the application process. Tell me about each part of the program and then tell me how that experience impacted your firm at that time. Some parts may not have had any impact, and that's fine.

\section{Note:}

Accelerator process: when/duration

How did that impact your firm? 
2.1 Tell me about the application process. Did you interview in person/Skype? With whom and for about how long?

2.2 Did anything during the application process affect your firm's strategy or progress?

2.3 What stage was your product at the time you applied? (idea, prototype, Beta, live, revenue)

2.4 Did anything change for your company during the time in-between being accepted and starting the program? What?

2.5 What happened on the first day of the program?

- What happened during the first week? (what else)

- The first month?

- The second month?

- The last month?

2.6 If not YC: Tell me the story about how you meet your mentors? (Mentor Matching process/assignment) How many meetings did you have with potential mentors?

2.7 If YC: Which YC partners did you work with? When? How often? Did anyone else give you feedback on your product or business? Who? How many people?

2.8 When did you get customer feedback? How?

2.9 Tell me about the evolution of your business - from when you first decided to start a business through the end of the accelerator program. (Note time markers)

iii. When did you first conceive your business idea? (month/year)

iv. When did you decide to apply to the accelerator? (month/year)

v. When did you make your first sale? (month/year)

2.10 When did you first start preparing for Demo Day? Lead me through your preparations, the actual day, and the following days or weeks.

2.11 Think back to the accelerator program, were there any other milestones, or themes during the program that we have not discussed?

2.12 When do you think your firm made the most progress? Why?

2.13 When do you think your firm learned the most? Why?

2.14 Tell me about your firm's progress after the accelerator. I want to hear about challenges as well as highlights - tell me both the good and the bad

2.15 Explain how your relationship with your cofounder(s) changed or developed during the program.

2.1 About how many seminars did you attend? From which seminars did you learn the most? What did you learn? Which did you learn the least?

2.2 How do you think the program's length affected what you got out of the program? Why?

2.3 Did the fact that the program is three months affect the strategies you choose? How?

\section{COHORT}

2.4 The next set of questions asks about your experience being part of a cohort.

A. How did you interact with your cohort? 
B. Do you think being part of a cohort affected your firm's development? How?

C. Can you give me an example of something you learned from your cohort?

D. How do you think being part of a cohort affected your pace?

E. Did being a part of a cohort influence your performance in any other way?

F. Anything else you think is important to know about being a part of a cohort?

\section{MENTORS \& ACCELERATOR FOUNDERS}

Get NUMBER of meetings, amount of forced meetings, degree of conflicting advice/confusion

2.5 Now, I'm going to ask you about your mentors. (Or founders advisors if YC)

A. How many mentors/other advisors did you have? What were there backgrounds? How did you meet with them?

B. How did your mentors or accelerator founders help you in each phase of the program?

C. Did their advice ever conflict with each other or with what you thought was best for your firm? How often? When? Tell me more about these conflicts, and how you resolved them.

D. What, if anything did you learn from your mentors or accelerator founders?

E. Did a mentor ever make an introduction for you? Tell me about the first introduction; Who made it? How did your conversation go? Did anything result from it? Was there a more fruitful introduction? Tell me the story about that introduction (Who made it, whom was it to, how did it go, what was the result).

TEAM

2.6 (Speaking to founders/CEO). Describe your leadership style in $3-5$ words. Describe each of your cofounders in $3-5$ words.

OR

(If speaking to other team member). Describe your CEO's leadership style in $3-5$ words. Describe yours in $3-5$ words.

2.7 Some teams like to solve problems together, while others tend more to divide and conquer. How does your team solve problems?

2.8 Some firms think about shutting down, but others don't. Did you ever think about it? If so, why didn't you? 
SECTION THREE-Wrap-up/overall (15 Minutes)

3 I would now like to wrap up with some overall questions.

3.1 Startups use a variety of metrics to monitor their progress. What metrics do you routinely monitor? How did you decide on those? Wait for result, and then ask for historical performance against those metrics.

3.2 In order to get a rough idea of your history, what have been your firm's quarterly burn rate, revenues, employee count and closed funding since inception? It's okay if the answer is 0 . When did you hire your first employee? Annual count, including cofounders, after that? When did you make your first sale? (month/year) annual after that. When did you raise your first round - friends and family included? Annual after that.

\begin{tabular}{|l|l|l|l|l|}
\hline Quarter/Year & Burn (\$) & Sales (\$) & Employee count & Funding (\$) \\
\hline & & & & \\
\hline & & & & \\
\hline & & & & \\
\hline & & & & \\
\hline
\end{tabular}

3.3 I'd like to ask you about your firms' innovation, for the product that you were working on during the accelerator program ... For each statement tell me if you agree if disagree -

The product that you launched during ACCEL was ... $\quad$ Yes/no

Far ahead of your original time goals

Slower than the industry norm

Much faster than you expected

Faster than the rest of your cohort's development time

At the end of the accelerator program, your opportunity

Much bigger than you expected?

Much more radical idea than most start-ups in the industry

Much smaller idea than you originally expected

Much bigger opportunity than the rest of your cohort's

At the end of the accelerator program, the quality of your product ...

Exceeded your original goals

Exceeded the quality of other startups in the industry

Was much better than you expected it to be

Was better than the rest of your cohort's product quality 
3.4 On a scale of $1-7$, where $1=$ far short of expectations, $4=$ as expected; $7=$ far exceeded expectations

Seven point Likert Ranging from

far short of as far exceeded

expectations expected expectations

A. During the time you were in the accelerator ...

1234567

B. The progress your firm made ...

C. The amount your firm learned from Mentor...

D. The amount your firm learned from the accelerator founders...

E. The amount your firm learned from the accelerator's educational seminars...

F. The amount your firm learned from your cohort...

G. The amount your firm learned from customers ...

H. The amount your firm learned about starting a business that you could use to start another business...

I. The amount your firm learned about this firm's business model...

J. The amount your firm learned about this firm's technology...

K. Overall, the amount your firm learned from the accelerator...

L. The number of contacts made to your firm by your mentors ...

M. The number of contacts made to your firm by the accelerator founders...

N. The number of contacts made to your firm by your cohort...

O. Overall, the number of contacts that your firm made ...

P. Overall the quality of the contacts made ...

Q. Overall, the results from introductions made during the program

3.5 In your own words, what did your firm learn by participating in the accelerator?

3.6 What would have happened to your venture if you were not accepted? Why?

3.7 To wrap up our conversation about the accelerator program, what advice would you give to firms considering applying to one?

3.8 Can you please give me your elevator pitch?

3.9 What did you find most surprising?

3.10 Anything you would change?

THANK YOU! 


\section{APPENDIX 3-MENTOR INTERVIEW GUIDE}

\section{INTERVIEW GUIDE}

Date:

Researcher 1:

Researcher 2:

\section{Respondent:}

Title:

Company:

\section{INTRODUCTION (5 Minutes)}

A. Provide background of researcher

B. Identify the purpose of the research: To understand how accelerators work with young firms.

C. Describe research involvement:

- Interview (60 minutes)

- Follow-up emails or phone conversations (if needed)

- Applicable internal reports or documents

D. Discuss information privacy: All information will remain confidential. Information gained from respondents at one interview will not be shared with respondents at another. Further, in the write-up, all corporate and individual names will be changed to mask identities.

E. Ask permission to begin recording the interview and have informant sign Human Subject's consent form agreeing to participate in the study.

F. Outline the flow of the interview. The interview has three sections and uses both open and closed-ended questions.

- In the first section, I will ask you short-answer questions about your experience.

- In the second section, I will ask you to describe the accelerator program. The questions are mainly open-ended and will take up the majority of the interview.

- In the final section, I will ask you a few short answer questions.

Depending on your level of involvement with the accelerator, you may not be able to answer every question - this is fine. 


\section{SECTION ONE - OVERVIEW (10 Minutes)}

1. I'd like to start by asking you a few questions about your background and the background of the firms you've mentored.

a. What is your primary title/role?

b. Gender

c. Highest educational level/subject

d. What year were you born?

e. Functional expertise

f. Prior work history -

briefly state firm, title, number of years

g. Have you ever started a company?

If so, how was it financed?

What happened (acquired, failed, still going, new CEO?)

What was your role?

h. Have you ever invested in a firm?

How many deals do you do a year?

What stage?

i. Do you mentor at any other accelerators? Which ones?

1.2 There are lots of reasons why mentors sign up to mentor at the accelerator. In a few words, could you tell me why you mentor? Why do you mentor at this accelerator?

1.3 How are accelerators different from VC? From Angels? From incubators? 


\section{SECTION TWO - ACCELERATION PROGRAM (45 Minutes)}

In this section, I'm going to ask you questions about the accelerator program.

Depending on how much time you spend at the accelerator, you may not be able to answer all of the questions that's fine, but please let me know when you are not certain.

\section{PROCESS}

2.1 Tell me about the program. Start by telling me about when you first meet the ventures, and then step through each week or month. (Note time markers, ask, about when is that?)

For each phase, please tell me about your involvement with the firms. Note which firms you interacted with, what advice you gave, and whether or not the firm took your advice. You may not have interacted during every phase, that's fine.

2.1.1 As far as you know, has the accelerator always run that way? Why/why not?

2.1.2 Is there a part of the program that helps firms more or less than you anticipated?

2.1.3 Is there anything else about accelerator's program that you think might be important to comment on?

2.2 How do you think limiting the program to three months affects what firms get out of the program? Why?

2.3 To wrap up our conversation about the program, do you have any comments on how the different parts of the program work together? Are there parts that you believe are particularly important?

\section{Cohort}

2.4 I'd now like to talk about having firms start and end in cohorts.

a. Have you noticed anything interesting about how firms interact with their cohort?

b. Do you think they benefit from their cohort? How?

c. How else does the cohort affect ventures?

d. What advice might you give to firms about the "cohort" effect?

e. Did you observe anything interesting or unexpected about firms when they are part of a cohort?

2.5 Was there anything else about ACCELERATOR program that you found interesting? 


\section{Firms}

2.6 I'm now going to ask you about the firms that you mentor. First, I'm going to ask you a few questions about your mentoring relationship with FIRM A.

\section{Mentoring details}

\# Hours per week did you meet with Firm.

Firm A Firm B Firm C

How did they request to see you?

What was the most important advice you gave to

firm?

Why was it important?

Was there any advice that they did not take, that you thought was important at the time?

Why didn't they take it?

How many Mentors did the firm have, including you

2.6.1 If you mentor again, would you change your involvement in any way? How?

2.7 Can you tell me about any surprises - firms that you thought would do better than they did? Or firms that did better than you expected?

\section{Mentorship}

2.8 How many mentors are at ACCELERATOR? How are they selected? What does mentorship mean at ACCELERATOR? How much time do mentors give? How many does the typical team meet with?

Now, I'm going to ask a few general questions about your style of mentorship.

2.9 Some mentors have standard advice that they share with most ventures while other mentors give more customized advice What, if any, standardized advice do you give (for example, rules of thumb)? How did you come up with that? Can you give me an example of customized advice? How did you know that?

2.10 Did ACCELERATOR ever give you guidance about how to give advice? What guidance did they give? When? [What types of advice to give, or when to give it]

2.11 How is mentoring in the accelerator different from mentoring firms who aren't part of an accelerator?

2.12 Have you read Lean Startup? What parts of the methodology does ACCEL use? Are there any parts that ACCEL Advises against? Why? 
a. What role do customers play in the program?

b. How do firms incorporate customer feedback? Is this different for accelerated firms than non accelerated firms? Anything surprise you about how firms have incorporated customer feedback?

\section{SECTION THREE-Wrap-up (10 Minutes)}

3 I would now like to wrap up with some overall questions. Overall, what do you think firms learn by participating in the accelerator?

3.1 Do you think firms that go through accelerators progress differently from other firms? How?

3.2 Some mentors try to accelerate all aspects of business formation, while others accelerate some activities, but actually try to decelerate other activities. Do you ever tell firms to slow down, not to rush? When and why? (resource acquisition, customer acquisition, routines, investments from outsiders)

3.3 To wrap up our conversation about your program, do you have any concluding comments about the various parts of the program?

3.4 Is there anything else that you would like to tell me?

3.5 Can you provide any of the following documents?

- Written Program schedule/calendars

- URLs of blogs

- Anything else that might be helpful?

\section{THANK YOU!!}




\section{REFERENCES}

Adler, P., \& Clark, K. B. 1991. Behind the learning curve: A sketch of the learning process. Management Science, 37(3): 267-281.

Agarwal, R., Ganco, M., \& Ziedonis, R. H. 2009. Reputations for toughness in patent enforcement: implications for knowledge spillovers via inventor mobility. Strategic Management Journal, 30(13): 1349-1374.

Aldrich, H. E., \& Yang, T. forthcoming. How Do Entrepreneurs Know What to Do? Learning and Organizing in New Ventures. Journal of Evolutionary Economics.

Allen, D., \& McCluskey, R. 1990. Structure, policy, services, and performance in the business incubator Industry. Entrepreneurship: Theory \& Practice, 15(2): 61-77.

Almeida, P., \& Kogut, B. 1999. Localization of knowledge and the mobility of engineers in regional networks. Management Science, 45(7): 905-917.

Argote, L. 1996. Organizational learning curves: persistence, transfer and turnover. International Journal of Technology Management, 11, 7(8): 759-769.

Argote, L. 1999. Organizational learning : creating, retaining, and transferring knowledge. Boston: Kluwer Academic.

Argote, L., \& Epple, D. 1990. Learning curves in manufacturing. Science, 247(4945): 920.

Argote, L., \& Ren, Y. 2012. Transactive memory systems: A microfoundation of dynamic capabilities. Journal of Management Studies, 49(8): 1375-1382.

Arrow, K. J. 1962. The economic implications of learning by doing. Review of Economic Studies, 29(3): 155-173.

Baker, T., Miner, A. S., \& Eesley, D. T. 2003. Improvising firms: bricolage, account giving and improvisational competencies in the founding process. Research Policy, 32(2): 255-276.

Barbero, J. L., Casillas, J. C., Ramos, A., \& Guitar, S. 2012. Revisiting incubation performance: How incubator typology affects results. Technological Forecasting and Social Change, 79(5): 888-902.

Barkema, H. G., \& Schijven, M. 2008. How do firms learn to make acquisitions? A review of past research and an agenda for the future. Journal of Management, 34(3): $594-634$.

Baron, J. N., Hannan, M. T., \& Burton, M. D. 1999. Building the iron cage: Determinants of managerial intensity in the early years of organizations. American Sociological Review, 64(4): 527-547.

Baum, J. A., Li, S. X., \& Usher, J. M. 2000. Making the next move: How experiential and 
vicarious learning shape the locations of chains' acquisitions. Administrative Science Quarterly, 45(4): 766-801.

Baum, J. A. C., \& Dahlin, K. B. 2007. Aspiration performance and railroads' patterns of learning from train wrecks and crashes. Organization Science, 18(3): 368-385.

Beckman, C. M., \& Haunschild, P. R. 2002. Network learning: The effects of partners' heterogeneity of experience on corporate acquisitions. Administrative Science Quarterly, 47(1): 92-124.

Bell, G. G., \& Zaheer, A. 2007. Geography, networks, and knowledge flow. Organization Science, 18(6): 955-972.

Benkard, C. L. 2000. Learning and forgetting: The dynamics of aircraft production. American Economic Review, 90(4): 1034-1054.

Bingham, C. B., \& Davis, J. P. 2012. Learning sequences: Their existence, effect and evolution. Academy of Management Journal, 55(3): 611-641.

Bingham, C. B., \& Eisenhardt, K. M. 2011. Rational heuristics: The "simple rules" that strategists learn from process experience. Strategic Management Journal, 32(13): $1437-1464$.

Bingham, C. B., Eisenhardt, K. M., \& Furr, N. R. 2007. What makes a process a capability? Heuristics, strategy, and effective capture of opportunities. Strategic

Entrepreneurship Journal, 1(1-2): 27-47.

Bingham, C. B., \& Haleblian, J. J. 2012. How firms learn heuristics: Uncovering missing components of organizational learning. Strategic Entrepreneurship Journal, 6(2): 152-177.

Bourgeois, L. J., \& Eisenhardt, K. M. 1988. Strategic decision processes in high velocity environments: Four cases in the microcomputer industry. Management Science, 34(7): 816-835.

Brinckmann, J., Grichnik, D., \& Kapsa, D. 2010. Should entrepreneurs plan or just storm the castle? A meta-analysis on contextual factors impacting the business planningperformance relationship in small firms. Journal of Business Venturing, 25(1): 24 40.

Brown, S. L., \& Eisenhardt, K. M. 1995. Product development: past research, present findings, and future directions. Academy of Management Review, 343-378.

Brown, S. L., \& Eisenhardt, K. M. 1997. The art of continuous change: Linking complexity theory and time-paced evolution in relentlessly shifting organizations. Administrative Science Quarterly, 42(1): 1-34.

Bruneel, J., Ratinho, T., Clarysse, B., \& Groen, A. 2012. The evolution of business 
incubators: Comparing demand and supply of business incubation services across different incubator generations. Technovation, 32(2): 110-121.

Chafkin, M. 2009, June 1. The start-up guru. Inc.com.

(http://www.inc.com/magazine/20090601/the-start-up-guru-y-combinators-paulgraham.html)

Chen, J., Reilly, R. R., \& Lynn, G. S. 2005. The impacts of speed-to-market on new product success: the moderating effects of uncertainty. IEEE Transactions on Engineering Management, 52(2): 199- 212.

Clark, C. 2008. The impact of entrepreneurs' oral "pitch" presentation skills on business angels' initial screening investment decisions. Venture Capital, 10(3): 257-279.

Clark, K. B., \& Fujimoto, T. 1991. Product development performance: Strategy, organization, and management in the world auto industry. Boston, Mass.: Harvard Business School Press.

Cohen, W. M., \& Levinthal, D. A. 1989. Innovation and learning: The two faces of R \& D. Economic Journal, 99(397): 569-596.

Cohen, W. M., \& Levinthal, D. A. 1990. Absorptive capacity: A new perspective on learning and innovation. Administrative Science Quarterly, 35(1): 128-152.

Cooper, R. G., \& Kleinschmidt, E. J. 1994. Determinants of timeliness in product development. Journal of Product Innovation Management, 11(5): 381-396.

Cyert, R. M., \& March, J. G. 1963. A behavioral theory of the firm. Englewood Cliffs, N.J.: Prentice-Hall.

D’Aveni, R. A., \& Gunther, R. E. 1994. Hypercompetition: Managing the dynamics of strategic maneuvering. New York: Maxwell Macmillan Canada.

Darr, E. D., Argote, L., \& Epple, D. 1995. The acquisition, transfer, and depreciation of knowledge in service organizations: Productivity in franchises. Management Science, 41(11): 1750-1762.

Davis, G. F. 1991. Agents without principles? The spread of the poison pill through the intercorporate network. Administrative Science Quarterly, 36(4): 583-613.

Delmar, F., \& Shane, S. 2003. Does business planning facilitate the development of new ventures? Strategic Management Journal, 24(12): 1165-1185.

Denrell, J. 2003. Vicarious learning, undersampling of failure, and the myths of management. Organization Science, 14(3): 227-243.

Devinney, T. M. 1987. Entry and learning. Management Science, 33(6): 706-724. 
Dierickx, I., \& Cool, K. 1989. Asset stock accumulation and sustainability of competitive advantage. Management Science, 35(12): 1504-1511.

DiMaggio, P. J., \& Powell, W. W. 1983. The iron cage revisited: Institutional isomorphism and collective rationality in organizational fields. American Sociological Review, 48(2): 147-160.

Dutton, J. M., \& Thomas, A. 1984. Treating progress functions as a managerial opportunity. Academy of Management Review, 9(2): 235-247.

Easterby-Smith, M., Lyles, M. A., \& Tsang, E. W. K. 2008. Inter-organizational knowledge transfer: Current themes and future prospects. Journal of Management Studies, 45(4): 677-690.

Edmondson, A. C. 2003. Speaking up in the operating room: How team leaders promote learning in interdisciplinary action teams. Journal of Management Studies, 40(6): 1419-1452.

Edmondson, A. C., Winslow, A. B., Bohmer, R. M., \& Pisano, G. P. 2003. Learning how and learning what: Effects of tacit and codified knowledge on performance improvement following technology adoption. Decision Sciences, 34(2): 197-224.

Eggers, J. P., \& Kaplan, S. 2009. Cognition and renewal: Comparing CEO and organizational effects on incumbent adaptation to technical change. Organization Science, 20(2): $461-477$.

Eisenhardt, K. M. 1989a. Building theories from case study research. Academy of Management Review, 14(4): 532-550.

Eisenhardt, K. M. 1989b. Making fast strategic decisions in high-velocity environments. Academy of Management Journal, 32(3): 543-576.

Eisenhardt, K. M., \& Brown, S. L. 1998. Time pacing: competing in markets that won't stand still. Harvard Business Review, 76(2): 59-69.

Eisenhardt, K. M., \& Graebner, M. E. 2007. Theory building from cases: Opportunities and challenges. Academy of Management Journal Archive, 50(1): 25-32.

Eisenhardt, K. M., \& Martin, J. A. 2000. Dynamic Capabiliite: What are they? Strategic Management Journal, 21(10/11): 1105-1121.

Eisenhardt, K. M., \& Tabrizi, B. N. 1995. Accelerating adaptive processes: Product innovation in the global computer industry. Administrative Science Quarterly, 40(1): 84-110.

Feld, B., \& Cohen, D. 2010. Do more faster: TechStars lessons to accelerate your startup. New York: Wiley. 
Feld, B., \& Mendelson, J. 2011. Venture deals: Be smarter than your lawyer and venture capitalist. New York: Wiley.

Feldman, M. S., \& March, J. G. 1981. Information in organizations as signal and symbol. Administrative Science Quarterly, 26(2): 171-186.

Fern, M. J., Cardinal, L. B., \& O’Neill, H. M. 2012. The genesis of strategy in new ventures: Escaping the constraints of founder and team knowledge. Strategic Management Journal. 33(4): 427-447.

Fiol, C. M., \& Lyles, M. A. 1985. Organizational learning. Academy of Management Review, 10(4): 803-813.

Gavetti, G., \& Levinthal, D. A. 2000. Looking forward and looking backward: Cognitive and experiential search. Administrative Science Quarterly, 45(1): 113-137.

Geron, T. 2012, April 30. Top startup incubators and accelerators: Y Combinator tops with $\$ 7.8$ billion in value - Forbes. Forbes.

(http://www.forbes.com/sites/tomiogeron/2012/04/30/top-tech-incubators-as-rankedby-forbes-y-combinator-tops-with-7-billion-in-value)

Gersick, C. J. . 1989. Marking time: Predictable transitions in task groups. Academy of Management Journal, 32(2): 274-309.

Gersick, C. J. 1991. Revolutionary change theories: A multilevel exploration of the punctuated equilibrium paradigm. Academy of Management Review, 16(1): 10-36.

Gersick, C. J. . 1994. Pacing strategic change: The case of a new venture. Academy of Management Journal, 37(1): 9-45.

Gersick, C. J. G. 1988. Time and transition in work teams: Toward a new model of group development. Academy of Management Journal, 31(1): 9-41.

Gibson, C., \& Vermeulen, F. 2003. A healthy divide: Subgroups as a stimulus for team learning behavior. Administrative Science Quarterly, 48(2): 202-239.

Glaser, B. G., \& Strauss, A. L. 1967. The discovery of grounded theory. Chicago: Aldine Publishing Co.

Greve, H. R. 1998. Performance, aspirations, and risky organizational change. Administrative Science Quarterly, 43(1): 58-86.

Greve, H. R. 2003. Organizational learning from performance feedback: A behavioral perspective on innovation and change. Cambridge: Cambridge University Press.

Gruber, M., MacMillan, I. C., \& Thompson, J. D. 2013. Escaping the prior knowledge corridor: What shapes the number and variety of market opportunities identified before market entry of technology start-ups? Organization Science. 24(1): 280-300. 
Hackett, S. M., \& Dilts, D. M. 2004. A systematic review of business incubation research. Journal of Technology Transfer, 29(1): 55-82.

Haleblian, J. J., \& Finkelstein, S. 1999. The influence of organizational acquisition experience on acquisition performance: A behavioral learning perspective. Administrative Science Quarterly, 44(1): 29-56.

Hallen, B. L. 2008. The causes and consequences of the initial network positions of new organizations: From whom do entrepreneurs receive investments? Administrative Science Quarterly, 53(4): 685.

Hallen, B. L., \& Eisenhardt, K. M. 2012. Catalyzing strategies and efficient tie formation: How entrepreneurial firms obtain investment ties. Academy of Management Journal, 55(1): 35-70.

Hambrick, D. C., Cho, T. S., \& Chen, M.-J. 1996. The influence of top management team heterogeneity on firms' competitive moves. Administrative Science Quarterly, 41(4): $659-684$.

Hamel, G. 1991. Competition for competence and interpartner learning within international strategic alliances. Strategic Management Journal, 12(S1): 83-103.

Haunschild, P. R. 1993. Interorganizational imitation: The impact of interlocks on corporate acquisition activity. Administrative Science Quarterly, 38(4): 564-592.

Haunschild, P. R., \& Miner, A. S. 1997. Modes of interorganizational imitation: The effects of outcome salience and uncertainty. Administrative Science Quarterly, 42(3): 472500 .

Haunschild, P. R., \& Sullivan, B. N. 2002. Learning from complexity: Effects of prior accidents and incidents on airlines' learning. Administrative Science Quarterly, 47(4): 609-643.

Hawk, A., Pacheco-De-Almeida, G., \& Yeung, B. Y. 2012. Fast-mover advantages: Speed capabilities and entry into the emerging submarket of Atlantic Basin LNG. Strategic Management Journal, forthcoming.

Hayward, M. L. A. 2002. When do firms learn from their acquisition experience? Evidence from 1990-1995. Strategic Management Journal, 23(1): 21-39.

Hayward, M. L. A., Shepherd, D. A., \& Griffin, D. 2006. A hubris theory of entrepreneurship. Management Science, 52(2): 160-172.

Heirman, A., \& Clarysse, B. 2007. Which tangible and intangible assets matter for innovation speed in start-ups? Journal of Product Innovation Management, 24(4): 303-315. 
Henry, C., Hill, F., \& Leitch, C. 2005. Entrepreneurship education and training: Can entrepreneurship be taught? Part II. Education + Training, 47(3): 158-169.

Hochberg, Y. V., Ljungqvist, A., \& Lu, Y. 2007. Whom you know matters: Venture capital networks and investment performance. Journal of Finance, 62(1): 251-301.

Hochberg, Y. V., Ljungqvist, A., \& Lu, Y. 2010. Networking as a barrier to entry and the competitive supply of venture capital. Journal of Finance, 65(3): 829-859.

Hsu, D. H. 2007. Experienced entrepreneurial founders, organizational capital, and venture capital funding. Research Policy, 36(5): 722-741.

Hu, S. 2012. A behavioral perspective on attention allocation among multiple goals: An exploratory examination of the automotive industry. Ph.D. dissertation.

http://search.proquest.com.libproxy.lib.unc.edu/pqdtft/docview/1019281975/13C6292

86EB5F693D34/1?accountid=14244, February 21, 2013, United States -- North

Carolina: The University of North Carolina at Chapel Hill.

Hu, S., Blettner, D., \& Bettis, R. A. 2011. Adaptive aspirations: Performance consequences of risk preferences at extremes and alternative reference groups. Strategic Management Journal, 32(13): 1426-1436.

Huber, G. P. 1985. Temporal stability and response-order biases in participant descriptions of organizational decisions. Academy of Management Journal, 28(4): 943-950.

Huber, G. P. 1991. Organizational learning: The contributing processes and the literatures. Organization Science, 2(1): 88-115.

Ingram, P. 2002. Interorganizational learning. In J. A. C. Baum (ed.), The Blackwell companion to organizations. Oxford, UK: Blackwell Business.

Ittner, C. D., Nagar, V., \& Rajan, M. V. 2001. An empirical examination of dynamic qualitybased learning models. Management Science, 47(4): 563-578.

Jaffe, A., Trajtenberg, M., \& Fogarty, M. 2000. Knowledge spillovers and patent citations: Evidence from a survey of inventors. American Economic Review, 90(2): 215-218.

Jaffe, A., Trajtenberg, M., \& Henderson, R. 1993. Geographic localization of knowledge spillovers as evidenced by patent citations. Quarterly Journal of Economics, 108(3): $577-598$.

Kane, A. A., Argote, L., \& Levine, J. M. 2005. Knowledge transfer between groups via personnel rotation: Effects of social identity and knowledge quality. Organizational Behavior and Human Decision Processes, 96(1): 56-71.

Kaplan, S., \& Tripsas, M. 2008. Thinking about technology: Applying a cognitive lens to technical change. Research Policy, 37(5): 790-805. 
Kessler, E. H., \& Bierly, P. E. 2002. Is faster really better? An empirical test of the implications of innovation speed. IEEE Transactions on Engineering Management, 49(1): 2-12.

Kessler, E. H., \& Chakrabarti, A. K. 1996. Innovation speed: A conceptual model of context, antecedents, and outcomes. Academy of Management Review, 21(4): 1143-1191.

Khanna, T., Gulati, R., \& Nohria, N. 1998. The dynamics of learning alliances: competition, cooperation, and relative scope. Strategic Management Journal, 19(3): 193-210.

Kim, J.-Y., \& Miner, A. S. 2007. Vicarious learning from the failures and near-failures of others: Evidence from the U.S. commercial banking industry. Academy of Management Journal ARCHIVE, 50(3): 687-714.

Klepper, S., \& Simons, K. L. 2000. Dominance by birthright: Entry of prior radio producers and competitive ramifications in the U.S. television receiver industry. Strategic Management Journal, 21(10-11): 997-1016.

Kogut, B., \& Zander, U. 1992. Knowledge of the firm, combinative capabilities, and the replication of technology. Organization Science, 3(3): 383-397.

Lant, T. K., Milliken, F. J., \& Batra, B. 1992. The role of managerial learning and interpretation in strategic persistence and reorientation: An empirical exploration. Strategic Management Journal, 13(8): 585-608.

Lapré, M. A., \& Van Wassenhove, L. N. 2001. Creating and transferring knowledge for productivity improvement in factories. Management Science, 47(10): 1311-1325.

Lee, J. 2006, February 21. Running a hatchery for replicant hackers. The New York Times. (http://www.nytimes.com/2006/02/21/business/businessspecial2/21startup.html)

Lee, T. W. 1999. Using qualitative methods in organizational research. Thousand Oaks, CA: Sage.

Leonard-Barton, D. 1992. Core capabilities and core rigidities: A paradox in managing new product development. New York: Wiley.

Levin, D. Z. 2000. Organizational learning and the transfer of knowledge: An investigation of quality improvement. Organization Science, 11(6): 630-647.

Levinthal, D. A. 1997. Adaptation on rugged landscapes. Management Science, 43(7): 934950.

Levinthal, D. A., \& March, J. G. 1981. A model of adaptive organizational search. Journal of Economic Behavior \& Organization, 2(4): 307-333.

Levinthal, D. A., \& March, J. G. 1993. The myopia of learning. Strategic Management Journal, 14: 95-95. 
Levitt, B., \& March, J. G. 1988. Organizational learning. Annual Review of Sociology, 14: 319-340.

Lieberman, M. B. 1984. The learning curve and pricing in the chemical processing industries. RAND Journal of Economics, 15(2): 213-228.

Lieberman, M. B., \& Montgomery, D. B. 1988. First-mover advantages. Strategic Management Journal, 9(S1): 41-58.

Lieberman, M. B., \& Montgomery, D. B. 1998. First-mover (dis) advantages: Retrospective and link with the resource-based view. Strategic Management Journal, 19(12): $1111-1125$.

Lynn, G. S., Skov, R. B., \& Abel, K. D. 1999. Practices that support team learning and their impact on speed to market and new product success. Journal of Product Innovation Management, 16(5): 439-454.

March, J. G. 1991. Exploration and exploitation in organizational learning. Organization Science, 2(1): 71-87.

Markman, G. D., Gianiodis, P. T., Phan, P. H., \& Balkin, D. B. 2005. Innovation speed: Transferring university technology to market. Research Policy, 34(7): 1058-1075.

Merton, R. K. 1968. The Matthew Effect in science. Science, 159(3810): 56-63.

Messick, D. M., \& Mackie, D. M. 1989. Intergroup relations. Annual Review of Psychology, 40(1): 45-81.

Meyer, C., \& Purser, R. E. 1993. Six steps to becoming a fast-cycle-time competitor. Research Technology Management, 36: 41-41.

Miles, M. B., \& Huberman, A. M. 1994. Qualitative data analysis : An expanded sourcebook (2nd ed.). Thousand Oaks, CA: Sage.

Miller, D., \& Shamsie, J. 2001. Learning across the life cycle: Experimentation and performance among the Hollywood studio heads. Strategic Management Journal, 22(8): 725-745.

Miller, P., \& Bound, K. 2011, June. The startup factories. (http://www.nesta.org.uk/library/documents/StartupFactories.pdf)

Miner, A. S., Bassoff, P., \& Moorman, C. 2001. Organizational improvisation and learning: A field study. Administrative Science Quarterly, 46(2): 304-337.

Miner, A. S., \& Haunschild, P. R. 1995. Population level learning. Research in Organizational Behavior, 17: 115-115.

Moorman, C., \& Miner, A. S. 1998. Organizational improvisation and organizational 
memory. Academy of Management Review, 23(4): 698-723.

Ocasio, W. 1997. Towards an attention-based view of the firm. Strategic Management Journal, 18(S1): 187-206.

Ozcan, P., \& Eisenhardt, K. M. 2009. Origin of alliance portfolios: Entrepreneurs, network strategies, and firm performance. Academy of Management Journal ARCHIVE, 52(2): 246-279.

Paas, F., Renkl, A., \& Sweller, J. 2004. Cognitive load theory: Instructional implications of the interaction between information structures and cognitive architecture. Instructional Science, 32(1-2): 1-8.

Pisano, G. P. 1994. Knowledge, integration, and the locus of learning: An empirical analysis of process development. Strategic Management Journal, 15: 85-100.

Pisano, G. P. 1996. Learning-before-doing in the development of new process technology. Research Policy, 25(7): 1097-1119.

Pisano, G. P., Bohmer, R. M., \& Edmondson, A. C. 2001. Organizational differences in rates of learning: Evidence from the adoption of minimally invasive cardiac surgery. Management Science, 47(6): 752-768.

Podolny, J. M., \& Stuart, T. E. 1995. A role-based ecology of technological change. American Journal of Sociology, 1224-1260.

Porter, M. E. 1996. What is strategy? Harvard Business Review. 74(6):61-78.

Rapping, L. 1965. Learning and World War II production functions. Review of Economics and Statistics, 47(1): 81-86.

Reagans, R., Argote, L., \& Brooks, D. 2005. Individual experience and experience working together: Predicting learning rates from knowing who knows what and knowing how to work together. Management Science, 51(6): 869-881.

Ries, E. 2011. The lean startup: How today's entrepreneurs use continuous innovation to create radically successful businesses. New York: Crown Business.

Rothaermel, F. T., \& Thursby, M. 2005a. Incubator firm failure or graduation? The role of university linkages. Research Policy, 34(7): 1076-1090.

Rothaermel, F. T., \& Thursby, M. 2005b. University-incubator firm knowledge flows: Assessing their impact on incubator firm performance. Research Policy, 34(3): 305320.

Santos, F. M., \& Eisenhardt, K. M. 2009. Constructing markets and shaping boundaries: Entrepreneurial power in nascent fields. Academy of Management Journal, 52(4): 643-671. 
Sarasvathy, S. D. 2001. Causation and effectuation: Toward a theoretical shift from economic inevitability to entrepreneurial contingency. Academy of Management Review, 243-263.

Schilling, M. A., Vidal, P., Ployhart, R. E., \& Marangoni, A. 2003. Learning by doing something else: Variation, relatedness, and the learning curve. Management Science, 49(1): 39-56.

Schoonhoven, C., Eisenhardt, K. M., \& Lyman, K. 1990. Speeding products to market: Waiting time to first product introduction in new firms. Administrative Science Quarterly, 35(1): 177-207.

Sitkin, S. B. 1992. Learning through failure: The strategy of small losses. Research in Organizational Behavior, 14: 231-231.

Smilor, R. W. 1987. Managing the incubator system: critical success factors to accelerate new company development. IEEE transactions on Engineering Management, 34(3): 146-155.

Song, M., Im, S., van der Bij, H., \& Song, L. Z. 2011. Does strategic planning enhance or impede innovation and firm performance? Journal of Product Innovation Management, 28(4): 503-520.

Stasser, G., \& Titus, W. 1987. Effects of information load and percentage of shared information on the dissemination of unshared information during group discussion. Journal of Personality and Social Psychology, 53(1): 81.

Staw, B. M. 1981. The escalation of commitment to a course of action. Academy of Management Review,6(4): 577-587.

Stigler, G. J. 1961. The economics of information. Journal of Political Economy, 69(3): 213-225.

Stinchcombe, A. L. 1965. Organizations and social structure. Handbook of Organizations, 44(2): 142-193.

Stuart, T. E., \& Podolny, J. M. 1996. Local search and the evolution of technological capabilities. Strategic Management Journal, 17(S1): 21-38.

Suddaby, R. 2006. From the editors: What grounded theory is not. Academy of Management Journal, 49(4): 633-642.

Terwiesch, C., \& Bohn, R. E. 2001. Learning and process improvement during production ramp-up. International Journal of Production Economics, 70(1): 1-19.

Tripsas, M., \& Gavetti, G. 2000. Capabilities, cognition, and inertia: Evidence from digital imaging. Strategic Management Journal, 21(10-11): 1147-1161. 
Turner, S. F., Mitchell, W., \& Bettis, R. A. 2013. Strategic momentum: How experience shapes temporal consistency of ongoing innovation. Journal of Management. In press.

(http://jom.sagepub.com.libproxy.lib.unc.edu/content/early/2012/09/26/01492063124 $\underline{\text { 58704.full) }}$

Tyre, M. J., \& Von Hippel, E. 1997. The situated nature of adaptive learning in organizations. Organization Science, 8(1): 71-83.

Van de Ven, A., \& Polley, D. 1992. Learning while innovating. Organization Science, 3(1): 92-116.

Vermeulen, F., \& Barkema, H. G. 2002. Pace, rhythm, and scope: Process dependence in building a profitable multinational corporation. Strategic Management Journal, 23(7): 637-653.

Waller, M. J., Zellmer-Bruhn, M. E., \& Giambatista, R. C. 2002. Watching the clock: Group pacing behavior under dynamic deadlines. Academy of Management Journal, 45(5): 1046-1055.

Wegner, D. M. 1987. Transactive memory: A contemporary analysis of the group mind. Theories of Group Behavior, 185: 208.

Westphal, J. D., Seidel, M.-D. L., \& Stewart, K. J. 2001. Second-order imitation: Uncovering latent effects of board network ties. Administrative Science Quarterly, 46(4): 717 747.

Wheelwright, S. C., \& Clark, K. B. 1994. Accelerating the design-build-test cycle for effective product development. International Marketing Review, 11(1): 32-46.

Winter, S. G., \& Szulanski, G. 2001. Replication as strategy. Organization Science, 12(6): 730-743.

Winter, S. G., Szulanski, G., Ringov, D., \& Jensen, R. J. 2012. Reproducing knowledge: Inaccurate replication and failure in franchise organizations. Organization Science, 23(3): 672-685.

Yang, T., \& Aldrich, H. E. 2012. Out of sight but not out of mind: Why failure to account for left truncation biases research on failure rates. Journal of Business Venturing. (http://www.sciencedirect.com/science/article/pii/S088390261200002X)

Yin, R. K. 2009. Case study research: Design and methods. Thousand Oaks, CA: Sage.

Zahra, S. A., \& George, G. 2002. Absorptive capacity: A review, reconceptualization, and extension. Academy of Management Review, 27(2): 185-203.

Zander, U., \& Kogut, B. 1995. Knowledge and the speed of the transfer and imitation of organizational capabilities: An Empirical Test. Organization Science, 6(1): 76-92. 
Zollo, M., \& Winter, S. G. 2002. Deliberate learning and the evolution of dynamic capabilities. Organization Science, 13(3): 339-351.

Zuckerman, E. W., \& Sgourev, S. V. 2006. Peer capitalism: Parallel relationships in the U.S. economy. American Journal of Sociology, 111(5): 1327-1366. 